\title{
Molecular characterization of Lhx8, an oocyte-specific transcription factor, and its interacting proteins in rainbow trout and cattle
}

\author{
Liyuan Fu
}

Follow this and additional works at: https://researchrepository.wvu.edu/etd

\section{Recommended Citation}

Fu, Liyuan, "Molecular characterization of Lhx8, an oocyte-specific transcription factor, and its interacting proteins in rainbow trout and cattle" (2016). Graduate Theses, Dissertations, and Problem Reports. 5629. https://researchrepository.wvu.edu/etd/5629

This Dissertation is protected by copyright and/or related rights. It has been brought to you by the The Research Repository @ WVU with permission from the rights-holder(s). You are free to use this Dissertation in any way that is permitted by the copyright and related rights legislation that applies to your use. For other uses you must obtain permission from the rights-holder(s) directly, unless additional rights are indicated by a Creative Commons license in the record and/ or on the work itself. This Dissertation has been accepted for inclusion in WVU Graduate Theses, Dissertations, and Problem Reports collection by an authorized administrator of The Research Repository @ WVU.

For more information, please contact researchrepository@mail.wvu.edu. 


\title{
MOLECULAR CHARACTERIZATION OF LHX8, AN \\ OOCYTE-SPECIFIC TRANSCRIPTION FACTOR, AND ITS \\ INTERACTING PROTEINS IN RAINBOW TROUT AND \\ CATTLE
}

\section{LIYUAN FU}

\author{
Dissertation submitted \\ to the Davis College of Agriculture, Natural Resources and Design \\ at West Virginia University
}

In partial fulfillment of the requirements for the degree of

\author{
Doctor of Philosophy in \\ Animal and Food Science \\ Jianbo Yao, Ph.D., Chair \\ Kenneth P. Blemings, Ph.D. \\ Hao Ma, Ph.D. \\ Shuo Wei, Ph.D. \\ Vagner A. Benedito, Ph.D.
}

Division of Animal and Nutritional Sciences

Morgantown, West Virginia

2016

Keywords: cattle, rainbow trout, oocyte, oogenesis, early embryogenesis, transcription factor, Lhx8, Figla, Sohlh1, Kpna7, and Borealin-2 


\section{ABSTRACT \\ Molecular Characterization of Lhx8, an Oocyte-Specific Transcription \\ Factor, and its Interacting Proteins in Rainbow Trout and Cattle}

\section{Liyuan Fu}

LIM homeobox $8(\operatorname{Lhx} 8)$ is an important transcription factor that is preferentially expressed in germ cells. $L h x 8$ null mice are infertile due to lack of oocytes and impairment of the transition from primordial follicles to primary follicles. Lhx 8 deficiency also affects the expression of many important oocyte-specific genes. To date, no attempts have been made to investigate the existence of any cellular factors that might interact with Lhx 8 protein in oocytes and early embryos. In this study, we report the characterization of rainbow trout and bovine $L h x 8$ genes and identification of important germ cell-specific nuclear factors that interact with Lhx8 protein in both species. In rainbow trout, two Lhx8 genes, Lhx $8 a$ and $L h x 8 b$, were identified, encoding proteins of 344 and 361 amino acids, respectively. The two proteins share $83 \%$ sequence identity and both transcripts are specifically expressed in the ovary. Quantitative real time PCR analysis demonstrated that both genes are expressed highly in pre-vitellogenic ovaries as well as in early stage embryos. Using a yeast two-hybrid screening system, a novel protein (Borealin-2) interacting with Lhx8 was identified. The interaction between either Lhx8a or Lhx8b and Borealin-2 was further confirmed by a bimolecular fluorescence complementation (BiFC) assay. Borealin-2 is a protein of 255 amino acids containing an Nbl1 domain, and its mRNA expression is restricted to the ovary and testis. A GFP reporter assay revealed that Borealin-2 is a nuclear protein. Results indicate that both Lhx8a and Lhx8b function through interaction with Borealin-2, which may play an important role during oogenesis and early embryogenesis in rainbow trout. The open reading frame (ORF) of bovine $L h x 8$ gene was amplified from cDNA of a bovine fetal ovary using primers designed based on a predicted bovine $L h x 8$ cDNA sequence and a partial 5'end transcript. The ORF of bovine $L h x 8 c D N A$ is $1,134 \mathrm{bp}$ in length encoding a protein of 377 amino acids. A splicing variant of $L h x 8$ (Lhx8_vl) was identified, which results from alternative splicing of exon 2 and 3, and encodes a protein of 293 amino acids. The predicted bovine Lhx8 protein contains two LIM domains and one homeobox domain. However, one of the LIM domains in the splicing variant, Lhx8_v1, is incomplete due to deletion of 83 amino acids near the $\mathrm{N}$ terminus. Both $L h x 8$ and $L h x 8_{-} v 1$ mRNA are specifically expressed in fetal ovaries and testis but not detectable in the somatic tissues as well as in granulosa and theca cells. Lhx8 mRNA is highly abundant in GV and MII stage oocytes as well as in early stage embryos but not detectable in morula and blastocyst stage embryos. Lhx8_v1 mRNA expression is detectable in oocytes and early embryo but not in morula and blastocyst stage embryos. A GFP reporter assay revealed that $\operatorname{Lhx} 8$ is a nuclear protein and the predicted monopartite NLS is required for its transport into the nucleus. Direct yeast two-hybrid analysis revealed that bovine Lhx 8 protein interacts with Figla, a basic helix-loop-helix 
transcription factor. The interaction between Lhx8 and Figla was confirmed by a co-immunoprecipitation assay. This is the first time that a direct protein-protein interaction between two germ cell-specific transcription factors essential for oocyte and follicular development is demonstrated. The study provides new information for studying the mechanisms of the regulatory roles of Lhx8 in oocyte/follicular development and early embryogenesis. 


\section{DEDICATION}

I would like to dedicate my research study to my advisor Dr. Jianbo Yao. Without his vision and guidance, this work would not have been possible, and I certainly wouldn't be here. I truly grew both as a researcher and a person while working with him and I cannot find enough words to express my gratitude. 


\section{ACKNOWLEDGEMENTS}

Foremost, I would like to express my gratitude to my advisor Dr. Jianbo Yao for giving me the opportunity to work in his lab, and for his patience, motivation, enthusiasm, and immense knowledge during my graduate career. I could not have imagined having a better advisor and mentor for my $\mathrm{PhD}$ study.

I gratefully acknowledge Dr. Benedito for helping me to improve my presentation, reading and writing skills in a scientific way. With his help, I become confident, and start loving science. He is an important mentor on my way of being a real scientist. I cannot appreciate more.

In contributing to my research. I specially want to thank Dr. Ma for helping me start my $\mathrm{PhD}$ project. He taught me how to do the lab work almost step by step, which paved the way for my following research. I have learnt a lot, especially being critical, careful and serious when doing science.

In contributing to my studies, I also want to thank Dr. Wei for trying to help me find solutions when I have difficulties with microinjection and Co-IP. With his help, I got important results for my research.

In contributing to my general knowledge in biochemistry, I want to thank Dr. Blemings. He helped me review the whole biochemistry class again during a summer. I learnt a lot by doing his quiz each week in that summer.

I wish to thank my labmates and also best friends: Lei, Jackie, Prasanthi, Jian, Lina, Xiaowei, Mingxiang, Wentao, Kristen and Josh. They are really sweet friends and nice colleagues. They helped me a lot and helped me go through difficult times. I really appreciate I have these good friends. We are like a Yao Lab family and we will be a family forever.

Lastly, and most importantly, I would like to thank my family especially my parents for their love, encouragement and un-wavering support. Having such a wonderful family support has always been one of the keys to my success and I thank them from the bottom of my heart. 
I owe my deepest gratitude to my husband. I am so grateful that I met him and get married with him. That's the most right thing I have ever done. He was with me every day and kept pushing me to finish the dissertation.

The financial support from the Division of Animal and Nutritional Sciences at West Virginia University and USDA are gratefully acknowledged. 


\section{TABLE OF CONTENTS}

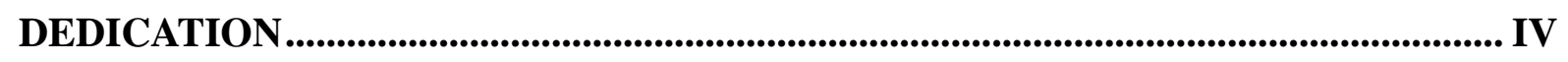

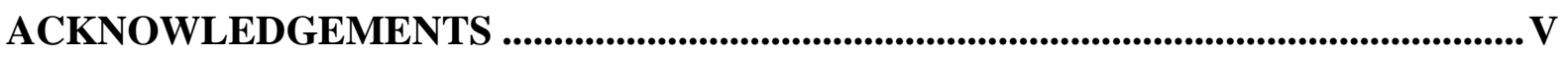

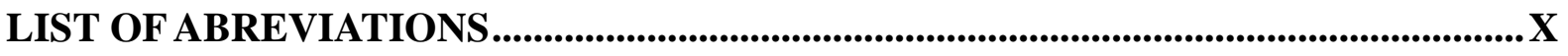

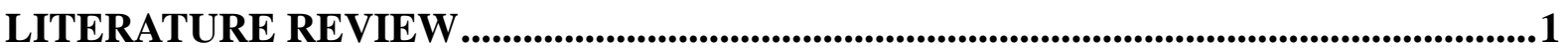

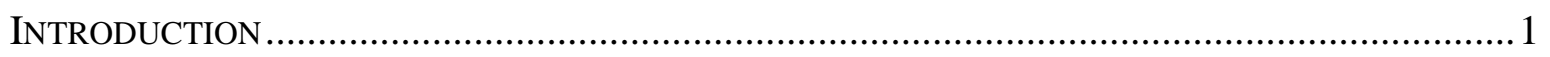

IMPORTANCE OF STUDYING OOCYTE-SPECIFIC GENES IN RAINBOW TROUT AND CATTLE ........... 1

OOCYTE-SPECIFIC GENES IMPORTANT FOR OOCYTE AND FOLLICULAR DEVELOPMENT .............. 3

Factor in the germline, alpha (Figla) ............................................................................. 3

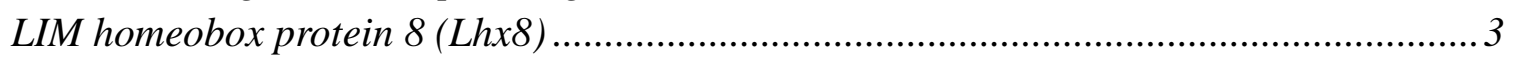

Spermatogenesis and oogenesis specific basic helix-loop-helix 1 (Sohlh1)....................... 4

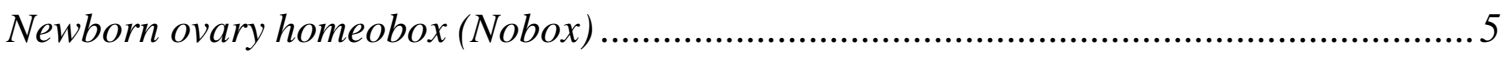

Octamer-binding transcription factor 4 (OCT-4) ............................................................ 5

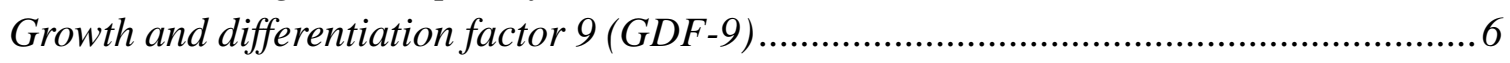

OOCYTE-SPECIFIC MATERNAL EFFECT GENES IMPORTANT FOR EARLY EMBRYOGENESIS ............7

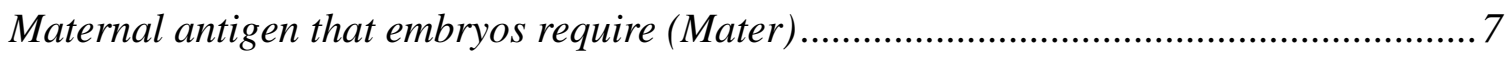

Zygote arrest 1 (Zarl) ............................................................................................... 8

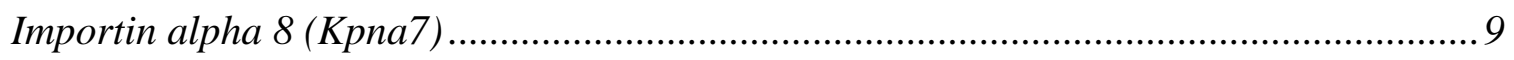

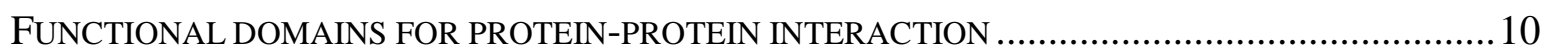

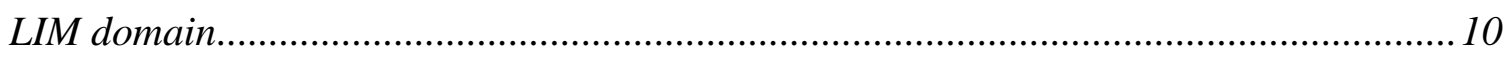

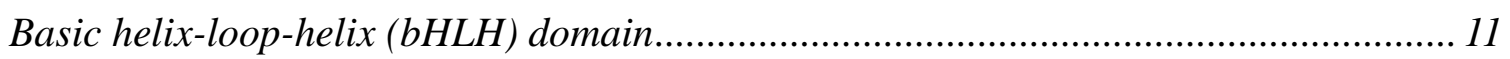

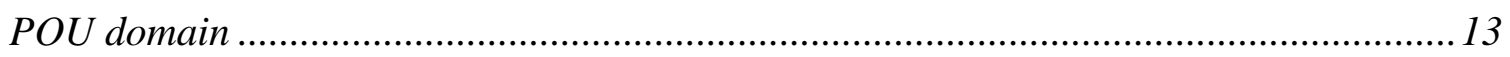

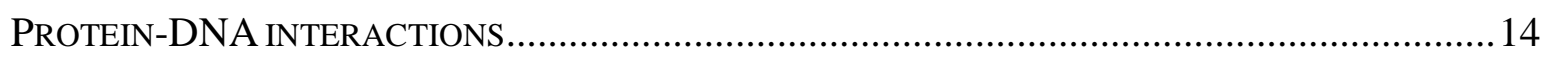

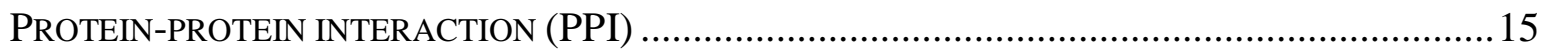

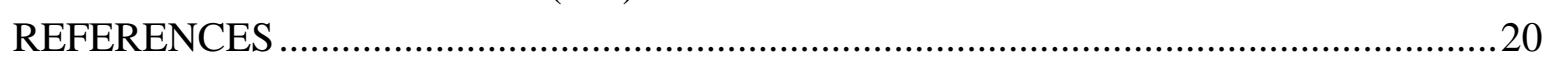

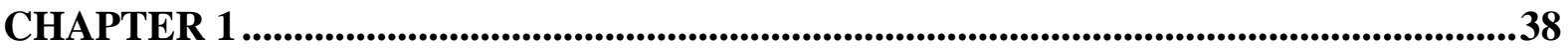

LHX8 INTERACTS WITH A NOVEL GERM CELL-SPECIFIC NUCLEAR FACTOR CONTAINING AN NBL1 DOMAIN IN RAINBOW TROUT (ONCORHYNCHUS

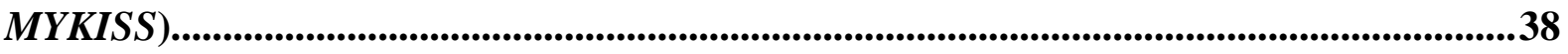

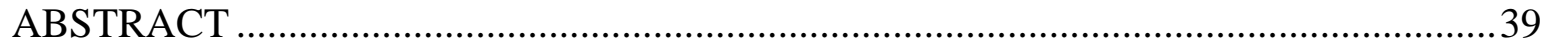

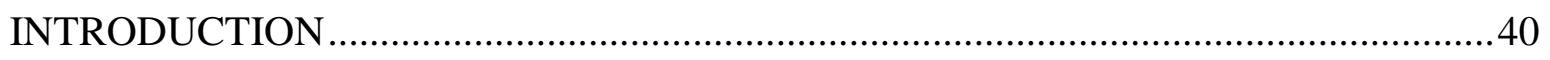

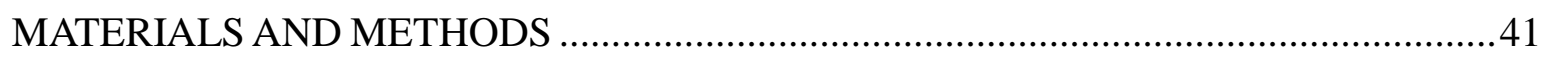

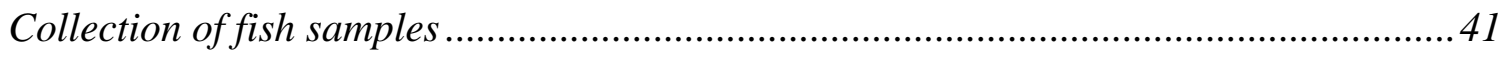

Reverse transcription polymerase chain reaction $(R T-P C R)$........................................... 41

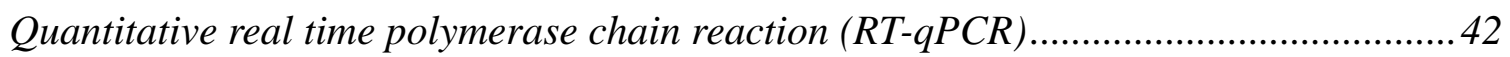

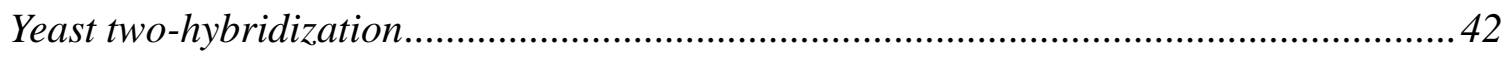

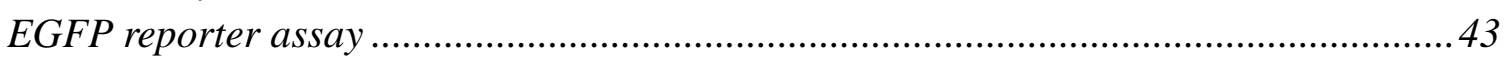

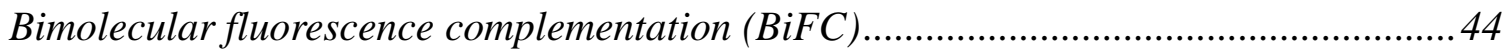

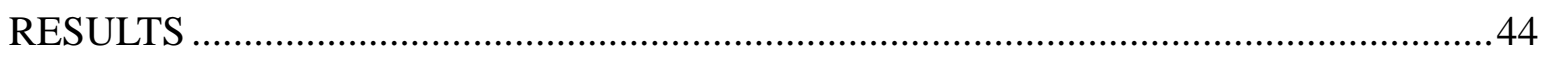


Identification and expression analysis of rainbow trout Lhx8 genes.................................4 44

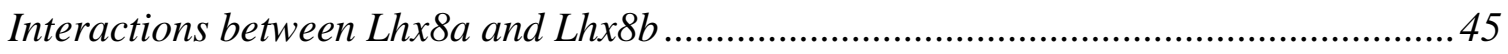

Identification of Borealin-2 as an Lhx8-interacting protein ..............................................46

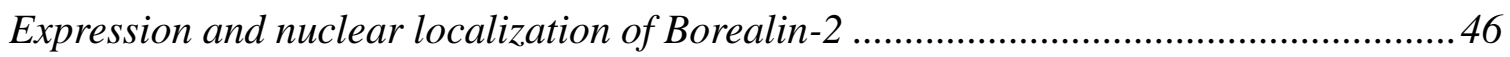

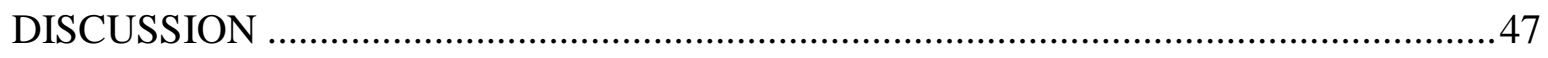

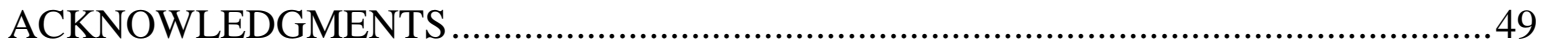

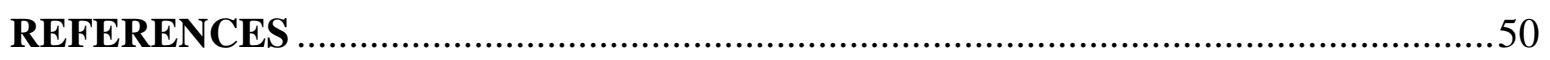

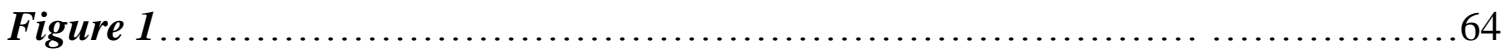

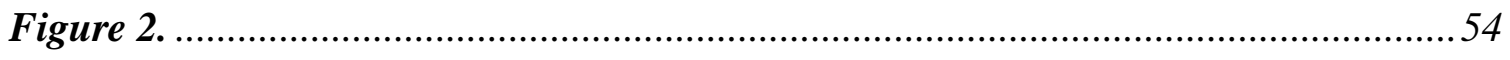

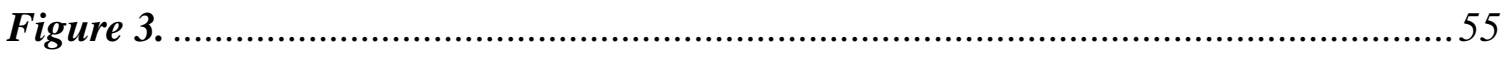

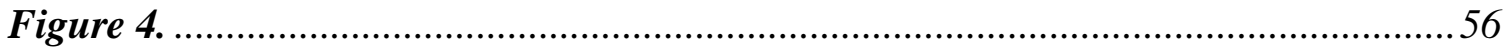

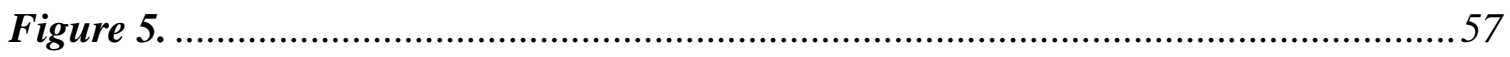

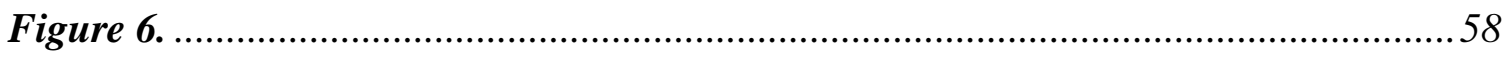

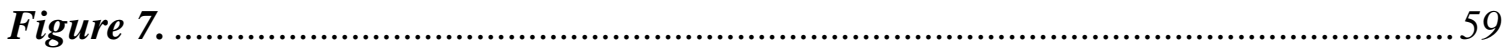

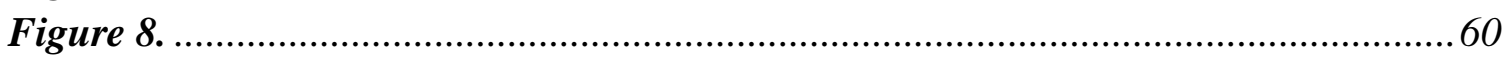

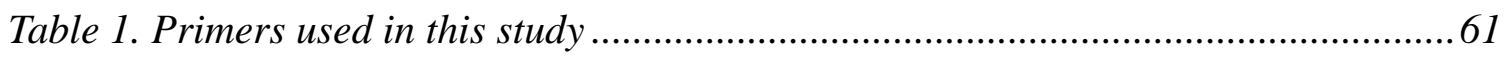

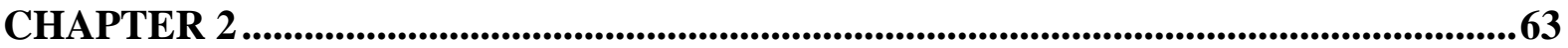

MOLECULAR CHARACTERIZATION OF BOVINE LHX8 AND IDENTIFICATION

OF ITS INTERACTING PARTNERS ............................................................................................63

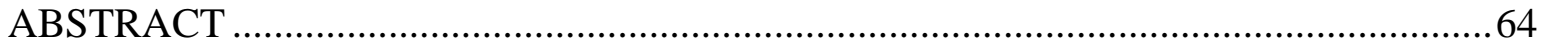

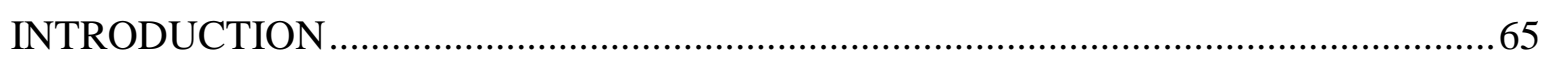

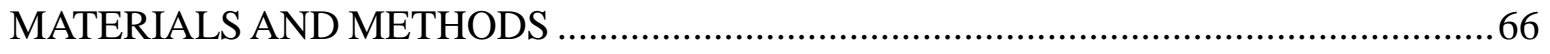

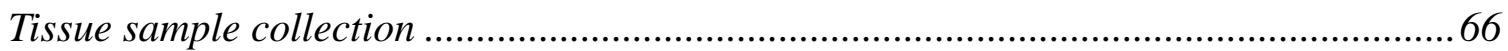

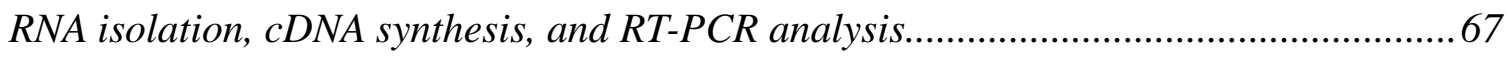

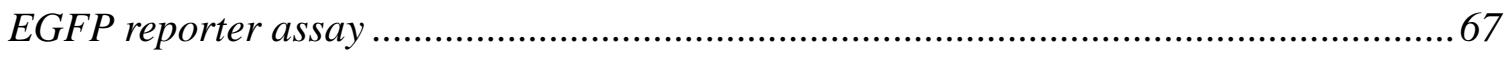

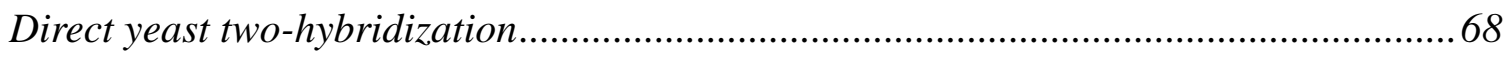

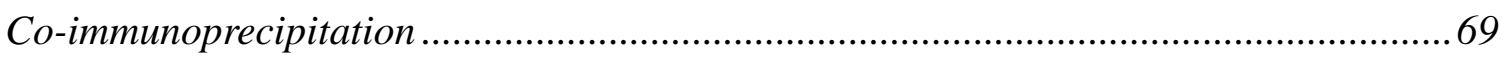

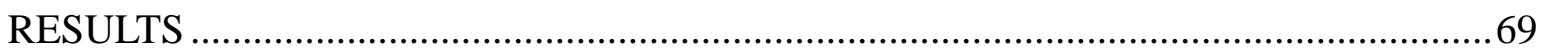

Cloning and analysis of bovine Lhx8 and Lhx8-v1 cDNA sequences...............................69

Expression of bovine Lhx8 and Lhx8-v1 mRNA in tissues and fetal ovaries .................... 70

Expression of bovine Lhx8 and Lhx8-v1 mRNA during oocyte maturation and early

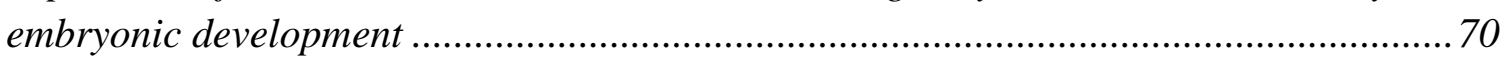

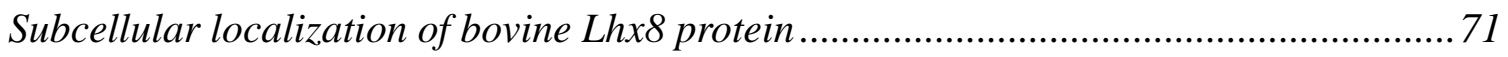

Evaluation of interactions of Lhx8 with Figla and Sohlh1 ............................................. 71

Lhx8: Figla interaction is dependent on the LIM domains of Lhx8 ................................ 72

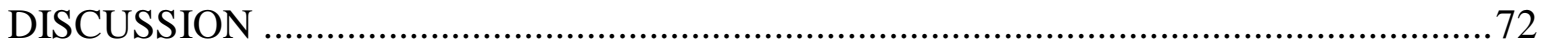

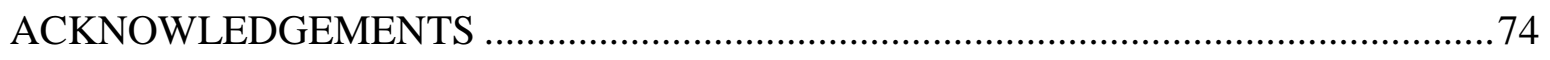

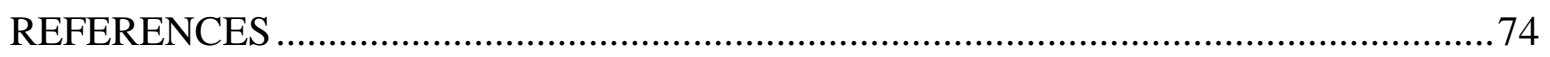

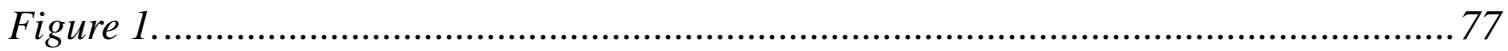

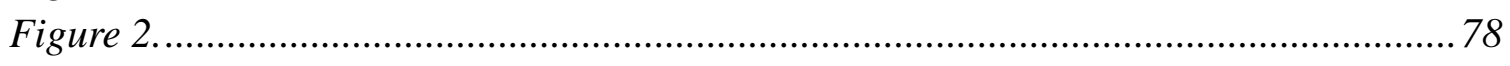

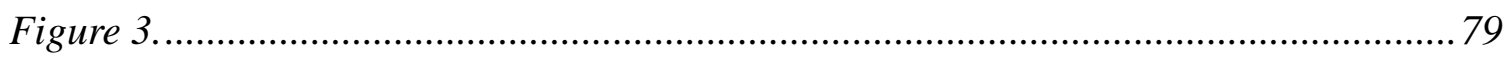

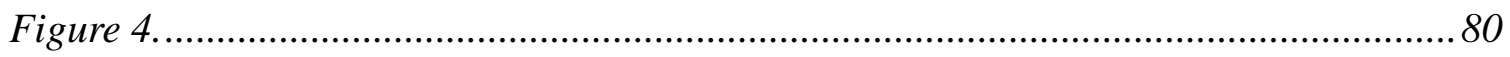

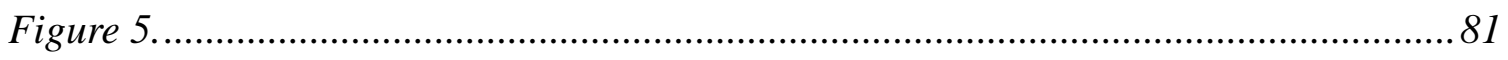




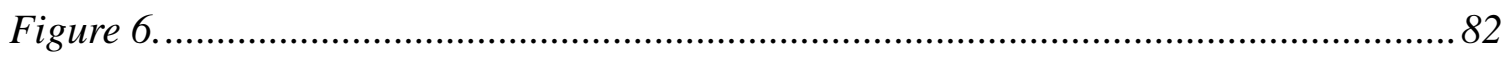

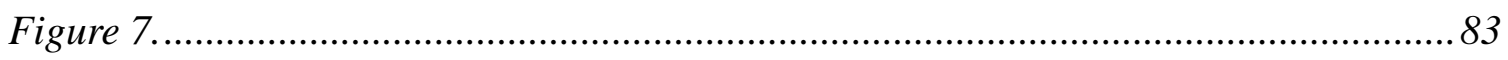

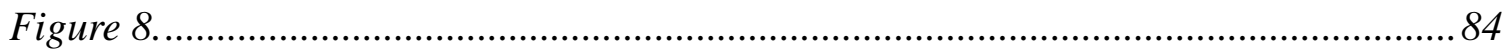

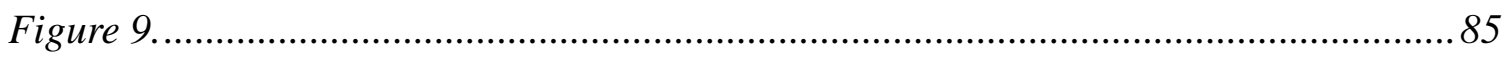

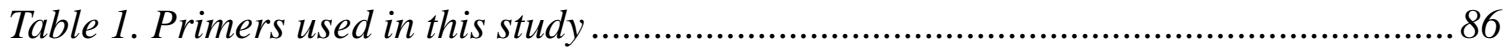

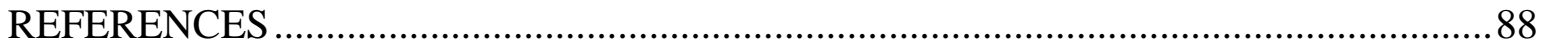

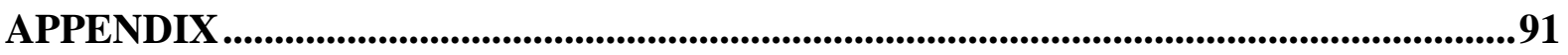

EVALUATION OF INTERACTIONS BETWEEN KPNA7 AND IMPORTANT

OOCYTE-SPECIFIC NUCLEAR FACTORS.............................................................

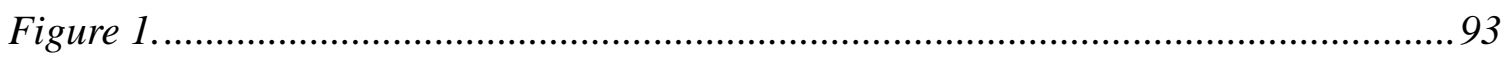

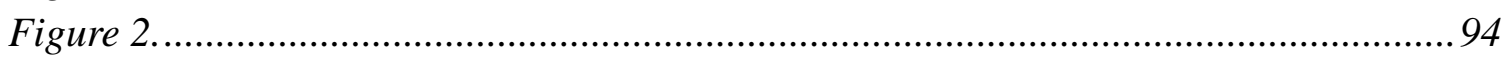

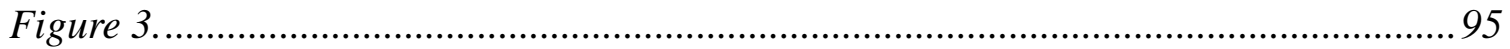

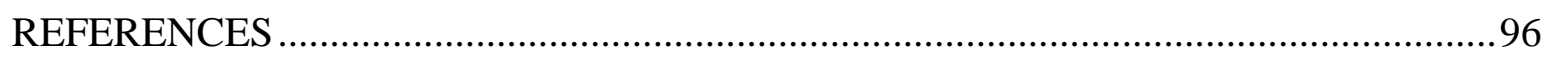




\section{LIST OF ABREVIATIONS}

AHR aromatic hydrocarbon receptor

ARM armadillo motifs

Arnt AHR nuclear-translocator

avt vasotocin

bHLH basic helix-loop-helix

BiFC bimolecular fluorescence complementation assay

BMP15 Bone Morphogenetic Protein15

cDNA Complementary DNA

ChIP chromatin immunoprecipitation

Cmah Cytidine monophosphate-N-acetylneuraminic acid hydroxylase

CRP C-reactive protein

DAPI 4, 6-diamidino-2-phenylindole

Dcx2 double cortin domain containing 2

Dppa3 Developmental Pluripotency Associated 3

EC cells embryonic carcinoma cells

ES cells embryonic stem cells

EST expressed sequence tags

Figla factor in the germline, $\alpha$

FOXL2 forkhead box L2

Gdf9 growth differentiation factor-9

GST Glutathione S-Transferase

GV germinal vesicle

IBB importin beta binding domain

Kpna7 importin alpha 7

Lhx 8 LIM homeobox 8

LIM Lin11, Isl-1 \& Mec-3

LMO2 LIM domain only 2 
Mvh mouse vasa homologue

Nlrp4c NLR family, pyrin domain containing 4c

NLSs Nuclear Localization signals

Nobox newborn ovary homeobox encoding gene

Oas1d 2',5'-oligoadenylate synthetase-like 8

Oas1h oligoadenylate synthetase $1 \mathrm{H}$

Padi6 Peptidyl Arginine Deiminase, Type VI

PHD plant homeo-domain motif

PIWIL2 piwi-like RNA-mediated gene silencing 2

POF premature ovarian failure

Pou5f1 POU Class 5 Homeobox 1

PPIs Protein-protein interactions

Rspo2 R-spondin 2

Sall4 Spalt-Like Transcription Factor 4

slc26 solute carrier/sulfate transporter

SRY sex determining region $\mathrm{Y}$

Tdrd6 Tdrd family member6

TFs transcription factors

TGF- $\beta$ transforming growth factor- $\beta$

Tsix $\mathrm{X}$-inactive specific transcript

VP16 Virus Protein 16

Xite $\mathrm{X}$-inactivation intergenic transcription elements

Zar1 Zygote arrest1

Zp1 zona pellucida 1

Zp3 zona pellucida 3

Mater Maternal Antigen That Embryos Require

mRNA Messenger RNA

POU Pit, Oct, Unc

RT-PCR Reverse Transcription Polymerase Chain Reaction 
SAGE Serial analysis of gene expression

Sohlh1 and Sohlh2 Spermatogenesis and Oogenesis Specific Basic Helix-Loop-Helix 1 and 2 


\section{LITERATURE REVIEW}

\section{Introduction}

The sophisticated transcriptional regulatory network during oogenesis and embryogenesis is established by a complex protein-protein and protein-DNA interaction network. Generally, proteins do not act alone. In living cells, protein interatomic system is built from protein-protein interactions. More and more research revealed that transcription factors heterodimerize with each other and control target genes expression in a combinatorial fashion (Tomioka, Nishimoto et al. 2002; Boyer, Lee et al. 2005; Okumura-Nakanishi, Saito et al. 2005). For example, direct interactions between POU-Homeodomain (POU-HD) and LIM-Homeodomain (LIM-HD) proteins are known to activate gene transcription (Xue et al. 1993). Analysis of interaction network of germ cell-specific proteins is important to understand the regulatory roles of these factors in oocyte and early embryonic development. Information relating to their expression and cellular localization is helpful in understanding their distinctive roles and their cooperative relationship. Transcription factors and other co-factors interact physically to control gene expression (Stampfel, Kazmar et al. 2015). Our lab has been interested in understanding the role of oocyte-specific genes that determine oocyte competence and early developmental potential in rainbow trout and cattle. We have discovered a number of novel oocyte-specific genes in both species. However, our understanding of the protein-protein interactions and regulatory networks of these key oocyte-specific factors is limited. This chapter summarizes our current knowledge of the functional roles of key oocyte-specific genes important for oocyte/follicle and early embryonic development. In addition, the functional domains for protein-DNA and protein-protein interactions are discussed.

\section{Importance of studying oocyte-specific genes in rainbow trout and cattle}

Due to overfishing and increasing demand for fish production, studies on producing high quality eggs are of interest to the aquaculture industry. From a biological point of view, the quality of an egg can be determined by its ability to be fertilized and develop into a normal 
embryo. Molecular, genetic and biochemical processes are important for egg production, lack of complete knowledge of these processes is a major gap to accomplish optimizing protocols for regulation of spawning. A fine balance of the spatio-temporal expression of key regulators must occur during oocyte development accompanied by massive structural and functional changes. In rainbow trout, approximately 240 genes were discovered to be developmentally regulated through the stages of oogenesis to control tissue remodeling, immunoregulation, cell-cycle progression, apoptosis and growth. A dramatic low expression of aromatase (cyp19a1), vitamin K-dependent protein $\mathrm{S}$ precursor gene and Cytidine monophosphate-N-acetylneuraminic acid hydroxylase (cmah) gene was observed with a contrasting increase in expression of aquaporin 4 (aqp4), solute carrier/sulfate transporter (slc26), vasotocin (avt), and Angiotensin converting enzyme 2 (ace2) during vitellogenesis and oocyte maturation (von Schalburg, Rise et al. 2005). All these genes function to achieve release of healthy eggs, which are ready to be fertilized. Synthesis, processing, and incorporation of maternal mRNAs, proteins, vitamins and hormones play an important role in a coordinated fashion for making a good quality egg.

Livestock such as cattle, sheep, and pigs have been used as important biomedical research models because they share similarities with humans during folliculogenesis, oogenesis and early embryogenesis. Reproductive techniques used in cattle, such as superovulation, oocyte culture, in-vitro fertilization, and embryo transfer, can be applied to human endocrinology and physiology studies. Bovine models have been used to study the genetics of mammalian oogenesis and mechanisms of premature ovarian failure in humans (Roberts et al. 2009).

In cattle, embryonic and fetal death are the major causes of reproductive loss (Sreenan et al. 1983). Evidence in lactating dairy cows subjected to timed artificial insemination indicates that $<50 \%$ of recovered embryos are viable by 7 days post insemination whereas fertilization rates are believed to be $>80 \%$ (Sartori et al. 2010). Such evidence supports a potential contribution of poor oocyte quality to impaired developmental capacity to day 7 post insemination in lactating dairy cows. An increased understanding of the role of oocyte-expressed genes in early embryonic development is therefore vital to a comprehensive 
understanding of the factors that limit fertility in vivo, and may ultimately lead to the development of approaches to enhance fertility.

\section{Oocyte-specific genes important for oocyte and follicular development}

\section{Factor in the germline, alpha (Figla)}

Factor in the germline, alpha (Figla) is a basic helix-loop-helix transcription factor that coordinates the expression of zona pellucida genes (Zp1, Zp2, and Zp3) (Liang, Soyal et al. 1997). Figla is essential for folliculogenesis and activation of oocyte-associated genes during normal oogenesis. In mouse, ablation of Figla can cause female infertility due to lack of primordial follicles, although this phenotype is not clearly seen in male mice $(\mathrm{Hu}$, Gauthier et al. 2010). Analysis of gene expression in Figla knockout mice using microarray and serial analysis of gene expression (SAGE) methods identified direct or indirect downstream target genes of Figla, such as Nlrp family members, POU Class 5 Homeobox 1 (Pou5f1), developmental pluripotency associated 3 (Dppa3), oligoadenylate synthetase 1H (Oas1h), and (Peptidyl Arginine Deiminase, Type VI (Padi6) (Joshi et al. 2007). Figla not only promotes the regulation of numerous oocyte-specific genes, but also inhibits testis-specific genes, such as Tdrd family member6 (Tdrd6), mouse vasa homologue (Mvh), and piwi-like RNA-mediated gene silencing 2 (PIWIL2) (Hu, Gauthier et al. 2010). A recent study indicated that Figla is negatively regulated by miR-212 during maternal to zygotic transition in bovine early embryos (Tripurani, Wee et al. 2013).

\section{LIM homeobox protein 8 (Lhx8)}

Germ cell-specific transcription factor Lhx 8 has a critical role in oocyte activation and survival. In mouse, Lhx8 is preferentially expressed in germ cells. Global knockout of Lhx8 leads to infertility and primordial like follicles are developed with no growth of oocyte (Choi, Ballow et al. 2008). Conditional knockout of Lhx8 in mice led to massive primordial oocyte activation. In addition, transition from the primary to secondary follicle stage had been confirmed to be blocked by conditional deletion of Lhx8 in mice (Ren, Suzuki et al. 2015). Lhx8 deficiency also negatively affects the expression of various oocyte-specific genes 
including Nobox (newborn ovary homeobox-encoding gene), Gdf9 (Growth differentiation factor-9), Bmp15 (Bone Morphogenetic Protein 15), Figla, Pou5f1, Oas1d (2',5'-oligoadenylate synthetase-like 8), Zp1 (zona pellucida 1), Zp3 (zona pellucida 3), and Nlrp4c (NLR family, pyrin domain containing 4c) (Choi, Ballow et al. 2008).

LIM domains in LIM homeodomain transcription factors mostly affect DNA binding negatively (Sanchez-Garcia, Osada et al. 1993; Bridwell, Price et al. 2001; Yaden, Savage et al. 2005). Evidence from a previous study with Lhx3 LIM domains interacting with DNA indicates that truncated LHX3 lacking LIM domains bind strongly to DNA, thus LIM domains can inhibit DNA binding affinity but not specificity (Bridwell, Price et al. 2001).

Lhx8 is also an active transcription factor in somatic tissues. It is important in development of basal forebrain cholinergic neurons and teeth (Shibaguchi, Kato et al. 2003; Mori, Yuxing et al. 2004). Recently, Lhx8 has been shown to repress lin28a expression by binding to its promoter region, which further regulates AKT activation thus promoting cell survival, growth, proliferation, migration and angiogenesis in response to extracellular signals (Ren, Suzuki et al. 2015).

\section{Spermatogenesis and oogenesis specific basic helix-loop-helix 1 (Sohlh1)}

Sohlh1 is an important germ cell-specific basic helix-loop-helix (bHLH) transcription factor, highly expressed in germ cell clusters, primordial and early primary oocytes in females and prespermatogonia and spermatogonia in males. Sohlh1 null mice are sterile due to defects in follicle development during primordial to primary follicle transition (Pangas, Choi et al. 2006). However, mutation of Sohlhl in mice, macaques and human patients didn't show obstructive azoospermia (Choi, Jeon et al. 2010; Suzuki, Ahn et al. 2012; Ramaswamy, Razack et al. 2014; Toyoda, Yoshimura et al. 2014). As a master regulator during oogenesis, Sohlh1 acts upstream of other oocyte-specific transcription factors, such as Nobox, Figla and Lhx 8 (Pangas, Choi et al. 2006; Suzumori, Pangas et al. 2007). Sohlh1 and Sohlh2 express exclusively during folliculogenesis. Recent studies showed that novel potentially deleterious Sohlh2 variants lead to Premature Ovarian Failure (POF) due to reduced protein production in Chinese and Serbian patients (Qin, Jiao et al. 2014). In addition, absence of three novel 
Sohlh1 variants potentially causing POF have been identified in 364 Chinese patients (Zhao, Li et al. 2015).

\section{Newborn ovary homeobox (Nobox)}

As an oocyte-specific homeobox gene, Nobox is highly expressed in mouse germ cell cysts, primordial and growing oocytes (Suzumori et al. 2002). Nobox was expressed as early as E15.5 and abundantly expressed throughout the process of folliculogenesis in oocytes (Suzumori, Yan et al. 2002; Rajkovic, Pangas et al. 2004). Nobox null female mice exhibit postnatal oocyte loss, atrophic ovaries and disrupted transition from primordial to growing follicles, which make them infertile. However, Nobox null males are fertile and normal (Rajkovic, Pangas et al. 2004). Nobox was reported to be a transcriptional activator of oocyte-specific genes. Microarray analysis using Nobox deficient ovaries and knock out studies showed significant down regulation of genes such as Pou5f1, Sall4 (Spalt-Like Transcription Factor 4), Nlrp4c, Rspo2 (R-spondin 2) (Choi et al. 2007), Gdf9 and Bmp15 (Dong, Albertini et al. 1996; Galloway, McNatty et al. 2000). Mutations in Nobox homeobox domain cause premature ovarian failure in human (Qin et al. 2007). In the recent study, Nobox-Foxl2 (Forkhead box L2) interaction complex acts as a negative regulator on Oct-4 transcriptional activity (Bouilly et al. 2014). Nobox can also bind with Pou5f1 and Gdf9 promoters (Choi et al. 2007).

\section{Octamer-binding transcription factor 4 (Oct-4)}

Oct-4 is a member of the POU domain family of octamer-binding proteins (Ryan and Rosenfeld 1997). The Oct-4 gene contains a conserved region of POU domain mediating sequence-specific DNA binding activity through both POU-specific and POU homeodomains (Herr and Cleary 1995). Oct-4 has been first discovered in the extracts of undifferentiated embryonic stem (ES) and embryonic carcinoma (EC) cells (Scholer et al. 1989). In human, Oct-4 expresses both maternally and zygotically (Abdel-Rahman et al. 1995). As a member of the POU family, Oct-4 appears able to function either as a transcriptional activator, or as a repressor (Ben-Shushan, Thompson et al. 1998). Oct-4 is highly expressed during mouse 
oogenesis and folliculogenesis till the 2- cell stage after fertilization. At 4-8 cell stage, zygotic Oct-4 gene starts express (Ovitt and Scholer 1998). Oct-4 plays an important role in establishment of pluripotential identity in the inner cell mass cells. Oct-4 deficient mouse embryos can develop to the blastocyst stage, but without the inner cell mass becoming pluripotency (Nichols, Zevnik et al. 1998).

POU factors are multifunctional complex involved in multiple protein-protein interactions that can activate or repress transcription, for example, Oct-4-Sox-2 (SRY (sex determining region Y)-box 2) heterodimer binding with Nanog homeobox (Nanog) promoter is at the top of regulatory hierarchy in the pluripotent genetic regulatory network (Rodda, Chew et al. 2005). By directly binding with Tsix (X-inactive specific transcript) and Xite (X-inactivation intergenic transcription elements) that are two regulatory noncoding RNA genes of the $\mathrm{X}$-inactivation center, Oct-4 triggers $\mathrm{X}$-chromosome pairing and counting (Donohoe et al. 2009).

Bovine Oct-4 shares high similarity in amino acid sequence with mouse Oct-4. Expression of Oct-4 mRNA in bovine oocyte is low, but after zygotic genome activation, Oct-4 transcription increases sharply (Kurosaka et al. 2004). Unlike mice, Oct-4 expression in cattle is not restricted to the inner cell mass during blastocyst development. It co-expresses with Dcx2 (double cortin domain containing 2) in the trophectoderm for some time after blastocyst formation (Berg, Smith et al. 2011). Clearly, the timing and mechanism of functional lineage restriction in blastocysts vary between the two species.

\section{Growth and differentiation factor 9 (Gdf-9)}

Growth and differentiation factor 9 (Gdf-9) is a member of the transforming growth factor- $\beta$ (TGF- $\beta$ ) superfamily. Recent studies in mice, human and sheep have characterized the important roles of this key factor. In mouse, complete loss of Gdf-9 leads to different effects in male and female. Gdf-9 knockout females are prone to infertility due to loss of granulosa cell mitotic ability at the end of primary stage (Dong et al. 1996), while males are not affected in terms of fertility. Furthermore, Gdf-9 influences all follicle components, including the oocyte, granulosa, and theca cells (Dong, Albertini et al. 1996; Carabatsos, 
Elvin et al. 1998; Elvin, Yan et al. 1999). An in vivo study in rats found that Gdf-9 stimulates the progression of primordial and primary follicles to small preantral follicles and causes increased expression of a theca cell specific marker, CYP17 (Vitt, McGee et al. 2000). During the final stages of follicle growth before ovulation, Gdf-9 supports the metabolic cascades including glycolysis and sterol biosynthesis (Sugiura et al. 2005). In the bovine ovary, Gdf-9 can promote proliferation but suppress differentiation of theca cells (Spicer, Aad et al. 2008). In humans, Gdf-9 mutations can cause premature ovarian failure and dizygotic twins (Dixit, Rao et al. 2006; Laissue, Christin-Maitre et al. 2006; Kovanci, Rohozinski et al. 2007; Zhao, Qin et al. 2007).

\section{Oocyte-specific maternal effect genes important for early embryogenesis}

During early embryonic development, before the embryonic genome activation, initial components and macromolecules are necessary for survival. Those crucial components are encoded by maternal-effect genes. The concept of maternal-effect genes has been characterized in mammals (Christians et al. 2000; Tong et al. 2000). These maternal factors are involved in various functions, initiating their activity right after fertilization in processing the male genome followed by removal of maternal detritus (RNA and protein) and finally in embryonic genome activation. Mutations in these maternal-effect genes caused arrested progression during the embryo cleavage-stage, which indicates maternal factors are involved in the regulation of important early steps during development. Maternal transcript and protein accumulation during oogenesis is crucial for the oocyte-to-embryo transition. Despite their important functions, very few mammalian maternal-effect genes have been characterized (Prolla, Baker et al. 1998; Christians, Davis et al. 2000; Tong, Gold et al. 2000; Howell, Bestor et al. 2001).

\section{Maternal antigen that embryos require (Mater)}

Mater is a maternal effect gene studied in mice and is critical for normal early embryonic development at the 2-cell stage (Tong et al. 2000). The transcripts of this gene are abundant in oocytes during oogenesis and eventually degraded during oocyte maturation and ovulation, 
while its protein product accumulates during oogenesis and persist during early embryogenesis. Mater null female mice show abnormal oogenesis, ovarian development, oocyte maturation, ovulation, fertilization and embryonic genome activation making them sterile while males are not generally affected. (Tong et al. 2000). Studies in both human and mouse indicate that the Mater protein harbors ATP-/GTP- binding domain, which suggests its involvement in intracellular signal transduction (Saraste et al. 1990). Mouse Mater protein has a leucine-rich repeat-like domain at the carboxyl-terminal, while human Mater has an amino-terminal pAAD_DAPIN domain, both of which correspond for protein-protein interactions (Kobe and Deisenhofer 1995; Pawlowski, Pio et al. 2001; Staub, Dahl et al. 2001). Furthermore, human Mater has an amino-terminal aldo_ket_red domain with oxidoreductase activity and a nuclear localization signal (NLS) (Bohren et al. 1989). Adding to the existing evidence, more studies support the critical role for maternal factors in the oocytes. (Barritt et al. 2001). Challenges in clinical IVF programs in normal early embryonic development may be due to lack of maternal factors in the fertilized ova, hence not all infertile women get cured. Whether specific maternal factors could help rescue early development or not is not known yet. If specific maternal factors are required, injecting the normal oocyte proteins into the oocytes of infertile women will provide IVF programs a novel therapy to improve fertilization rates.

\section{Zygote arrest1 (Zar1)}

Zar1, an oocyte specific maternal-effect gene, is important during the oocyte-to-embryo transition. In mouse, Zar1 null males are normal, while Zar1 null females are infertile due to embryo arrest at the one-cell stage. One-cell stage arrest of Zar1 null females indicates that Zar1 functions before embryonic genome activation (Wu et al. 2003a). Less than $20 \%$ of the embryos from Zar1 null females developed to the two cell stage and no embryos progressed to the four-cell stage ( $\mathrm{Wu}$ et al. 2003a). This progression in a normal embryo is where completion of meiotic-to-mitotic cell cycle transition and embryonic genome activation occur (Schultz 1993; Aoki, Worrad et al. 1997; Latham 1999; Jeanblanc, Salvaing et al. 2008).

In human, mouse, rat, frog, zebrafish and pufferfish, Zar1 contains a highly conserved, 
atypical plant homeo-domain (PHD), a motif of C8 (Aasland, Gibson et al. 1995; Wu, Wang et al. 2003; Uzbekova, Roy-Sabau et al. 2006) and cysteines [C-X2-C-X13-C-X2-C-X4-C-X1-C-X17-C-X2-C] are present indicating a selective pressure to keep the C-terminus intact (Wu et al. 2003b). The PHD motif is involved in protein-protein interactions of chromatin-mediated transcriptional regulation (Aasland, Gibson et al. 1995; Jacobson and Pillus 1999). Most PHD-containing proteins act as transcriptional regulators, such as activators, repressors, and cofactors. In a few proteins, the PHD motif is associated with histone deacetylase and functions in transcriptional silencing (Aapola, Liiv et al. 2002; Zhou, Santoro et al. 2002). Further investigations into the functions of the interactions of Zar1 in vivo will further reveal the regulatory actions of the Zar1 protein throughout oocyte and embryo development.

In cattle, Zar1 is expressed in ovary, testis, muscle, and myocardium as well as the oocyte, zygote, and all the stages of embryonic development till blastocyst formation (Brevini et al. 2004). Different from mouse, Zar1 transcripts persists beyond genome activation to the blastocyst stage. RNA polymerase II inhibition experiment suggests that bovine Zar1 is not only of maternal origin but also one of the first embryonic genes to be expressed (Wu et al. 2003b). A prolonged presence of Zar1 during early embryogenesis coupled with the expression of Zar1 in some somatic tissues indicate that Zar1 perhaps regulates transcription during an extended period of embryonic development, even into adult life (Brevini et al. 2004). In addition, Zar1 can also regulate meiosis and post meiotic differentiation of male and female germ cells via expressing shorter splicing variants, which suggests a central role of Zar1 in early reproductive processes (Uzbekova, Roy-Sabau et al. 2006).

\section{Importin alpha 8 (Kpna7)}

Before embryonic genome activation, transcription and chromatin remodeling factors are necessary for initiation of transcription. Importins serve as major carriers to transport proteins from the cytoplasm to the nucleus. Ions and small proteins $(<40 \mathrm{kDa})$ can passively diffuse through the nuclear pore. However, large proteins $(>40 \mathrm{kDa})$ are translocated by an energy-dependent, signal-mediated transport system involving importin $\alpha$ and $\beta$, the best 
characterized nuclear transport systems to date (Gorlich and Kutay 1999; Weis 2003). Nuclear localization signals (NLSs) of proteins are recognized and bound by importin $\alpha$ and importin $\beta$. Importin $\beta$ helps in translocation of the protein complex by docking to the pore.

In human, there are six KPNA family members which are further classified into three subfamilies based on their sequence homology. The first subfamily includes KPNA2 (Cuomo, Kirch et al. 1994; Weis, Mattaj et al. 1995). The second subfamily consists of KPNA4 and KPNA3, and the third subfamily KPNA1, KPNA5 and KPNA6 (Cortes, Ye et al. 1994; Kohler, Ansieau et al. 1997; Seki, Tada et al. 1997; Nachury, Ryder et al. 1998; Kohler, Speck et al. 1999). Different subfamilies share $~ 50 \%$ sequence identity. Every member has the same structural motifs including an $\mathrm{N}$-terminal importin beta binding domain (IBB) and several repeated armadillo (ARM) motifs which contain NLS-binding pockets (Peifer, Berg et al. 1994; Gorlich, Henklein et al. 1996).

Bovine KPNA family members share high sequence identity with human/mouse counterparts. KPNA7 has been characterized as a novel oocyte-specific gene in recent years (Tejomurtula, Lee et al. 2009). Bovine KPNA7 shares 53\%, 45\%, 45\%, 41\%, $40 \%$ and $40 \%$ sequence homology with KPNA2, KPNA4, KPNA3, KPNA1, KPNA5 and KPNA6, respectively (Tejomurtula, Lee et al. 2009). Therefore, KPNA7 was grouped together with KPNA2 as the first subfamily of the KPNA family (Tejomurtula, Lee et al. 2009). Compared to other KPNA family members, KPNA7 has at least a 30 times higher expression level in GV (germinal vesicle) oocytes. KPNA7 knockdown leads to impaired development of oocytes at the blastocyst stage in cattle, which suggested KPNA7 might be an essential importin aiding in translocation of essential oocyte-specific nuclear factors required for maternal to embryonic transition (Tejomurtula, Lee et al. 2009).

\section{Functional domains for protein-protein interaction}

\section{LIM (Lin11, Isl-1 and Mec-3) domain}

The LIM domain, a cysteine-rich sequence, is recognized as a tandem zinc-finger structure that functions as a modular protein-binding interface. In human, 135 LIM protein coding sequences are located within 58 genes. Human LIM proteins comprise 1-5 LIM 
domains and can be connected with other domains, such as homeodomains, catalytic domains, cytoskeletal-binding domains, or other protein-binding modules (SH3, LD or PDZ domains.). These features give diverse functions to the LIM proteins. Many LIM proteins perform as regulators of gene expression, signal transduction, cytoarchitecture, cell motility, and cell adhesion. LIM homeodomain proteins have specific transcriptional roles during development (Hobert and Westphal 2000). Various proteins binding to LIM domains informed our present understanding of the role of LIM proteins in diverse biological processes. As LIM proteins interact with other protein domains, the protein-docking ability of LIM domain enables the protein to act as an adaptor providing a mechanism to recruit molecules and subsequently affect activity. For example, the functions of LIM domains in LMO2 (LIM domain only 2 ) and CRP (C-reactive protein) family members are assembly of other protein complexes (Louis, Pino et al. 1997; Ecarnot-Laubriet, De Luca et al. 2000; Knoll, Hoshijima et al. 2002; $\mathrm{Xu}$, Huang et al. 2003). With the identification of more proteins binding with LIM domain, LIM proteins functions have been discovered in more diverse biological processes. Moreover, subcellular location is crucial in determining protein function, which defines multiple functions of LIM proteins as kinases, phosphatases and transcription factors (Cyert 2001). LIM domains have the ability of targeting the proteins either by directing their own location or by communication with other partners to specify subcellular localization. For instance, LIM domains in zyxin are required for cell-substratum attachment (Nix et al. 2001) and also necessary for localization of Testin LIM Domain Protein (TES) to focal adhesions (Garvalov, Higgins et al. 2003). LIM proteins also help in exporting proteins from the nucleus through their nuclear export signals thus preventing nuclear accumulation (Campana et al. 2003). For example, zyxin commutes between the cytoplasm and the nucleus (Nix and Beckerle 1997; Nix, Fradelizi et al. 2001). It is common that LIM proteins are active in both nucleus and the cytoplasm indicating that they may have distinct roles. Studies relating to their subcellular localization and partners are necessary to completely understand their precise roles.

\section{Basic helix-loop-helix (bHLH) domain}

Transcription factors containing helix-loop-helix family play important regulatory roles 
in various transcriptional networks and developmental pathways (Murre, McCaw et al. 1989; Sun, Copeland et al. 1991; Murre, Bain et al. 1994). In Xenopus laevis, Drosophila melanogaster, and mice, numerous bHLH proteins have been discovered, these bHLH proteins are involved in a broad array of processes including cellular differentiation, lineage commitment, and sex determination. Also, some important metabolic pathways, such as phosphate uptake and phospholipid biosynthesis require bHLH proteins (Berben, Legrain et al. 1990; Hoshizaki, Hill et al. 1990; Nikoloff, Mcgraw et al. 1992). bHLH proteins are crucial for some multicellular organisms' developmental processes, such as neurogenesis, myogenesis, hematopoiesis and pancreatic development (Bain, Maandag et al. 1994; Zhuang, Soriano et al. 1994; Lee, Hollenberg et al. 1995; Porcher, Swat et al. 1996).

bHLH proteins have been classified into seven groups with respect to their tissue distribution, dimerization capabilities, and DNA-binding specificities (Massari and Murre 2000). Class I proteins are well known as E proteins including E12, E47, HEB, and E2-2. They are capable of forming homo or heterodimers (Murre et al. 1989). Class II bHLH proteins exhibit a tissue-restricted expression pattern. Most proteins in this class cannot form homodimers but preferentially bind canonical and non-canonical E-box proteins (Murre et al. 1989). Class III bHLH proteins contain a leucine zipper motif (LZ) adjacent to the bHLH motif, examples include the Myc family of transcription factors and microphthalmia-associated transcription factors (Henthorn, Stewart et al. 1991; Zhao, Zhao et al. 1993). Class IV bHLH proteins are able to dimerize with Myc proteins or with each other, such as Mad, Max, and Mxi (Blackwood and Eisenman 1991; Ayer, Kretzner et al. 1993; Zervos, Gyuris et al. 1993). Class V bHLH proteins lack a basic region, examples include Id and emc (Benezra, Davis et al. 1990; Ellis, Spann et al. 1990; Garrell and Modolell 1990). Class VI bHLH proteins have a proline in the basic region, examples include Hairy and Enhancer of split in Drosophila (Klambt, Knust et al. 1989; Rushlow, Hogan et al. 1989). Class VII bHLH proteins contain bHLH-PAS domain, such as aromatic hydrocarbon receptor (Ahr), Ahr nuclear-translocator (Arnt), hypoxia-inducible factor 1alpha and Drosophila Single-minded and period proteins (Crews 1998).

HLH proteins have also been discovered to associate with other transcription factors and 
regulate tissue specific gene expression and tumorigenesis. For example, class II HLH protein TAL1 together with LIM transcription factor Lmo2 induce T-cell leukemia (Larson et al. 1996). Additionally, HLH proteins are able to induce gene expression involved in the signal transduction of downstream pathways. For example, TFE3 HLH region is required to activate PAI-1 expression in a TGF-beta-dependent manner (Hua et al. 1998). DNA binding, dimerization, transactivation and repression are the main functions of proteins as regulators in the developmental pathways, cell growth, and cell death. The mechanism of how HLH proteins regulate gene expression is largely unknown.

\section{POU (Pit, Oct, Unc) domain}

POU domain, as a conserved structural motif, was identified in three mammalian homeodomain containing transcription factors which act as developmental regulators (Bodner, Castrillo et al. 1988; Clerc, Corcoran et al. 1988; Finney, Ruvkun et al. 1988; Herr, Sturm et al. 1988; Ingraham, Chen et al. 1988; Ko, Fast et al. 1988; Muller, Ruppert et al. 1988; Scheidereit, Cromlish et al. 1988; Sturm, Das et al. 1988). More and more new members have been discovered, many with important roles in cellular differentiation and ontogenetic development (He, Treacy et al. 1989; Monuki, Kuhn et al. 1990; Scholer, Ruppert et al. 1990; Suzuki, Rohdewohld et al. 1990; Hara, Rovescalli et al. 1992). A knockout study of Oct-2 has revealed its crucial role during later stages of B-cell maturation (Corcoran et al. 1993). An increasing number of POU domain proteins have been discovered and shown to be essential in development or terminal differentiation.

POU domain spans 150-160 amino acids comprised of a highly conserved 75-82 amino acids POU-specific domain and carboxyl-terminal region of 60 amino acids which is the POU homeodomain. A less conserved linker region connects both POU specific and POU homeodomains. POU domain proteins recognize longer DNA motifs compared to POU homeodomains (Clerc, Corcoran et al. 1988; Muller, Ruppert et al. 1988; Nelson, Albert et al. 1988; Sturm, Das et al. 1988). That is to say that direct high-affinity binding to the DNA target sites not only requires POU homeodomain, but also a POU specific domain (Ingraham, Flynn et al. 1990; Botfield, Jancso et al. 1992; Verrijzer, Alkema et al. 1992). In addition to 
DNA binding function, POU domain proteins also can interact with other proteins. For example, Oct1 directly interacts with VP16 (Virus Protein 16) when recruited to the viral promoter as a complex (Stern and Herr 1991). In addition, POU domain proteins often have close proximity to other transcription factors and subsequently enhance transcription. For instance, Pit-1 together with the estrogen receptor have been characterized as a prolactin gene enhancer (Day, Koike et al. 1990; Simmons, Voss et al. 1990). During development or tissue specific regulation, POU domain proteins exhibit both positive and negative functions in regulation of different promoters. For example, Oct-6 activates synthetic promoters of JC virus, but represses the $\mathrm{P}_{\mathrm{o}}$ gene promoter (Monuki, Kuhn et al. 1990; He, Gerrero et al. 1991).

In early embryogenesis and cell type specific differentiation, abundant expression of POU domain proteins suggested key roles as developmental regulators. For example, Unc-86 in C. elegans is necessary for the specification and maintenance of particular neural phenotypes (Finney and Ruvkun 1990). A knockout study of Oct-2 has justified its crucial role during later stages of B-cell maturation (Corcoran et al. 1993). Till now, an increasing number of POU domain proteins have been found to be essential in development or terminal differentiation. Subsequent knockout studies will define the exact functions of numerous POU domain proteins in these processes.

\section{Protein-DNA interactions}

Differential gene expression is regulated at both the transcriptional and post-transcriptional levels. Active or inactive transcription is due to physical binding of transcription factors (TFs) to their cis-regulatory elements as promoters, enhancers or repressors. Most TFs include at least two domains which are the DNA binding domain and the transcription regulation domain. TFs use their DNA binding domain to target DNA sequences while the transcription regulation domain serves to activate or inhibit transcription (Walhout 2006). TFs are basically grouped by DNA binding domains. To date, more than 100 different DNA binding domains have been identified (Kummerfeld and Teichmann 2006). Computational prediction of genes encoding these domains gives a basic understanding of the factors but is not sufficient to understand the specific functions. 
To identify protein-DNA interactions between TFs and target DNA elements, two strategies have been developed which are "TF-centered" and "gene-centered" (Deplancke, Mukhopadhyay et al. 2006). TF-centered is most widely used and it is based on chromatin immunoprecipitation (ChIP) (Elnitski et al. 2006). In ChIP assay, DNA bound to the TF are pulled down using anti-TF antibody. Microarrays, PCR, cloning and sequencing are subsequently applied to identify the bound DNA sequence. The typical method to define gene-centered protein-DNA interactions is the yeast one-hybrid (Y1H) assay. In Y1H system, uncharacterized, predicted TFs will be discovered by binding to a DNA, which is defined as "DNA bait" (Li and Herskowitz 1993; Wang and Reed 1993; Hartley, Temple et al. 2000; Walhout, Sordella et al. 2000; Deplancke, Dupuy et al. 2004; Dupuy, Li et al. 2004). This method allows large scale, unbiased identification of TF-DNA interactions.

Any large-scale, high-throughput assays have the potential for false positives. Some interactions detected in vitro may not occur in vivo. On the other hand, interactions in vivo do not necessarily have to occur in vitro (Walhout 2006). Protein-DNA interactions occur in several specific cells over a short time period during development. In order to get high-confidence interactions, high stringency criteria to filter the data requires attention to sensitivity and specificity. Multiple and complementary methods should be used to obtain comprehensive, high-quality protein-DNA interactions.

\section{Protein-protein interaction (PPI)}

Different cellular mechanisms and functions require different sets of direct and indirect interactions among the proteins. Physical direct interactions do not cover much of all the protein interactions due to limited theoretically potential interaction space (Aloy and Russell 2004). It is not necessary for proteins to form a stable direct interactions to gain a specific function. There are many alternative ways to regulate a function, such as by catalyzing downstream reactions in a metabolic pathway, transcriptional or post-transcriptional regulation, and interacting to form a large complex. As a matter of fact, indirect interactions are the major superset of functional protein-protein associations (Eisenberg, Marcotte et al. 2000; Huynen, Snel et al. 2000). 
Traditionally, proteins are identified as catalysts, signaling molecules, or building blocks in cells based on their individual actions. Protein-protein interactions have to be considered as functional modules with contextual or cellular function in the post-genomic era. There are permanent PPIs which are strong and irreversible, and transient PPIs which are weak and will undergo oligomeric changes. Transient complexes can also be subdivided into weak and strong based on the tendency of changes in their oligomeric states (Nooren and Thornton 2003).

Weak PPIs are not easy to detect compared to the permanent PPIs. However, high-throughput yeast two-hybrid screens can be used for transient interactions (Shoemaker and Panchenko 2007). Although a high false-positive rate cannot be ignored, Yeast two-hybridization $(\mathrm{Y} 2 \mathrm{H})$ is still the most popular assay for large scale detection of PPIs (Bruckner et al. 2009). 3000 PPIs were unraveled in human using Y2H. 159 PPIs have been verified by using Co-immunoprecipitation (Co-IP) and Glutathione S-Transferase Pull Down (GST-pull down). 195 disease proteins have been discovered as novel interaction partners (Stelzl, Worm et al. 2005). Another high throughput assay is tandem affinity purification run in conjunction with mass spectroscopy (Collins and Choudhary 2008). Because of technical advances, transient interactions can be detected on a small-scale by using tandem affinity purification combined with mass spectrometry (TAP-MS) together with crosslinking (Tagwerker, Flick et al. 2006; Stingl, Schauer et al. 2008). Other methods using cell systems for PPI screening, the bimolecular fluorescence complementation (BiFC) assay, which is able to detect transient PPIs in the cell without protein purification (Morell et al. 2007). Those above experimental methods can be high throughput but not comprehensive. Computational tools will also allow PPI prediction with increased confidence. There are many computational methods to predict PPIs based on structural data, genomic context information, experimental data, and methods of combining data sources (Cho, Park et al. 2004; Obenauer and Yaffe 2004; Shoemaker and Panchenko 2007; Shoemaker and Panchenko 2007; Xia, Wang et al. 2010). With the improvement of PPI detection methods, more and more PPIs from system and structural biology will be unraveled. In light of the development of internet and database, PPI information can be retrieved from numerous online resources. Primary interaction 
databases provide accurate experimental data generated from biochemical, biophysical and genetic techniques (Salwinski, Miller et al. 2004; Kerrien, Aranda et al. 2012; Licata, Briganti et al. 2012; Orchard, Kerrien et al. 2012; Schaefer, Fontaine et al. 2012; Chatr-Aryamontri, Breitkreutz et al. 2013; Orchard, Ammari et al. 2014). On the other hand, to provide comprehensive predictions and integrate both known and predicted interactions, some online resources, such as STRING, GeneMANIA (Zuberi et al. 2013), FunCoup (Schmitt et al. 2014), 12D (Niu, Otasek et al. 2010) and ConsensusPathDB (Niu, Otasek et al. 2010) use different algorithms to provide a critical assessment of PPIs.

Protein-protein interactions are driven by conserved domains in them. With genome duplication and evolution, the scope and the number of paralogous interacting proteins expand and keep specific to avoid unwanted cross-talk (Zarrinpar, Park et al. 2003; Capra, Perchuk et al. 2012). There is evident that the interacting proteins often coevolve to feature specificity of protein-protein interface (Ovchinnikov et al. 2014) without involving non-functional intermediates (Aakre et al. 2015).

The "Interactome" network, represents the protein-protein interaction network so far without dynamic or steady state information due to timing and location of the interactions (Jeong, Mason et al. 2001; Li, Armstrong et al. 2004). A small number of proteins which are considered as "hubs" interact with many proteins, whereas most proteins have few partners. Both biological and non-biological networks are sensitive to hub removal but resistant to random node removal (Jeong et al. 2001). In yeast, lethality is threefold more likely upon of hub removal than non-hub removal (Winzeler, Shoemaker et al. 1999; Jeong, Mason et al. 2001; Giaever, Chu et al. 2002). Hubs play a key role in PPIs dynamically regulated both in time and space (Han et al. 2004). Hubs also have been divided into two groups: "party" hubs which are many proteins' partners simultaneously. "Date" hubs which interact with different partners at different times or locations (Han et al. 2004). Party hubs are important for the functions mediated by their partners. Date hubs connect modules in a wide range, which contribute to a global organization of biological modules. In silico experiments uncovered that removal of party hubs does not affect connectivity, however a vast majority of the effect occurs when attacks against all date hubs (Han et al. 2004). Discriminating between date and 
party hubs will allow us to better understand properties of the interactome, such as stability and flexibility of selective advantages (Han et al. 2004).

In addition, PPI networks not only provide new ideas for the protein functions but also may help reveal genetic organization principles of functional cellular networks in spatial and temporal aspects (Ge et al. 2003). In human ES cells, Nanog is the central regulator of transcription. A mini-interactome of Nanog associated proteins has been constructed, which serves as a functional module aiming to maintain ES cell pluripotency (Wang et al. 2006). Another PPI network of cell cycle genes suggested "just in time", which pointed out that not all the genes in a subunit are expressed at the same time (de Lichtenberg, Jensen et al. 2005; Wu, Guo et al. 2009). In addition, multiple interactions among critical factors also influence other members' functions positively or negatively. In the complex maintaining pluripotency, target genes regulated by Nanog are combinatorially controlled by other proteins, such as Oct4 and Sox 2 (Wang et al. 2006). About 95\% of multiexon genes in human have been affected by alternative splicing. mRNA variants are expressed differently in human cells and tissues (Pan, Shai et al. 2008; Wang, Sandberg et al. 2008). Brain and other tissue regulated exons with conserved interaction surfaces have more interactions in PPI networks than other proteins (Ellis et al. 2012). Thus, tissue dependent PPI networks are usually remodeled by alternative exons (Ellis, Barrios-Rodiles et al. 2012). In addition, post translational modification (PTMs) including phosphorylation, methylation, ubiquitination and acetylation play a widespread role in the interactome dynamics (Wilkins and Kummerfeld 2008). PTMs can alter the structure of proteins and subsequently affect their capacity to interact (Seet et al. 2006). In some cases, a single modification of just one amino acid can switch on/off the interaction of a domain. For example, protein phosphorylation modulates $\mathrm{SH} 2$ protein interaction (Yaffe 2002). Methylation of arginine can either facilitate or block PPIs. In yeast, post translational arginine methylation affects PPIs in a subset of the yeast interactome (Erce, Abeygunawardena et al. 2013).

Collectively, developmental competence of an oocyte requires synthesizing and accumulating transcripts and proteins which are the key factors for folliculogenesis, germ cell maturation, fertilization, and early embryogenesis. We have identified oocyte-derived genes 
that promote oogenesis and embryogenesis in rainbow trout and cattle using genomic tools and published reports in mouse and human candidate genes of interest. In this study, major emphasis is placed on characterization of the $\operatorname{Lhx} 8$ and identification of its protein interaction partners in rainbow trout and cattle, which will provide new information for investigating the mechanisms of the regulatory roles of Lhx8 during folliculogenesis, oogenesis and early embryogenesis. 


\section{REFERENCES}

Aakre, C. D., J. Herrou, et al. (2015). "Evolving New Protein-Protein Interaction Specificity through Promiscuous Intermediates." Cell 163(3): 594-606.

Aapola, U., I. Liiv, et al. (2002). "Imprinting regulator DNMT3L is a transcriptional repressor associated with histone deacetylase activity." Nucleic Acids Research 30(16): 3602-3608.

Aasland, R., T. J. Gibson, et al. (1995). "The PHD finger: implications for chromatin-mediated transcriptional regulation." Trends Biochem Sci 20(2): 56-59.

Abdel-Rahman, B., M. Fiddler, et al. (1995). "Expression of transcription regulating genes in human preimplantation embryos." Hum Reprod 10(10): 2787-2792.

Aloy, P. and R. B. Russell (2004). "Ten thousand interactions for the molecular biologist." Nat Biotechnol 22(10): 1317-1321.

Aoki, F., D. M. Worrad, et al. (1997). "Regulation of transcriptional activity during the first and second cell cycles in the preimplantation mouse embryo." Developmental Biology 181(2): 296-307.

Arber, S. and P. Caroni (1996). "Specificity of single LIM motifs in targeting and LIM/LIM interactions in situ." Genes Dev 10(3): 289-300.

Ayer, D. E., L. Kretzner, et al. (1993). "Mad - a Heterodimeric Partner for Max That Antagonizes Myc Transcriptional Activity." Cell 72(2): 211-222.

Bain, G., E. C. Maandag, et al. (1994). "E2A proteins are required for proper B cell development and initiation of immunoglobulin gene rearrangements." Cell 79(5): 885-892.

Barabasi, A. L. and Z. N. Oltvai (2004). "Network biology: understanding the cell's functional organization." Nat Rev Genet 5(2): 101-113.

Barritt, J., S. Willadsen, et al. (2001). "Cytoplasmic transfer in assisted reproduction." Hum Reprod Update 7(4): 428-435.

Ben-Shushan, E., J. R. Thompson, et al. (1998). "Rex-1, a gene encoding a transcription factor expressed in the early embryo, is regulated via Oct-3/4 and Oct-6 binding to an octamer site and a novel protein, Rox-1, binding to an adjacent site." Mol Cell Biol 
18(4): 1866-1878.

Benezra, R., R. L. Davis, et al. (1990). "The protein Id: a negative regulator of

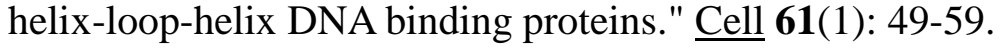

Berben, G., M. Legrain, et al. (1990). "The yeast regulatory gene PHO4 encodes a helix-loop-helix motif." Yeast 6(5): 451-454.

Berg, D. K., C. S. Smith, et al. (2011). "Trophectoderm lineage determination in cattle." Dev Cell 20(2): 244-255.

Blackwood, E. M. and R. N. Eisenman (1991). "Max - a Helix-Loop-Helix Zipper Protein That Forms a Sequence-Specific DNA-Binding Complex with Myc." Science 251(4998): 1211-1217.

Bodner, M., J. L. Castrillo, et al. (1988). "The Pituitary-Specific Transcription Factor-Ghf-1 Is a Homeobox-Containing Protein." Cell 55(3): 505-518.

Bohren, K. M., B. Bullock, et al. (1989). "The Aldo-Keto Reductase Superfamily - Cdnas and Deduced Amino-Acid Sequences of Human Aldehyde and Aldose Reductases." Journal of Biological Chemistry 264(16): 9547-9551.

Botfield, M. C., A. Jancso, et al. (1992). "Biochemical characterization of the Oct-2 POU domain with implications for bipartite DNA recognition." Biochemistry 31(25): $5841-5848$.

Bouilly, J., R. A. Veitia, et al. (2014). "NOBOX is a key FOXL2 partner involved in ovarian folliculogenesis." Journal of Molecular Cell Biology 6(2): 175-177.

Boyer, L. A., T. I. Lee, et al. (2005). "Core transcriptional regulatory circuitry in human embryonic stem cells." Cell 122(6): 947-956.

Brevini, T. A., F. Cillo, et al. (2004). "Expression pattern of the maternal factor zygote arrest 1 (Zar1) in bovine tissues, oocytes, and embryos." Mol Reprod Dev 69(4): 375-380.

Bridwell, J. A., J. R. Price, et al. (2001). "Role of the LIM domains in DNA recognition by the Lhx3 neuroendocrine transcription factor." Gene 277(1-2): 239-250.

Bridwell, J. L., J. R. Price, et al. (2001). "Role of the LIM domains in DNA recognition by the Lhx3 neuroendocrine transcription factor." Gene 277(1-2): 239-250.

Bruckner, A., C. Polge, et al. (2009). "Yeast two-hybrid, a powerful tool for systems biology." 
Int J Mol Sci 10(6): 2763-2788.

Campana, W. M., R. R. Myers, et al. (2003). "Identification of PINCH in Schwann cells and DRG neurons: shuttling and signaling after nerve injury." Glia 41(3): 213-223.

Capra, E. J., B. S. Perchuk, et al. (2012). "Adaptive Mutations that Prevent Crosstalk Enable the Expansion of Paralogous Signaling Protein Families." Cell 150(1): 222-232.

Carabatsos, M. J., J. Elvin, et al. (1998). "Characterization of oocyte and follicle development in growth differentiation factor-9-deficient mice." Dev Biol 204(2): 373-384.

Chatr-Aryamontri, A., B. J. Breitkreutz, et al. (2013). "The BioGRID interaction database: 2013 update." Nucleic Acids Res 41(Database issue): D816-823.

Cho, S., S. G. Park, et al. (2004). "Protein-protein interaction networks: from interactions to networks." J Biochem Mol Biol 37(1): 45-52.

Choi, Y., D. J. Ballow, et al. (2008). "Lim homeobox gene, lhx 8, is essential for mouse oocyte differentiation and survival." Biol Reprod 79(3): 442-449.

Choi, Y., S. Jeon, et al. (2010). "Mutations in SOHLH1 gene associate with nonobstructive azoospermia." Hum Mutat 31(7): 788-793.

Choi, Y., Y. Qin, et al. (2007). "Microarray analyses of newborn mouse ovaries lacking Nobox." Biol Reprod 77(2): 312-319.

Christians, E., A. A. Davis, et al. (2000). "Maternal effect of Hsf1 on reproductive success." Nature 407(6805): 693-694.

Clerc, R. G., L. M. Corcoran, et al. (1988). "The B-Cell-Specific Oct-2 Protein Contains Pou Box-Type and Homeo Box-Type Domains." Genes \& Development 2(12A): 1570-1581.

Collins, M. O. and J. S. Choudhary (2008). "Mapping multiprotein complexes by affinity purification and mass spectrometry." Curr Opin Biotechnol 19(4): 324-330.

Corcoran, L. M., M. Karvelas, et al. (1993). "Oct-2, Although Not Required for Early B-Cell Development, Is Critical for Later B-Cell Maturation and for Postnatal Survival." Genes \& Development 7(4): 570-582.

Cortes, P., Z. S. Ye, et al. (1994). "RAG-1 interacts with the repeated amino acid motif of the human homologue of the yeast protein SRP1." Proc Natl Acad Sci U S A 91(16): 7633-7637. 
Crews, S. T. (1998). "Control of cell lineage-specific development and transcription by bHLH-PAS proteins." Genes Dev 12(5): 607-620.

Cuomo, C. A., S. A. Kirch, et al. (1994). "Rch1, a protein that specifically interacts with the RAG-1 recombination-activating protein." Proc Natl Acad Sci U S A 91(13): 6156-6160.

Cyert, M. S. (2001). "Regulation of nuclear localization during signaling." J Biol Chem 276(24): 20805-20808.

Davidson, E. H., J. P. Rast, et al. (2002). "A genomic regulatory network for development." Science 295(5560): 1669-1678.

Day, R. N., S. Koike, et al. (1990). "Both Pit-1 and the Estrogen-Receptor Are Required for Estrogen Responsiveness of the Rat Prolactin Gene." Molecular Endocrinology 4(12): 1964-1971.

de Lichtenberg, U., L. J. Jensen, et al. (2005). "Dynamic complex formation during the yeast cell cycle." Science 307(5710): 724-727.

Deplancke, B., D. Dupuy, et al. (2004). "A gateway-compatible yeast one-hybrid system." Genome Res 14(10B): 2093-2101.

Deplancke, B., A. Mukhopadhyay, et al. (2006). "A gene-centered C. elegans protein-DNA interaction network." Cell 125(6): 1193-1205.

Dixit, H., L. K. Rao, et al. (2006). "Missense mutations in the BMP15 gene are associated with ovarian failure." Hum Genet 119(4): 408-415.

Dong, J. W., D. F. Albertini, et al. (1996). "Growth differentiation factor-9 is required during early ovarian folliculogenesis." Nature 383(6600): 531-535.

Donohoe, M. E., S. S. Silva, et al. (2009). "The pluripotency factor Oct4 interacts with Ctcf and also controls X-chromosome pairing and counting." Nature 460(7251): 128-U147.

Dupuy, D., Q. R. Li, et al. (2004). "A first version of the Caenorhabditis elegans Promoterome." Genome Res 14(10B): 2169-2175.

Ecarnot-Laubriet, A., K. De Luca, et al. (2000). "Downregulation and nuclear relocation of MLP during the progression of right ventricular hypertrophy induced by chronic pressure overload." Journal of Molecular and Cellular Cardiology 32(12): 2385-2395.

Eisenberg, D., E. M. Marcotte, et al. (2000). "Protein function in the post-genomic era." 
Nature 405(6788): 823-826.

Ellis, H. M., D. R. Spann, et al. (1990). "extramacrochaetae, a negative regulator of sensory organ development in Drosophila, defines a new class of helix-loop-helix proteins." Cell 61(1): 27-38.

Ellis, J. D., M. Barrios-Rodiles, et al. (2012). "Tissue-specific alternative splicing remodels protein-protein interaction networks." Mol Cell 46(6): 884-892.

Ellis, J. D., M. Barrios-Rodiles, et al. (2012). "Tissue-Specific Alternative Splicing Remodels Protein-Protein Interaction Networks." Molecular Cell 46(6): 884-892.

Elnitski, L., V. X. Jin, et al. (2006). "Locating mammalian transcription factor binding sites: a survey of computational and experimental techniques." Genome Res 16(12): 1455-1464.

Elvin, J. A., C. Yan, et al. (1999). "Molecular characterization of the follicle defects in the growth differentiation factor 9-deficient ovary." Mol Endocrinol 13(6): 1018-1034.

Erce, M. A., D. Abeygunawardena, et al. (2013). "Interactions affected by arginine methylation in the yeast protein-protein interaction network." $\underline{\text { Mol Cell Proteomics }}$ 12(11): 3184-3198.

Feuerstein, R., X. K. Wang, et al. (1994). "The Lim/Double Zinc-Finger Motif Functions as a Protein Dimerization Domain." Proceedings of the National Academy of Sciences of the United States of America 91(22): 10655-10659.

Finney, M. and G. Ruvkun (1990). "The unc-86 gene product couples cell lineage and cell identity in C. elegans." Cell 63(5): 895-905.

Finney, M., G. Ruvkun, et al. (1988). "The C. elegans cell lineage and differentiation gene unc-86 encodes a protein with a homeodomain and extended similarity to transcription factors." Cell 55(5): 757-769.

Galloway, S. M., K. P. McNatty, et al. (2000). "Mutations in an oocyte-derived growth factor gene (BMP15) cause increased ovulation rate and infertility in a dosage-sensitive manner." Nat Genet 25(3): 279-283.

Garraway, L. A. and E. S. Lander (2013). "Lessons from the cancer genome." Cell 153(1): $17-37$.

Garrell, J. and J. Modolell (1990). "The Drosophila Extramacrochaetae Locus, an Antagonist 
of Proneural Genes That, Like These Genes, Encodes a Helix-Loop-Helix Protein." Cell 61(1): 39-48.

Garvalov, B. K., T. E. Higgins, et al. (2003). "The conformational state of Tes regulates its zyxin-dependent recruitment to focal adhesions." J Cell Biol 161(1): 33-39.

Ge, H., A. J. M. Walhout, et al. (2003). "Integrating 'omic' information: a bridge between genomics and systems biology." Trends in Genetics 19(10): 551-560.

Giaever, G., A. M. Chu, et al. (2002). "Functional profiling of the Saccharomyces cerevisiae genome." Nature 418(6896): 387-391.

Gorlich, D., P. Henklein, et al. (1996). "A 41 amino acid motif in importin-alpha confers binding to importin-beta and hence transit into the nucleus." EMBO J 15(8): 1810-1817.

Gorlich, D. and U. Kutay (1999). "Transport between the cell nucleus and the cytoplasm." Annual Review of Cell and Developmental Biology 15: 607-660.

Guelzim, N., S. Bottani, et al. (2002). "Topological and causal structure of the yeast transcriptional regulatory network." Nat Genet 31(1): 60-63.

Han, J. D., N. Bertin, et al. (2004). "Evidence for dynamically organized modularity in the yeast protein-protein interaction network." Nature 430(6995): 88-93.

Hara, Y., A. C. Rovescalli, et al. (1992). "Structure and evolution of four POU domain genes expressed in mouse brain." Proc Natl Acad Sci U S A 89(8): 3280-3284.

Hartley, J. L., G. F. Temple, et al. (2000). "DNA cloning using in vitro site-specific recombination." Genome Research 10(11): 1788-1795.

He, X., R. Gerrero, et al. (1991). "Tst-1, a member of the POU domain gene family, binds the promoter of the gene encoding the cell surface adhesion molecule P0." Mol Cell Biol 11(3): 1739-1744.

He, X., M. N. Treacy, et al. (1989). "Expression of a large family of POU-domain regulatory genes in mammalian brain development." Nature 340(6228): 35-41.

Hennessy, B. T., D. L. Smith, et al. (2005). "Exploiting the PI3K/AKT pathway for cancer drug discovery." Nature Reviews Drug Discovery 4(12): 988-1004.

Henthorn, P. S., C. C. Stewart, et al. (1991). "The gene encoding human TFE3, a transcription factor that binds the immunoglobulin heavy-chain enhancer, maps to Xp11.22." 
Genomics 11(2): 374-378.

Herr, W. and M. A. Cleary (1995). "The POU domain: versatility in transcriptional regulation by a flexible two-in-one DNA-binding domain." Genes Dev 9(14): 1679-1693.

Herr, W., R. A. Sturm, et al. (1988). "The Pou Domain - a Large Conserved Region in the Mammalian Pit-1, Oct-1, Oct-2, and Caenorhabditis-Elegans Unc-86 Gene-Products." Genes \& Development 2(12A): 1513-1516.

Hobert, O. and H. Westphal (2000). "Functions of LIM-homeobox genes." Trends Genet 16(2): $75-83$.

Hoshizaki, D. K., J. E. Hill, et al. (1990). "The Saccharomyces cerevisiae INO4 gene encodes a small, highly basic protein required for derepression of phospholipid biosynthetic enzymes." J Biol Chem 265(8): 4736-4745.

Howell, C. Y., T. H. Bestor, et al. (2001). "Genomic imprinting disrupted by a maternal effect mutation in the Dnmt1 gene." Cell 104(6): 829-838.

Hu, W., L. Gauthier, et al. (2010). "FIGLA, a basic helix-loop-helix transcription factor, balances sexually dimorphic gene expression in postnatal oocytes." $\underline{\text { Mol Cell Biol }}$ 30(14): 3661-3671.

Hua, X. X., X. D. Liu, et al. (1998). "Synergistic cooperation of TFE3 and Smad proteins in TGF-beta-induced transcription of the plasminogen activator inhibitor-1 gene." Genes \& Development 12(19): 3084-3095.

Huynen, M., B. Snel, et al. (2000). "Predicting protein function by genomic context: quantitative evaluation and qualitative inferences." Genome Res 10(8): 1204-1210.

Ingraham, H. A., R. P. Chen, et al. (1988). "A tissue-specific transcription factor containing a homeodomain specifies a pituitary phenotype." Cell 55(3): 519-529.

Ingraham, H. A., S. E. Flynn, et al. (1990). "The Pou-Specific Domain of Pit-1 Is Essential for Sequence-Specific, High-Affinity DNA-Binding and DNA-Dependent Pit-1-Pit-1 Interactions." Cell 61(6): 1021-1033.

Ivanov, A. A., F. R. Khuri, et al. (2013). "Targeting protein-protein interactions as an anticancer strategy." Trends in Pharmacological Sciences 34(7): 393-400.

Jacobson, S. and L. Pillus (1999). "Modifying chromatin and concepts of cancer." Curr Opin 
Genet Dev 9(2): 175-184.

Jeanblanc, M., J. Salvaing, et al. (2008). "[Embryonic genome activation]." Gynecol Obstet Fertil 36(11): 1126-1132.

Jeong, H., S. P. Mason, et al. (2001). "Lethality and centrality in protein networks." Nature 411(6833): 41-42.

Jeong, H., S. P. Mason, et al. (2001). "Lethality and centrality in protein networks." Nature 411(6833): 41-42.

Joshi, S., H. Davies, et al. (2007). "Ovarian gene expression in the absence of FIGLA, an oocyte-specific transcription factor." BMC Dev Biol 7: 67.

Kadrmas, J. L. and M. C. Beckerle (2004). "The LIM domain: from the cytoskeleton to the nucleus." Nat Rev Mol Cell Biol 5(11): 920-931.

Kerrien, S., B. Aranda, et al. (2012). "The IntAct molecular interaction database in 2012." Nucleic Acids Research 40(D1): D841-D846.

Klambt, C., E. Knust, et al. (1989). "Closely related transcripts encoded by the neurogenic gene complex enhancer of split of Drosophila melanogaster." EMBO J 8(1): 203-210.

Knoll, R., M. Hoshijima, et al. (2002). "The cardiac mechanical stretch sensor machinery involves a $\mathrm{Z}$ disc complex that is defective in a subset of human dilated cardiomyopathy." Cell 111(7): 943-955.

Ko, H. S., P. Fast, et al. (1988). "A Human Protein-Specific for the Immunoglobulin Octamer DNA Motif Contains a Functional Homeobox Domain." Cell 55(1): 135-144.

Kobe, B. and J. Deisenhofer (1995). "Proteins with Leucine-Rich Repeats." Current Opinion in Structural Biology 5(3): 409-416.

Kohler, M., S. Ansieau, et al. (1997). "Cloning of two novel human importin-alpha subunits and analysis of the expression pattern of the importin-alpha protein family." FEBS Lett 417(1): 104-108.

Kohler, M., C. Speck, et al. (1999). "Evidence for distinct substrate specificities of importin alpha family members in nuclear protein import." Mol Cell Biol 19(11): 7782-7791.

Kovanci, E., J. Rohozinski, et al. (2007). "Growth differentiating factor-9 mutations may be associated with premature ovarian failure." Fertility and Sterility 87(1): 143-146. 
Kummerfeld, S. K. and S. A. Teichmann (2006). "DBD: a transcription factor prediction database." Nucleic Acids Res 34(Database issue): D74-81.

Kurosaka, S., S. Eckardt, et al. (2004). "Pluripotent lineage definition in bovine embryos by Oct4 transcript localization." Biol Reprod 71(5): 1578-1582.

Laissue, P., S. Christin-Maitre, et al. (2006). "Mutations and sequence variants in GDF9 and BMP15 in patients with premature ovarian failure." Eur J Endocrinol 154(5): 739-744.

Lall, S., D. Grun, et al. (2006). "A genome-wide map of conserved microRNA targets in C. elegans." Curr Biol 16(5): 460-471.

Larson, R. C., I. Lavenir, et al. (1996). "Protein dimerization between Lmo2 (Rbtn2) and Tal1 alters thymocyte development and potentiates T cell tumorigenesis in transgenic mice." Embo Journal 15(5): 1021-1027.

Latham, K. E. (1999). "Mechanisms and control of embryonic genome activation in mammalian embryos." Int Rev Cytol 193: 71-124.

Lee, J. E., S. M. Hollenberg, et al. (1995). "Conversion of Xenopus Ectoderm into Neurons by Neurod, a Basic Helix-Loop-Helix Protein." Science 268(5212): 836-844.

Li, J. J. and I. Herskowitz (1993). "Isolation of ORC6, a component of the yeast origin recognition complex by a one-hybrid system." Science 262(5141): 1870-1874.

Li, S. M., C. M. Armstrong, et al. (2004). "A map of the interactome network of the metazoan C-elegans." Science 303(5657): 540-543.

Liang, L., S. M. Soyal, et al. (1997). "FIGalpha, a germ cell specific transcription factor involved in the coordinate expression of the zona pellucida genes." Development 124(24): 4939-4947.

Licata, L., L. Briganti, et al. (2012). "MINT, the molecular interaction database: 2012 update." Nucleic Acids Research 40(D1): D857-D861.

Louis, H. A., J. D. Pino, et al. (1997). "Comparison of three members of the cysteine-rich protein family reveals functional conservation and divergent patterns of gene expression." J Biol Chem 272(43): 27484-27491.

Lubzens, E., G. Young, et al. (2010). "Oogenesis in teleosts: How fish eggs are formed." General and Comparative Endocrinology 165(3): 367-389. 
Massari, M. E. and C. Murre (2000). "Helix-loop-helix proteins: regulators of transcription in eucaryotic organisms." Mol Cell Biol 20(2): 429-440.

Monuki, E. S., R. Kuhn, et al. (1990). "Expression and activity of the POU transcription factor SCIP." Science 249(4974): 1300-1303.

Morell, M., A. Espargaro, et al. (2007). "Detection of transient protein-protein interactions by bimolecular fluorescence complementation: the Abl-SH3 case." Proteomics 7(7): 1023-1036.

Mori, T., Z. Yuxing, et al. (2004). "The LIM homeobox gene, L3/Lhx8, is necessary for proper development of basal forebrain cholinergic neurons." Eur J Neurosci 19(12): 3129-3141.

Muller, M. M., S. Ruppert, et al. (1988). "A cloned octamer transcription factor stimulates transcription from lymphoid-specific promoters in non-B cells." Nature 336(6199): 544-551.

Murre, C., G. Bain, et al. (1994). "Structure and function of helix-loop-helix proteins." Biochim Biophys Acta 1218(2): 129-135.

Murre, C., P. S. McCaw, et al. (1989). "A new DNA binding and dimerization motif in immunoglobulin enhancer binding, daughterless, MyoD, and myc proteins." Cell 56(5): 777-783.

Murre, C., P. S. Mccaw, et al. (1989). "Interactions between Heterologous Helix-Loop-Helix Proteins Generate Complexes That Bind Specifically to a Common DNA-Sequence." Cell 58(3): 537-544.

Nachury, M. V., U. W. Ryder, et al. (1998). "Cloning and characterization of hSRP1 gamma, a tissue-specific nuclear transport factor." Proc Natl Acad Sci U S A 95(2): 582-587.

Nelson, C., V. R. Albert, et al. (1988). "Activation of cell-specific expression of rat growth hormone and prolactin genes by a common transcription factor." Science 239(4846): 1400-1405.

Nichols, J., B. Zevnik, et al. (1998). "Formation of pluripotent stem cells in the mammalian embryo depends on the POU transcription factor Oct4." Cell 95(3): 379-391.

Nikoloff, D. M., P. Mcgraw, et al. (1992). "The Ino2 Gene of Saccharomyces-Cerevisiae 
Encodes a Helix-Loop-Helix Protein That Is Required for Activation of Phospholipid-Synthesis." Nucleic Acids Research 20(12): 3253-3253.

Niu, Y., D. Otasek, et al. (2010). "Evaluation of linguistic features useful in extraction of interactions from PubMed; application to annotating known, high-throughput and predicted interactions in I2D." Bioinformatics 26(1): 111-119.

Nix, D. A. and M. C. Beckerle (1997). "Nuclear-cytoplasmic shuttling of the focal contact protein, zyxin: A potential mechanism for communication between sites of cell adhesion and the nucleus." Journal of Cell Biology 138(5): 1139-1147.

Nix, D. A., J. Fradelizi, et al. (2001). "Targeting of zyxin to sites of actin membrane interaction and to the nucleus." J Biol Chem 276(37): 34759-34767.

Nooren, I. M. and J. M. Thornton (2003). "Diversity of protein-protein interactions." EMBO J 22(14): 3486-3492.

Obenauer, J. C. and M. B. Yaffe (2004). "Computational prediction of protein-protein interactions." Methods Mol Biol 261: 445-468.

Okumura-Nakanishi, S., M. Saito, et al. (2005). "Oct-3/4 and Sox2 regulate Oct-3/4 gene in embryonic stem cells." J Biol Chem 280(7): 5307-5317.

Orchard, S., M. Ammari, et al. (2014). "The MIntAct project-IntAct as a common curation platform for 11 molecular interaction databases." Nucleic Acids Research 42(D1): D358-D363.

Orchard, S., S. Kerrien, et al. (2012). "Protein interaction data curation: the International Molecular Exchange (IMEx) consortium." Nat Methods 9(4): 345-350.

Ovchinnikov, S., H. Kamisetty, et al. (2014). "Robust and accurate prediction of residue-residue interactions across protein interfaces using evolutionary information." Elife 3.

Ovitt, C. E. and H. R. Scholer (1998). "The molecular biology of Oct-4 in the early mouse embryo." Mol Hum Reprod 4(11): 1021-1031.

Pan, Q., O. Shai, et al. (2008). "Deep surveying of alternative splicing complexity in the human transcriptome by high-throughput sequencing." Nat Genet 40(12): 1413-1415.

Pangas, S. A., Y. Choi, et al. (2006). "Oogenesis requires germ cell-specific transcriptional 
regulators Sohlh1 and Lhx8." Proc Natl Acad Sci U S A 103(21): 8090-8095.

Pangas, S. A., Y. Choi, et al. (2006). "Oogenesis requires germ cell-specific transcriptional regulators Sohlh1 and Lhx8." Proceedings of the National Academy of Sciences of the United States of America 103(21): 8090-8095.

Pawlowski, K., F. Pio, et al. (2001). "PAAD - a new protein domain associated with apoptosis, cancer and autoimmune diseases." Trends in Biochemical Sciences 26(2): 85-87.

Peifer, M., S. Berg, et al. (1994). "A repeating amino acid motif shared by proteins with diverse cellular roles." Cell 76(5): 789-791.

Porcher, C., W. Swat, et al. (1996). "The T cell leukemia oncoprotein SCL/tal-1 is essential for development of all hematopoietic lineages." Cell 86(1): 47-57.

Prolla, T. A., S. M. Baker, et al. (1998). "Tumour susceptibility and spontaneous mutation in mice deficient in Mlh1, Pms1 and Pms2 DNA mismatch repair." Nat Genet 18(3): 276-279.

Qin, Y., Y. Choi, et al. (2007). "NOBOX homeobox mutation causes premature ovarian failure." Am J Hum Genet 81(3): 576-581.

Qin, Y., X. Jiao, et al. (2014). "Novel variants in the SOHLH2 gene are implicated in human premature ovarian failure." Fertil Steril 101(4): 1104-1109 e1106.

Rajkovic, A., S. A. Pangas, et al. (2004). "NOBOX deficiency disrupts early folliculogenesis and oocyte-specific gene expression." Science 305(5687): 1157-1159.

Ramaswamy, S., B. S. Razack, et al. (2014). "Spermatogonial SOHLH1 nucleocytoplasmic shuttling associates with initiation of spermatogenesis in the rhesus monkey (Macaca mulatta)." Mol Hum Reprod 20(4): 350-357.

Ren, Y., H. Suzuki, et al. (2015). "Lhx8 regulates primordial follicle activation and postnatal folliculogenesis." BMC Biol 13: 39.

Roberts, R. M., G. W. Smith, et al. (2009). "Research priorities. Farm animal research in crisis." Science 324(5926): 468-469.

Rodda, D. J., J. L. Chew, et al. (2005). "Transcriptional regulation of nanog by OCT4 and SOX2." J Biol Chem 280(26): 24731-24737. 
Rushlow, C. A., A. Hogan, et al. (1989). "The Drosophila Hairy Protein Acts in Both Segmentation and Bristle Patterning and Shows Homology to N-Myc." Embo Journal 8(10): 3095-3103.

Ryan, A. K. and M. G. Rosenfeld (1997). "POU domain family values: flexibility, partnerships, and developmental codes." Genes Dev 11(10): 1207-1225.

Salwinski, L., C. S. Miller, et al. (2004). "The Database of Interacting Proteins: 2004 update." Nucleic Acids Res 32(Database issue): D449-451.

Sanchez-Garcia, I., H. Osada, et al. (1993). "The cysteine-rich LIM domains inhibit DNA binding by the associated homeodomain in Isl-1." EMBO J 12(11): 4243-4250.

Saraste, M., P. R. Sibbald, et al. (1990). "The P-loop--a common motif in ATP- and GTP-binding proteins." Trends Biochem Sci 15(11): 430-434.

Schaefer, M. H., J. F. Fontaine, et al. (2012). "HIPPIE: Integrating protein interaction networks with experiment based quality scores." PLoS One 7(2): e31826.

Scheidereit, C., J. A. Cromlish, et al. (1988). "A Human Lymphoid-Specific Transcription Factor That Activates Immunoglobulin Genes Is a Homoeobox Protein." Nature 336(6199): 551-557.

Schmeichel, K. L. and M. C. Beckerle (1994). "The Lim Domain Is a Modular Protein-Binding Interface." Cell 79(2): 211-219.

Schmitt, T., C. Ogris, et al. (2014). "FunCoup 3.0: database of genome-wide functional coupling networks." Nucleic Acids Res 42(Database issue): D380-388.

Scholer, H. R., A. K. Hatzopoulos, et al. (1989). "A family of octamer-specific proteins present during mouse embryogenesis: evidence for germline-specific expression of an Oct factor." EMBO J 8(9): 2543-2550.

Scholer, H. R., S. Ruppert, et al. (1990). "New Type of Pou Domain in Germ Line-Specific Protein Oct-4." Nature 344(6265): 435-439.

Schultz, R. M. (1993). "Regulation of zygotic gene activation in the mouse." Bioessays 15(8): $531-538$.

Seet, B. T., I. Dikic, et al. (2006). "Reading protein modifications with interaction domains." Nat Rev Mol Cell Biol 7(7): 473-483. 
Seki, T., S. Tada, et al. (1997). "Cloning of a cDNA encoding a novel importin-alpha homologue, Qip1: discrimination of Qip1 and Rch1 from hSrp1 by their ability to interact with DNA helicase Q1/RecQL." Biochem Biophys Res Commun 234(1): 48-53.

Shannon, P., A. Markiel, et al. (2003). "Cytoscape: a software environment for integrated models of biomolecular interaction networks." Genome Res 13(11): 2498-2504.

Shibaguchi, T., J. Kato, et al. (2003). "Expression and role of Lhx8 in murine tooth development." Arch Histol Cytol 66(1): 95-108.

Shoemaker, B. A. and A. R. Panchenko (2007). "Deciphering protein-protein interactions. Part I. Experimental techniques and databases." PLoS Comput Biol 3(3): e42.

Shoemaker, B. A. and A. R. Panchenko (2007). "Deciphering protein-protein interactions. Part II. Computational methods to predict protein and domain interaction partners." PLoS Comput Biol 3(4): e43.

Shoemaker, B. A. and A. R. Panchenko (2007). "Deciphering protein-protein interactions. Part II. Computational methods to predict protein and domain interaction partners." Plos Computational Biology 3(4): 595-601.

Simmons, D. M., J. W. Voss, et al. (1990). "Pituitary cell phenotypes involve cell-specific Pit-1 mRNA translation and synergistic interactions with other classes of transcription factors." Genes Dev 4(5): 695-711.

Spicer, L. J., P. Y. Aad, et al. (2008). "Growth differentiation factor 9 (GDF9) stimulates proliferation and inhibits steroidogenesis by bovine theca cells: influence of follicle size on responses to GDF9." Biol Reprod 78(2): 243-253.

Stampfel, G., T. Kazmar, et al. (2015). "Transcriptional regulators form diverse groups with context-dependent regulatory functions." Nature 528(7580): 147-151.

Staub, E., E. Dahl, et al. (2001). "The DAPIN family: a novel domain links apoptotic and interferon response proteins." Trends in Biochemical Sciences 26(2): 83-85.

Stelzl, U., U. Worm, et al. (2005). "A human protein-protein interaction network: a resource for annotating the proteome." Cell 122(6): 957-968.

Stern, S. and W. Herr (1991). "The herpes simplex virus trans-activator VP16 recognizes the Oct-1 homeo domain: evidence for a homeo domain recognition subdomain." Genes Dev 
5(12B): 2555-2566.

Stingl, K., K. Schauer, et al. (2008). "In vivo interactome of Helicobacter pylori urease revealed by tandem affinity purification." Mol Cell Proteomics 7(12): 2429-2441.

Sturm, R. A., G. Das, et al. (1988). "The Ubiquitous Octamer-Binding Protein Oct-1 Contains a Pou Domain with a Homeo Box Subdomain." Genes \& Development 2(12A): 1582-1599.

Sugiura, K., F. L. Pendola, et al. (2005). "Oocyte control of metabolic cooperativity between oocytes and companion granulosa cells: energy metabolism." Developmental Biology 279(1): 20-30.

Sun, X. H., N. G. Copeland, et al. (1991). "Id proteins Id1 and Id2 selectively inhibit DNA binding by one class of helix-loop-helix proteins." Mol Cell Biol 11(11): 5603-5611.

Suzuki, H., H. W. Ahn, et al. (2012). "SOHLH1 and SOHLH2 coordinate spermatogonial differentiation." Dev Biol 361(2): 301-312.

Suzuki, N., H. Rohdewohld, et al. (1990). "Oct-6 - a Pou Transcription Factor Expressed in Embryonal Stem-Cells and in the Developing Brain." Embo Journal 9(11): 3723-3732.

Suzumori, N., S. A. Pangas, et al. (2007). "Candidate genes for premature ovarian failure." Curr Med Chem 14(3): 353-357.

Suzumori, N., C. N. Yan, et al. (2002). "Nobox is a homeobox-encoding gene preferentially expressed in primordial and growing oocytes." Mechanisms of Development 111(1-2): $137-141$.

Tagwerker, C., K. Flick, et al. (2006). "A tandem affinity tag for two-step purification under fully denaturing conditions - Application in ubiquitin profiling and protein complex identification combined with in vivo cross-linking." Molecular \& Cellular Proteomics 5(4): 737-748.

Tejomurtula, J., K. B. Lee, et al. (2009). "Role of importin alpha8, a new member of the importin alpha family of nuclear transport proteins, in early embryonic development in cattle." Biol Reprod 81(2): 333-342.

Tomioka, M., M. Nishimoto, et al. (2002). "Identification of Sox-2 regulatory region which is under the control of Oct-3/4-Sox-2 complex." Nucleic Acids Res 30(14): 3202-3213. 
Tong, Z. B., L. Gold, et al. (2000). "Mater, a maternal effect gene required for early embryonic development in mice." Nat Genet 26(3): 267-268.

Toyoda, S., T. Yoshimura, et al. (2014). "Auto-regulation of the Sohlh1 gene by the SOHLH2/SOHLH1/SP1 complex: implications for early spermatogenesis and oogenesis." PLoS One 9(7): e101681.

Tripurani, S. K., G. Wee, et al. (2013). "MicroRNA-212 post-transcriptionally regulates oocyte-specific basic-helix-loop-helix transcription factor, factor in the germline alpha (FIGLA), during bovine early embryogenesis." PLoS One 8(9): e76114.

Uzbekova, S., M. Roy-Sabau, et al. (2006). "Zygote arrest 1 gene in pig, cattle and human: evidence of different transcript variants in male and female germ cells." Reprod Biol Endocrinol 4: 12.

Verrijzer, C. P., M. J. Alkema, et al. (1992). "The DNA binding specificity of the bipartite POU domain and its subdomains." EMBO J 11(13): 4993-5003.

Vitt, U. A., E. A. McGee, et al. (2000). "In vivo treatment with GDF-9 stimulates primordial and primary follicle progression and theca cell marker CYP17 in ovaries of immature rats." Endocrinology 141(10): 3814-3820.

Walhout, A. J. (2006). "Unraveling transcription regulatory networks by protein-DNA and protein-protein interaction mapping." Genome Res 16(12): 1445-1454.

Walhout, A. J. M., R. Sordella, et al. (2000). "Protein interaction mapping in C-elegans using proteins involved in vulval development." Science 287(5450): 116-122.

Wang, E. T., R. Sandberg, et al. (2008). "Alternative isoform regulation in human tissue transcriptomes." Nature 456(7221): 470-476.

Wang, J., S. Rao, et al. (2006). "A protein interaction network for pluripotency of embryonic stem cells." Nature 444(7117): 364-368.

Wang, M. M. and R. R. Reed (1993). "Molecular cloning of the olfactory neuronal transcription factor Olf-1 by genetic selection in yeast." Nature 364(6433): 121-126.

Weis, K. (2003). "Regulating access to the genome: nucleocytoplasmic transport throughout the cell cycle." Cell 112(4): 441-451.

Weis, K., I. W. Mattaj, et al. (1995). "Identification of hSRP1 alpha as a functional receptor 
for nuclear localization sequences." Science 268(5213): 1049-1053.

Wilkins, M. R. and S. K. Kummerfeld (2008). "Sticking together? Falling apart? Exploring the dynamics of the interactome." Trends Biochem Sci 33(5): 195-200.

Winzeler, E. A., D. D. Shoemaker, et al. (1999). "Functional characterization of the S. cerevisiae genome by gene deletion and parallel analysis." Science 285(5429): 901-906.

Wu, X. M., J. Guo, et al. (2009). "The properties of hub proteins in a yeast-aggregated cell cycle network and its phase sub-networks." Proteomics 9(20): 4812-4824.

Wu, X. M., M. M. Viveiros, et al. (2003). "Zygote arrest 1 (Zar1) is a novel maternal-effect gene critical for the oocyte-to-embryo transition." Nature Genetics 33(2): 187-191.

Wu, X. M., P. Wang, et al. (2003). "Zygote arrest 1 (Zar1) is an evolutionarily conserved gene expressed in vertebrate ovaries." Biology of Reproduction 69(3): 861-867.

Xia, J. F., S. L. Wang, et al. (2010). "Computational methods for the prediction of protein-protein interactions." Protein Pept Lett 17(9): 1069-1078.

Xu, Z., S. Huang, et al. (2003). "Identification of a TAL1 target gene reveals a positive role for the LIM domain-binding protein Ldb1 in erythroid gene expression and differentiation." Mol Cell Biol 23(21): 7585-7599.

Xue, D., Y. Tu, et al. (1993). "Cooperative interactions between the Caenorhabditis elegans homeoproteins UNC-86 and MEC-3." Science 261(5126): 1324-1328.

Yaden, B. C., J. J. Savage, et al. (2005). "DNA recognition properties of the LHX3b LIM homeodomain transcription factor." Mol Biol Rep 32(1): 1-6.

Yaffe, M. B. (2002). "How do 14-3-3 proteins work?-- Gatekeeper phosphorylation and the molecular anvil hypothesis." FEBS Lett 513(1): 53-57.

Yu, H. Y., D. Greenbaum, et al. (2004). "Genomic analysis of essentiality within protein networks." Trends in Genetics 20(6): 227-231.

Zarrinpar, A., S. H. Park, et al. (2003). "Optimization of specificity in a cellular protein interaction network by negative selection." Nature 426(6967): 676-680.

Zervos, A. S., J. Gyuris, et al. (1993). "Mxi1, a Protein That Specifically Interacts with Max to Bind Myc-Max Recognition Sites." Cell 72(2): 223-232.

Zhao, G. Q., Q. Zhao, et al. (1993). "TFEC, a basic helix-loop-helix protein, forms 
heterodimers with TFE3 and inhibits TFE3-dependent transcription activation." $\underline{\text { Mol Cell }}$ Biol 13(8): 4505-4512.

Zhao, H., Y. Qin, et al. (2007). "Analyses of GDF9 mutation in 100 Chinese women with premature ovarian failure." Fertil Steril 88(5): 1474-1476.

Zhao, S., G. Li, et al. (2015). "Transcription factor SOHLH1 potentially associated with primary ovarian insufficiency." Fertil Steril 103(2): 548-553 e545.

Zhou, Y., R. Santoro, et al. (2002). "The chromatin remodeling complex NoRC targets HDAC1 to the ribosomal gene promoter and represses RNA polymerase I transcription." EMBO J 21(17): 4632-4640.

Zhuang, Y., P. Soriano, et al. (1994). "The Helix-Loop-Helix Gene E2a Is Required for B-Cell Formation." Cell 79(5): 875-884.

Zuberi, K., M. Franz, et al. (2013). "GeneMANIA prediction server 2013 update." Nucleic Acids Res 41(Web Server issue): W115-122. 


\section{CHAPTER 1}

Lhx8 interacts with a novel germ cell-specific nuclear factor containing an Nbl1 domain in rainbow trout (Oncorhynchus mykiss)

Liyuan Fu, Prasanthi P. Koganti, Jian Wang, Lei Wang, Cheng-Lun Wang and Jianbo Yao*

Division of Animal and Nutritional Sciences, West Virginia University, Morgantown, WV 26506 USA

Short title: Lhx8 interacts with Borealin-2

*Corresponding author

Jianbo Yao

West Virginia University

Morgantown, WV 26506-6108

U.S.A.

Tel.: 304-293-1948

Fax: 304-293-2232

E-mail: jianbo.yao@mail.wvu.edu 


\begin{abstract}
LIM homeobox $8(\operatorname{Lhx} 8)$ is an important transcription factor that is preferentially expressed in germ cells. $L h x 8$ null mice are infertile due to lack of oocytes and impairment of the transition from primordial follicles to primary follicles. Lhx8 deficiency also affects the expression of many important oocyte-specific genes. To date, no attempts have been made to investigate the existence of any cellular factors that might interact with Lhx8 protein in oocytes and early embryos. In this study, we report the characterization of rainbow trout Lhx8 genes and identification of a novel germ cell-specific nuclear factor that interacts with Lhx8. Two $L h x 8$ genes, $L h x 8 a$ and $L h x 8 b$, were identified, encoding proteins of 344 and 361 amino acids, respectively. The two proteins share $83 \%$ sequence identity and both transcripts are specifically expressed in the ovary. Quantitative real time PCR analysis demonstrated that both genes are expressed highly in pre-vitellogenic ovaries as well as in early stage embryos. Using a yeast two-hybrid screening system, a novel protein (Borealin-2) interacting with Lhx 8 was identified. The interaction between either Lhx $8 \mathrm{a}$ or Lhx $8 \mathrm{~b}$ and Borealin-2 was further confirmed by a bimolecular fluorescence complementation (BiFC) assay. Borealin-2 is a protein of 255 amino acids containing an Nbll domain, and its mRNA expression is restricted to the ovary and testis. A GFP reporter assay revealed that Borealin-2 is a nuclear protein. Collectively, results indicate that both $\operatorname{Lhx} 8 \mathrm{a}$ and Lhx $8 \mathrm{~b}$ function through interaction with Borealin-2, which may play an important role during oogenesis and early embryogenesis in rainbow trout.
\end{abstract}

Keywords: Borealin-2, oocyte, protein-protein interaction, oogenesis 


\section{INTRODUCTION}

Through gene knockout studies in mouse, the functional roles of many oocyte-specific factors during folliculogenesis and early embryonic development have been revealed (Zheng and Dean 2007). A number of key oocyte-specific nuclear factors known to be vital in follicular development are transcription factors, which include factor in the germline alpha (Figla) (Soyal et al. 2000), newborn ovary homeobox (Nobox) (Rajkovic et al. 2004), and LIM homeobox 8 (Lhx8) (Pangas et al. 2006). However, our understanding of the regulatory mechanisms of these important transcription factors in oocyte and follicular development is far from complete, particularly in species like fish.

Rainbow trout is a major fish species cultivated widely in the world for food production and sport fisheries. It is also utilized as a model species in research (Thorgaard et al. 2002). Understanding the functional contribution of oocyte-specific genes to egg quality will help us develop biomarkers for prediction of egg quality in rainbow trout. Our previous studies have resulted in the discovery of a number of novel oocyte-specific genes in rainbow trout, which include Oorp-t (Ramachandra et al. 2007), Rtgst-1 (Qiu et al. 2008), Fbxoo (Wang et al. 2013) and Knpa7 (Wang et al. 2014).

Lhx 8 is a member of the LIM-homeobox transcription factor family and its transcript is detected in oocytes of follicles of various stages in mouse ovary (Pangas et al. 2006). Lhx8 protein is located in the nucleus of oocytes and is increasingly expressed during primordial follicle activation (Choi et al. 2008). Lhx8 null mice are infertile due to lack of oocytes and impairment of the transition from primordial follicles to primary follicles (Choi et al. 2008) Conditional deletion of Lhx8 from oocytes of primary follicles leads to primary follicle death and severe loss of the secondary and antral follicles (Ren et al. 2015). Lhx 8 deficiency affects the expression of many important oocyte-expressed genes such as Gdf9, Pou5f1, Nobox and Kitl (Choi et al. 2008). In somatic tissues, Lhx8 plays an important role in the development of basal forebrain cholinergic neurons (Mori et al. 2004). Lhx8 protein contains two LIM domains and one homeobox domain, which can promote protein interactions by regulating the activity of related molecules (Hobert and Westphal 2000; Toyama et al. 1998).

Given the functional importance of Lhx8, understanding what proteins interact with it 
may provide insights into gene regulatory networks during oocyte and follicular development. In this study, we report the characterization of two rainbow trout Lhx8 genes, Lhx8a and $L h x 8 b$, and the discovery of a novel germ cell-specific nuclear protein, Borealin 2, which interacts with Lhx8 proteins. The results indicate that both Lhx8a and Lhx8b function through interaction with Borealin-2, which may play an important role in oocyte and embryonic development in rainbow trout.

\section{MATERIALS AND METHODS}

\section{Collection of fish samples}

Mature eggs collected from three female fish spawns at the National Center for Cool and Cold Water Aquaculture (Kearneysville, WV) were artificially fertilized and raised in a flow-through system at $13.8{ }^{\circ} \mathrm{C}$. Embryonic samples were collected at specific time points after fertilization that included $0,3,7.5,11.5,18,27,34$ hours, 2, 3, 4, 5, 6, 8, 10, 12, 16 and 25 days post-fertilization. Different tissue samples, including testis, brain, muscle, ovary, stomach, gill, head kidney, small intestine, spleen, heart and liver were collected from adult fish. Ovarian samples at pre-vitellogenesis $(\sim 0.65 \mathrm{~mm})$, early vitellogenesis $(0.65 \sim 1.1 \mathrm{~mm})$, mid-vitellogenesis $(1.1 \sim 2.1 \mathrm{~mm})$, and late vitellogenesis $(2.1 \sim 4.0 \mathrm{~mm})$ were collected as described previously (Ramachandra et al. 2007). All samples were fast-frozen in liquid nitrogen, and stored at $-80{ }^{\circ} \mathrm{C}$ until use.

\section{Reverse transcription polymerase chain reaction (RT-PCR)}

Total RNA from different tissues was isolated using Trizol reagent according to the manufacturer's instructions (Invitrogen, Carlsbad, CA). After DNase I treatment, the RNA was converted to cDNA using oligo $(\mathrm{dT})_{18}$ primer and SuperScript III reverse transcriptase (Invitrogen, Carlsbad, CA). RT-PCR was performed in a $25-\mu 1$ reaction using gene specific primers (Table 1) under the following conditions: 5 min denaturation at $94{ }^{\circ} \mathrm{C}$ followed by 30 cycles of $94{ }^{\circ} \mathrm{C}$ for $30 \mathrm{sec}, 58{ }^{\circ} \mathrm{C}$ for $45 \mathrm{sec}$, and $72{ }^{\circ} \mathrm{C}$ for $30 \mathrm{sec}$, and a final extension at $72{ }^{\circ} \mathrm{C}$ for $10 \mathrm{~min}$. Rainbow trout $\beta$-actin gene (Actb) was used as a control for RNA quantity. 


\section{Quantitative real time polymerase chain reaction (RT-qPCR)}

Total RNA from ovaries and embryos was isolated using Trizol reagent. RNA isolated from embryos was further purified using lithium chloride precipitation. Following DNase I treatment, the RNA was converted to cDNA using a mixture of oligo (dT) 18 primer and random hexamers, and SuperScript III reverse transcriptase (Invitrogen, Carlsbad, CA). RT-qPCR was performed on a Bio-Rad CFX96 ${ }^{\mathrm{TM}}$ Real-Time PCR Detection System using $\mathrm{iQ}^{\mathrm{TM}}$ SYBR Green Supermix (Bio-Rad, Hercules, CA) in a $10-\mu 1$ reaction. Rainbow trout $\beta$-actin or 18S rRNA gene was used as endogenous controls. The primers used in RT-qPCR analysis are listed in Table 1. Cycling parameters were set at $95^{\circ} \mathrm{C}$ for $3 \mathrm{~min}$ followed by 40 cycles of $95^{\circ} \mathrm{C}$ for $10 \mathrm{sec}$ and $60^{\circ} \mathrm{C}$ for $1 \mathrm{~min}$. Melting-curve analyses were included after the amplification. Standard curves for each gene and the endogenous controls were constructed using serial dilutions of a pooled cDNA sample. The quantity of the target genes and the endogenous control genes in each sample was determined from respective standard curves. The quantity of the target mRNA was then normalized to the quantity of Actb mRNA (for gene expression in ovaries) or 18S ribosomal RNA (18S rRNA) (for gene expression in embryos). One-way analysis of variance (ANOVA) followed by Tukey's multiple comparison tests was performed on normalized gene expression values using JMP (SAS Institute, Cary, NC).

\section{Yeast two-hybridization}

The Matchmaker Two-Hybrid System (Clontech Laboratories, Mountain View, CA) was used to evaluate interactions between Lhx8a and Lhx $8 \mathrm{~b}$, and identify proteins that interact with Lxh8 proteins. Interaction between Lhx8a and Lhx8b was assayed by direct yeast two hybrid analysis. The coding regions of Lhx $8 \mathrm{a}$ and Lhx $8 \mathrm{~b}$ were cloned in-frame into pGBKT7 or pGADT7 vector. The pGBKT7 constructs (pGBKT7-Lhx8a or pGBKT7-Lhx8b) were transformed into Y2HGold strain cells and the pGADT7 constructs (pGADT7-Lhx8a or pGADT7-Lhx8b) were transformed into Y187 strain cells. All transformants were tested for toxicity and auto-activation before mating according to the manufacturer's protocol. After mating for $24 \mathrm{~h}$ at $30{ }^{\circ} \mathrm{C}$, yeast cells were plated on synthetic double dropout selection 
medium DDO/X/A and incubated at $30{ }^{\circ} \mathrm{C}$ for 3 days. Single blue colonies $(>2 \mathrm{~mm})$ were selected and streaked onto fresh QDO/X/A quadruple dropout plates (lacking adenine, histidine, tryptophan and leucine and supplemented with X- $\alpha-\mathrm{Gal}$ and Aureobasidin A).

To identify Lhx8 interacting proteins, a rainbow trout oocyte cDNA library in pGADT7 plasmid was screened with the bait expression plasmid, pGBKT7-Lhx8b. Yeast cells harboring the cDNA library were mated with Gold yeast cells containing pGBKT7-Lhx8b plasmid for $24 \mathrm{~h}$ at $30^{\circ} \mathrm{C}$, followed by plating and incubation on DDO/X/A plates for 3-5 days. Blue colonies were re-streaked on QDO/X/A plates for high stringent selection. Plasmids were isolated from blue colonies grown on QDO/X/A plates, and then transformed into competent $E$. coli cells using carbenicillin to select for pGADT7-resistant clones. The plasmids from the resistant clones were sequenced and the sequences were used to BLAST against the GenBank database.

To further confirm the screening results, the selected plasmid was re-transformed into the host strain, directly mated with yeast cells harboring the bait plasmid for $24 \mathrm{~h}$ and then plated onto $\mathrm{QDO} / \mathrm{X} / \mathrm{A}$ plates. The transformants were tested for $\beta$-galactosidase activity by yeast $\beta$-galactosidase liquid assay as described previously (Wang et al. 2014).

\section{EGFP reporter assay}

The coding region of rainbow trout wild-type Borealin-2 was PCR-amplified using gene-specific primers containing NdeI and EcoRI sites (Table 1) and cloned in-frame with the EGFP sequence in pcDNA3-EGFP vector (Addgene, Cambridge, MA) to generate the expression plasmid, pcDNA3-EGFP-Borealin-2-wt. The mutant Borealin-2 was generated by 2-step PCR using primers designed to produce a mutant with the NLS deleted (Table 1) and cloned in-frame with the EGFP sequence in pcDNA3-EGFP vector (pcDNA3-EGFP-Borealin-2- $\triangle \mathrm{NLS}$ ). Both constructs were confirmed by sequencing.

HEK 293 cells were plated onto 20-mm diameter Poly-D-lysine-coated coverslips (Neuvitro, El Monte, CA) placed inside 6-well plates. Twenty-four hours after seeding, cells were transfected with constructs expressing either the EGFP-tagged wild-type Borealin-2 (pcDNA3-EGFP-Borealin-2-wt) or the mutant Borealin-2 (pcDNA-EGFP-Borealin-2- $\Delta$ NLS). 
Twenty-four hours after transfection, cells on coverslips were washed with 1 x PBS and fixed in methanol for 5 min followed by DAPI staining. Cells were analyzed using a fluorescence microscope (MIF Zeiss Fluorescent).

\section{Bimolecular fluorescence complementation (BiFC)}

The BiFC plasmids, pBiFC-VN173 and pBiFC-VC155, were obtained from Addgene (Cambridge, MA). Coding regions of Lhx8a, Lhx8b and Borealin-2 were PCR-amplified and cloned into pBiFC-VN173 and pBiFC-VC155 vectors, generating pBiFC-VN173-Lhx8a, pBiFC-VC155-Lhx8a, pBiFC-VN173-Lhx8b, pBiFC-VC155-Lhx8b, and pBiFC-VC155-Borealin-2 fusion constructs. HEK293 cells were co-transfected with equal amounts of a VN and a VC fusion constructs. Single transfections using either pBiFC-VN173-Lhx8a or pBiFC-VN173-Lhx8b were served as negative controls. YFP signals due to BiFC were measured by fluorescence microscopy (MIF Zeiss Fluorescent).

\section{RESULTS}

\section{Identification and expression analysis of rainbow trout $L h x 8$ genes}

Through searching a rainbow trout oocyte transcriptome database and the genome sequence (Berthelot et al. 2014), we identified two distinctive Lhx8 genes (named Lhx8a and Lhx $8 b$ ). They are located on different chromosomes, with $L h x 8 a$ being on chromosome 28 and Lhx $8 b$ being on chromosome 8 . The Lhx8a cDNA sequence (1,956 bp) contains an open reading frame $(\mathrm{ORF})$ of $1,035 \mathrm{bp}$ encoding a protein of 344 amino acids. The Lhx $8 b$ cDNA $(1,373 \mathrm{bp})$ contains an ORF of 1,086 bp encoding a protein of 361 amino acids. Both proteins contain two LIM domains and one homeobox domain. They share $83 \%$ sequence identity and the sequence differences between the two proteins are mainly located at the $\mathrm{C}$ terminus (Fig. 1). The LIM and homeobox domains are very well conserved between two proteins, indicating that both proteins are functional.

Tissue distribution analysis of $L h x 8 a$ and $L h x 8 b$ mRNA by RT-PCR revealed that both transcripts are predominantly expressed in the ovary but barely detectable or undetectable in other tissues (Fig. 2A). To further analyze the function of $L h x 8 a$ and $L h x 8 b$ during ovarian 
and embryonic development, we performed quantitative real-time PCR (RT-qPCR) analysis using samples collected from different stages of vitellogenesis and embryogenesis. Similar expression profiles of $L h x 8 a$ and $L h x 8 b$ during vitellogenesis were observed. Both genes show higher expression in ovaries at early vitellogenic stages relative to late stages of vitellogenesis (Fig. 3A, 3B). During early embryogenesis, the expression of both genes is high in early stage embryos but declines to an undetectable level in late stage embryos (Fig. 3C, 3D).

\section{Interactions between Lhx8a and Lhx8b}

LIM domain is a unique double-zinc finger motif, which is believed to function as a dimerization domain (Breen et al. 1998b). To determine if Lhx8a and Lhx8b can form homodimer or heterodimer through their LIM domains, we performed yeast two hybrid assays to assess the interactions between Lhx8a and Lhx8b. The assays demonstrated that Lhx 8a and Lhx8b not only can interact with each other, but also interact with itself (Fig. 4A). Further evaluation of the binding affinity of protein-protein interactions by $\beta$-galactosidase assays showed significantly higher $\beta$-galactosidase activities in yeast cells expressing the interacting partners relative to the control cells (Fig. 4B). To verify the interactions between Lhx 8a and Lhx8b observed by yeast two hybrid assays, we performed bimolecular fluorescence complementation (BiFC) assays to visualize protein interactions in living cells. Mammalian expression plasmids encoding Lhx8a or Lhx8b fused to the N-terminal fragment of yellow fluorescent protein (VN), or the C-terminal fragment of yellow fluorescent protein (VC), were generated and transfected into HEK293 cells. Fluorescence microscopy was applied to determine the BiFC efficiency of paired VN and VC fused Lhx8 proteins. Yellow fluorescent signals were observed in cells expressing Lhx8a-VN and Lhx8a-VC, Lhx8b-VN and Lhx8b-VC, and Lhx8a-VN and Lhx8b-VC (Fig. 4C). BiFC signals of these protein complexes were predominantly cytoplasmic distribution in most cells, although some cells exhibited minor nuclear-enriched fluorescence or a more ubiquitous protein complex expression. No BiFC signals were detected in single transfections with either Lhx8a-VN or Lhx 8b-VN. Collectively, the results indicate that Lhx 8a and Lhx8b may form heterodimer or 
homodimer.

\section{Identification of Borealin-2 as an Lhx8-interacting protein}

To identify cellular proteins that might interact with Lhx8 protein, we performed a yeast two hybrid screening using Lhx $8 \mathrm{~b}$ as a bait. Two identical cDNA clones from a rainbow trout oocyte cDNA library were identified. Sequence analysis of the isolated clones revealed that they code for a novel protein of 255 amino acids containing an Nbl1 domain. The novel protein is named as Borealin-2. The interactions between Borealin-2 and Lhx8a or Lhx8b were confirmed by retransformation of Borealin-2-AD fusion construct into Y187 yeast cells followed by mating with the Y2Gold cells expressing either Lhx8a-BD or Lhx8b-BD fusion proteins (Fig. 5A). Further confirmation of the interactions between Borealin-2 and Lhx8a or Lhx 8 b were performed by $\beta$-galactosidase (Fig. 5B) and BiFC assays (Fig. 5C).

To determine if the Nbl1 domain is responsible for interaction with Lhx8 proteins, we performed a yeast two-hybrid assay using a mutant construct expressing Borealin-2 with its Nbl1 domain deleted. Blue colonies were readily detectable within three days when yeast cells expressing the wild type Borealin-2 was mated with yeast cells expressing either BD-fused Lhx8a or Lhx8b. However, only a few light blue colonies appeared after five days when cells expressing the mutant Borealin-2 was mated with cells containing either Lhx 8a-BD or Lhx8b-BD (Fig. 6A). This result was verified by a $\beta$-galactosidase assay. As shown in Fig. 6B, the mutant Borealin-2 protein displayed a markedly decreased interaction with either Lhx8a or Lhx8b, indicating that the Nbl1 domain of Borealin-2 is required for interaction with Lhx8 proteins in vitro.

\section{Expression and nuclear localization of Borealin-2}

Borealin-2 is a novel gene that has not been characterized yet. Through database mining, we identified the orthologous genes in other species including chicken (NP_001263267.1), X. laevis (NP_001086415.1), and zebrafish (NP_001189356.1). The Nbl1 domain is conserved among these species. Tissue distribution analysis revealed that the expression of rainbow trout Borealin-2 mRNA is restricted to the ovary and testis (Fig. 7A). RT-qPCR analysis 
showed that expression of Borealin-2 mRNA is high in early stage oocytes and embryos and reaches an undetectable level in $5 \mathrm{dpf}$ embryos (Fig. 7B, 7C) and thereafter.

Borealin-2 was predicted to possess a typical nuclear localization signal (NLS) indicating that it is a nuclear factor. To determine if Borealin-2 is a nuclear protein and if the predicted NLS is required for its nuclear localization, we performed a GFP reporter assay. HEK293 cells were transfected with expression constructs expressing either an EGFP-tagged wild-type Borealin-2 or a mutant Borealin-2 lacking the NLS. Fig. 8 shows that the wild-type Borealin-2 is exclusively localized to the nucleus of the transfected cells, while the mutant Borealin-2 is enriched in the cytoplasm of the cells. The result confirms that Borealin-2 is a nuclear protein and the predicted NLS is required for its nuclear localization.

\section{DISCUSSION}

LIM homeodomain genes play vital roles in tissue patterning and differentiation (Mori et al. 2004). Lhx8 represents the first LIM homeodomain family member that plays a crucial role in oogenesis (Pangas et al. 2006). In this study, we characterized the rainbow trout Lhx8 genes and discovered a novel oocyte-specific nuclear protein that interacts with Lhx8 proteins.

In rainbow trout, we identified $2 L h x 8$ genes, $L h x 8 a$ and $L h x 8 b$, which are located on two different chromosomes. The existence of two distinct Lhx8 genes in this species is most likely a result of genome duplication (Allendorf and Thorgaard 1984). The functional domains (LIM and homeobox) are very well conserved between the two proteins, indicating that Lhx8a and Lhx8b are functionally similar. Both Lhx8a and Lhx8b transcripts are predominantly expressed in the ovary, which is consistent with findings in mouse (Choi et al. 2008), chicken (Inoue et al. 2006) and pig (Fang et al. 2009).

The LIM domain is a protein-protein interaction interface (Schmeichel and Beckerle 1994) and is believed to function in protein dimerization (Breen et al. 1998b). Lhx8 contains two LIM domains with each having two zinc fingers. To determine if Lhx8a and Lhx8b regulate transcription in a homomeric or heteromeric fashion, we performed yeast two hybridization followed by BiFC assay to evaluate the Lhx8a:Lhx8b, Lhx8a:Lhx8a and 
Lhx 8b:Lhx8b interactions. Results show that Lhx8a and Lhx $8 b$ can interact each other or itself, indicating that the two proteins may form homodimers or heterodimers.

Protein-protein interactions are critical in many biological and developmental processes. For example, decreased functional interaction between Figla and Tcf3 in human could cause premature ovarian failure (Zhao et al. 2008). A mini interactome centered around Nanog is required to maintain ES cell pluripotency (Wang et al. 2006). In mouse, Lhx8 and Isl1 interaction is required for cholinergic gene expression in embryonic stem cell derived neurons (Cho et al. 2014). In addition, the Lhx8-Msx1 complex has been discovered to play important roles during mouse early tooth development (Zhao et al. 2013). In the present study, we identified Borealin-2, a novel nuclear protein that interacts with both Lhx8a and Lhx8b through a yeast two-hybrid screening. Borealin-2 is a paralogue of Borealin (also known as cell division cycle-associated protein 8 or Dasra-B), which is a subunit of the chromosomal passenger complex (CPC) required for stability of the bipolar mitotic spindle (Gassmann et al. 2004) and plays a crucial role in early embryonic development in mouse (Yamanaka et al. 2008; Zhang et al. 2009). However, Borealin-2 has never been studied experimentally. It was named after Borealin as it contains an Nbl1 (or Borealin_N) domain. Interestingly, Borealin-2 has orthologs in chicken, X. laevis, and zebrafish but not in any mammalian species.

We provided evidence that Borealin-2 mRNA is specifically expressed in ovary and testis and the expression of Borealin-2 mRNA is developmentally regulated during vitellogenesis and early embryogenesis. We also demonstrated that Borealin-2 protein is localized in the nucleus and deletion of the Nbl1 domain leads to dramatically decreased interaction between Borealin-2 and Lhx8a or Lhx8b, indicating the Nbl1 domain is responsible for protein: protein interaction. As a germ cell-specific nuclear protein abundantly present in oocyte and early embryos, Borealin-2 may play a crucial role in oocyte and early embryonic development through interactions with Lhx8a and Lhx8b.

In summary, the present study characterized the rainbow trout $L h x 8$ genes and identified Borealin-2 as a novel germ cell-specific nuclear factor that interacts with rainbow trout Lhx8 proteins. The novel protein deserves further investigation with respect to its influence on the development of oocytes and early embryos in fish as well as in other species. 


\section{ACKNOWLEDGMENTS}

This study was supported by the USDA ARS Cooperative Agreement No. 58-1930-0-059. It is published with the approval of the director of the West Virginia Agricultural and Forestry Experiment Station as scientific paper No. xxxx. 


\section{REFERENCES}

Allendorf FW, Thorgaard GH. 1984. Evolutionary Genetics of Fishes. in:Tetraploidy and the Evolution of Salmonid Fishes Ch, ed Turner B. J. 55-93 Plenum Press

Berthelot C, Brunet F, Chalopin D, Juanchich A, Bernard M, Noel B, Bento P, Da Silva C, Labadie K, Alberti A, Aury JM, Louis A, Dehais P, Bardou P, Montfort J, Klopp C, Cabau C, Gaspin C, Thorgaard GH, Boussaha M, Quillet E, Guyomard R, Galiana D, Bobe J, Volff JN, Genet C, Wincker P, Jaillon O, Roest Crollius H, Guiguen Y. 2014. The rainbow trout genome provides novel insights into evolution after whole-genome duplication in vertebrates. Nature communications 5:3657.

Breen JJ, Agulnick AD, Westphal H, Dawid IB. 1998. Interactions between LIM domains and the LIM domain-binding protein Ldb1. J Biol Chem 273(8):4712-4717.

Cho HH, Cargnin F, Kim Y, Lee B, Kwon RJ, Nam H, Shen R, Barnes AP, Lee JW, Lee S, Lee SK. 2014. Isl1 directly controls a cholinergic neuronal identity in the developing forebrain and spinal cord by forming cell type-specific complexes. PLoS Genet 10(4):e1004280.

Choi Y, Ballow DJ, Xin Y, Rajkovic A. 2008. Lim homeobox gene, lhx8, is essential for mouse oocyte differentiation and survival. Biol Reprod 79(3):442-449.

Fang W, Li GQ, Li ML, Wang W, Xu YX. 2009. The Pig Lhx8 Gene: cDNA Cloning, Bioinformatic Analysis and Expression Level in Tissues and Preimplantation Embryos. Agr Sci China 8(12):1503-1510.

Gassmann R, Carvalho A, Henzing AJ, Ruchaud S, Hudson DF, Honda R, Nigg EA, Gerloff DL, Earnshaw WC. 2004. Borealin: a novel chromosomal passenger required for stability of the bipolar mitotic spindle. J Cell Biol 166(2):179-191.

Hobert O, Westphal H. 2000. Functions of LIM-homeobox genes. Trends Genet 16(2):75-83.

Inoue M, Kawakami M, Tatsumi K, Manabe T, Makinodan M, Matsuyoshi H, Kirita T, Wanaka A. 2006. Expression and regulation of the LIM homeodomain gene L3/Lhx8 suggests a role in upper lip development of the chick embryo. Anat Embryol (Berl) 211(3):247-253. 
Mori T, Yuxing Z, Takaki H, Takeuchi M, Iseki K, Hagino S, Kitanaka J, Takemura M, Misawa H, Ikawa M, Okabe M, Wanaka A. 2004. The LIM homeobox gene, L3/Lhx8, is necessary for proper development of basal forebrain cholinergic neurons. Eur $\mathbf{J}$ Neurosci 19(12):3129-3141.

Pangas SA, Choi Y, Ballow DJ, Zhao Y, Westphal H, Matzuk MM, Rajkovic A. 2006. Oogenesis requires germ cell-specific transcriptional regulators Sohlh1 and Lhx8. Proc Natl Acad Sci U S A 103(21):8090-8095.

Qiu GF, Weber GM, Rexroad CE, 3rd, Yao J. 2008. Identification of RtGST-1, a novel germ cell-specific mRNA-like transcript predominantly expressed in early previtellogenic oocytes in rainbow trout (Oncorhynchus mykiss). Mol Reprod Dev 75(5):723-730.

Rajkovic A, Pangas SA, Ballow D, Suzumori N, Matzuk MM. 2004. NOBOX deficiency disrupts early folliculogenesis and oocyte-specific gene expression. Science 305(5687):1157-1159.

Ramachandra RK, Lankford SE, Weber GM, Rexroad CE, 3rd, Yao J. 2007. Identification of OORP-T, a novel oocyte-specific gene encoding a protein with a conserved oxysterol binding protein domain in rainbow trout. Mol Reprod Dev 74(4):502-511.

Ren Y, Suzuki H, Jagarlamudi K, Golnoski K, McGuire M, Lopes R, Pachnis V, Rajkovic A. 2015. Lhx8 regulates primordial follicle activation and postnatal folliculogenesis. BMC Biol 13:39.

Schmeichel KL, Beckerle MC. 1994. The LIM domain is a modular protein-binding interface. Cell 79(2):211-219.

Soyal SM, Amleh A, Dean J. 2000. FIGalpha, a germ cell-specific transcription factor required for ovarian follicle formation. Development 127(21):4645-4654.

Thorgaard GH, Bailey GS, Williams D, Buhler DR, Kaattari SL, Ristow SS, Hansen JD, Winton JR, Bartholomew JL, Nagler JJ, Walsh PJ, Vijayan MM, Devlin RH, Hardy RW, Overturf KE, Young WP, Robison BD, Rexroad C, Palti Y. 2002. Status and opportunities for genomics research with rainbow trout. Comp Biochem Physiol B Biochem Mol Biol 133(4):609-646. 
Toyama R, Kobayashi M, Tomita T, Dawid IB. 1998. Expression of LIM-domain binding protein (ldb) genes during zebrafish embryogenesis. Mech Dev 71(1-2):197-200.

Wang J, Rao S, Chu J, Shen X, Levasseur DN, Theunissen TW, Orkin SH. 2006. A protein interaction network for pluripotency of embryonic stem cells. Nature 444(7117):364-368.

Wang L, Ma H, Fu L, Yao J. 2014. Kpna7 interacts with egg-specific nuclear factors in the rainbow trout (Oncorhynchus mykiss). Mol Reprod Dev 81(12):1136-1145.

Wang L, Tripurani SK, Wanna W, Rexroad CE, 3rd, Yao J. 2013. Cloning and characterization of a novel oocyte-specific gene encoding an F-Box protein in rainbow trout (Oncorhynchus mykiss). Reprod Biol Endocrinol 11:86.

Yamanaka Y, Heike T, Kumada T, Shibata M, Takaoka Y, Kitano A, Shiraishi K, Kato T, Nagato M, Okawa K, Furushima K, Nakao K, Nakamura Y, Taketo MM, Aizawa S, Nakahata T. 2008. Loss of Borealin/DasraB leads to defective cell proliferation, p53 accumulation and early embryonic lethality. Mech Dev 125(5-6):441-450.

Zhang Q, Lin G, Gu Y, Peng J, Nie Z, Huang Y, Lu G. 2009. Borealin is differentially expressed in ES cells and is essential for the early development of embryonic cells. Mol Biol Rep 36(3):603-609.

Zhao H, Chen ZJ, Qin Y, Shi Y, Wang S, Choi Y, Simpson JL, Rajkovic A. 2008. Transcription factor FIGLA is mutated in patients with premature ovarian failure. Am J Hum Genet 82(6):1342-1348.

Zhao M, Gupta V, Raj L, Roussel M, Bei M. 2013. A network of transcription factors operates during early tooth morphogenesis. Mol Cell Biol 33(16):3099-3112.

Zheng P, Dean J. 2007. Oocyte-specific genes affect folliculogenesis, fertilization, and early development. Semin Reprod Med 25(4):243-251. 
Figure 1.

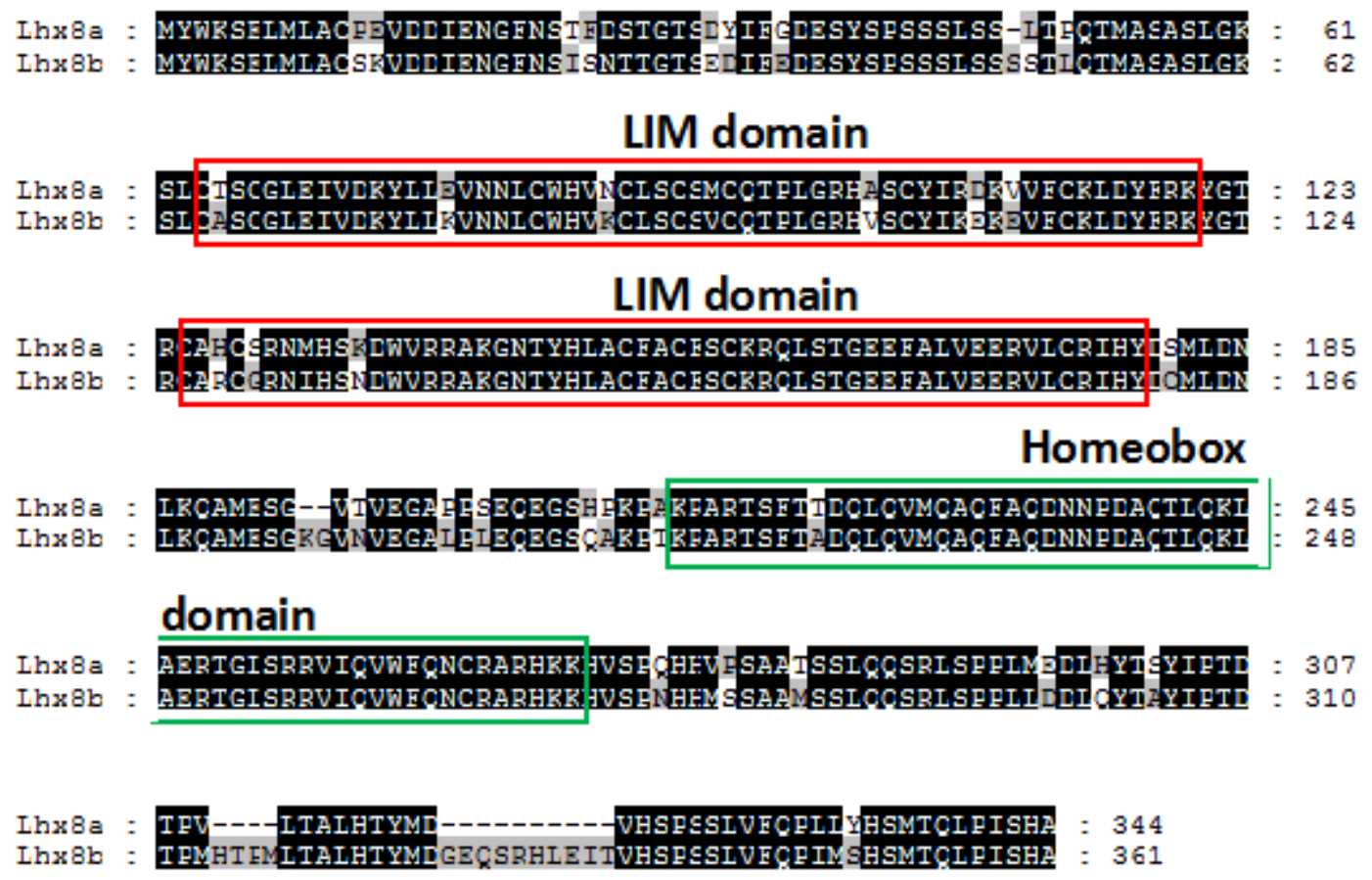

Figure 1. Comparison of protein sequences between Lhx8a and Lhx8b. Sequence alignment was performed using Clustal Omega (http://www.ebi.ac.uk/Tools/msa/clustalo/). The functional domains were determined by searching the Pfam database (http://pfam.xfam.org/search). The LIM and Homeobox domains are indicated by red and green boxes, respectively. 


\section{Figure 2.}

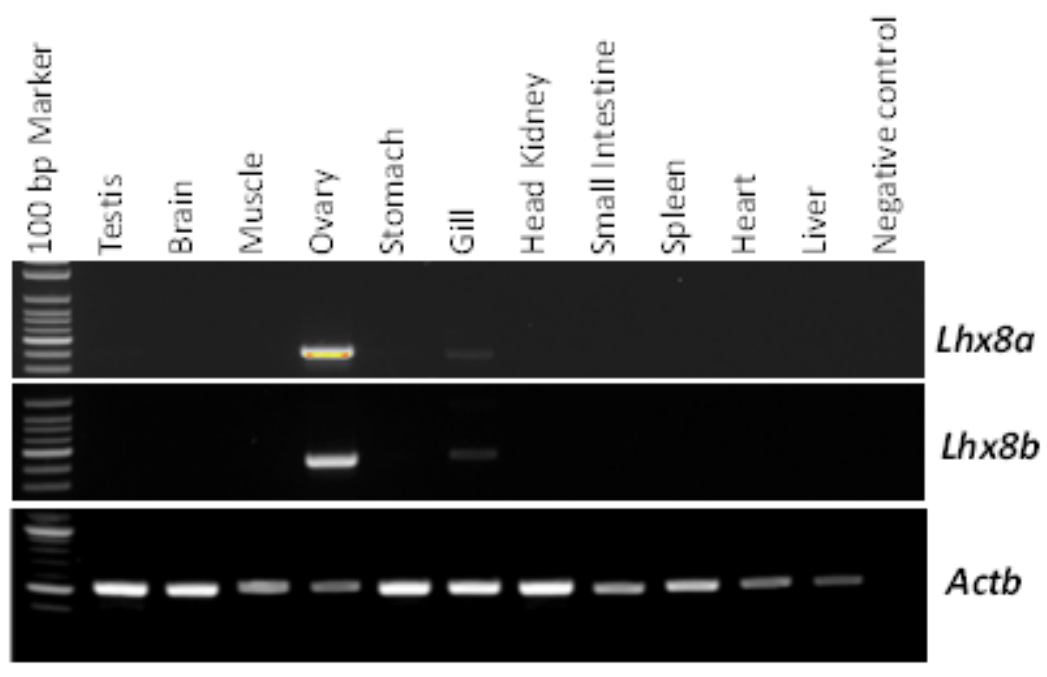

Figure 2. Analysis of $L h x \& a$ and $L h x 8 b$ mRNA expression. A: Tissue distribution analysis of $L h x 8 a$ and $L h x 8 b$ mRNA by RT-PCR. Trout tissues tested include testis, brain, muscle, ovary, stomach, gill, head kidney, small intestine, spleen, heart, and liver. M, 100-bp DNA marker; Trout $\beta$-actin was used as a control for RNA quality. 


\section{Figure 3.}

A

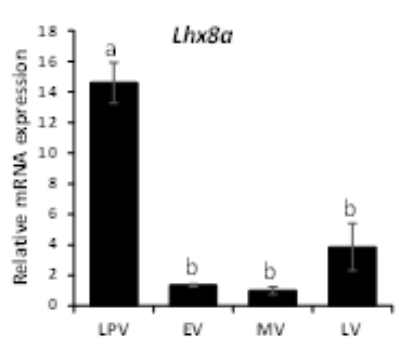

B

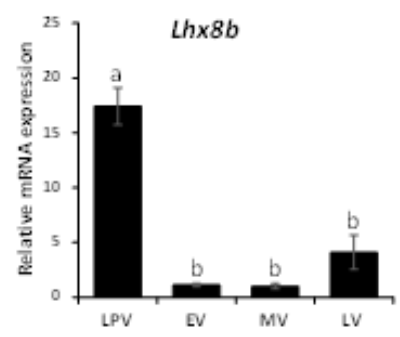

C

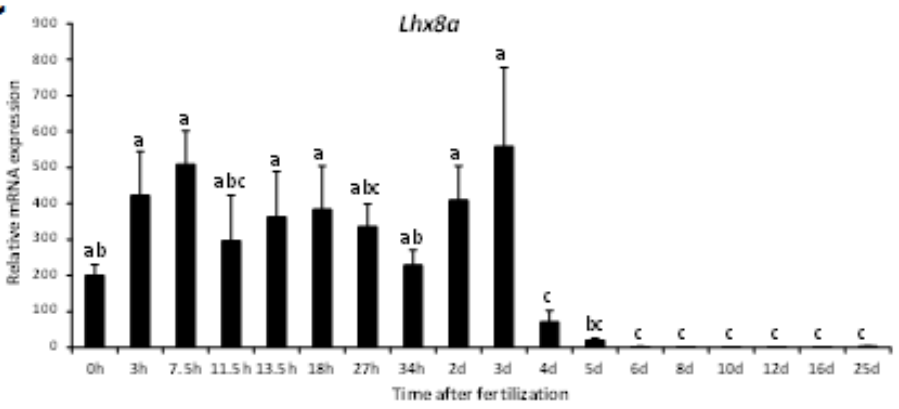

D

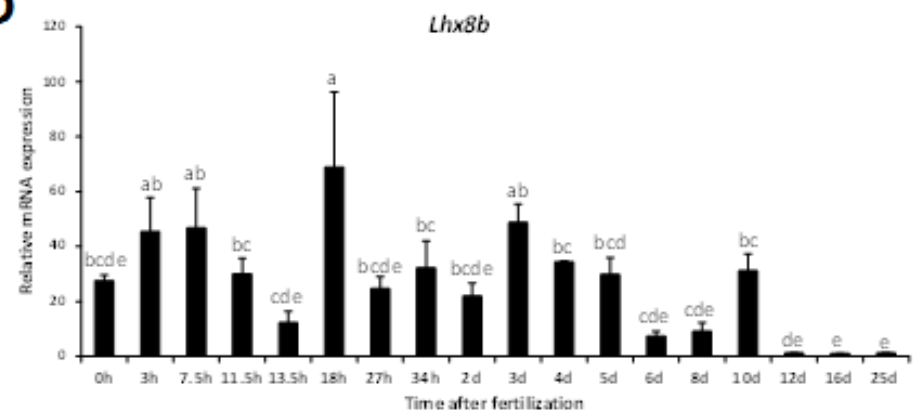

Figure 3. RT-qPCR analysis of $L h x 8 a$ and $L h x 8 b$ mRNA expression during ovarian development. Ovarian samples at different developmental stages including late pre-, early-, mid-, and late-vitellogenesis were used in the analysis. The quantity of Lhx8a and Lhx8b mRNA was normalized to the quantity of $\beta$-actin transcript. Means of the normalized gene expression values $(n=4)$ for each stage of ovarian development were calculated and expressed as relative abundance. Star indicates significant difference $(\mathrm{P}<0.05)$. $\mathbf{D}$ and $\mathbf{E}$ : RT-qPCR analysis of $L h x 8 a$ and $L h x 8 b$ mRNA expression during embryonic development. Embryos $(\mathrm{n}=4)$ were collected at $0,3.5,7.5,11.5,13.5,18,27,34$ hours, $2,3,4,5,6,8,10,12,16$, and 25 days post-fertilization. Rainbow trout $18 S$ rRNA gene was used as an endogenous control. Different letters indicate significant difference $(\mathrm{P}<0.05)$. 


\section{Figure 4.}

A

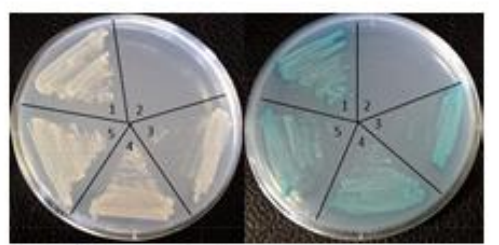

1. Positive control

2. Negative control

3. pGBKT7-Lhx8a + pGADT7-Lhx8a

4. $p$ GBKT7-Lhx8a + pGADT7-Lhx $8 b$

5. pGBKT7-Lhx8b + pGADT7-Lhx8b

B

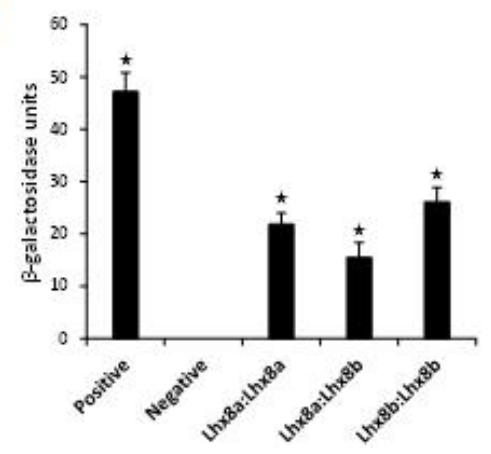

C

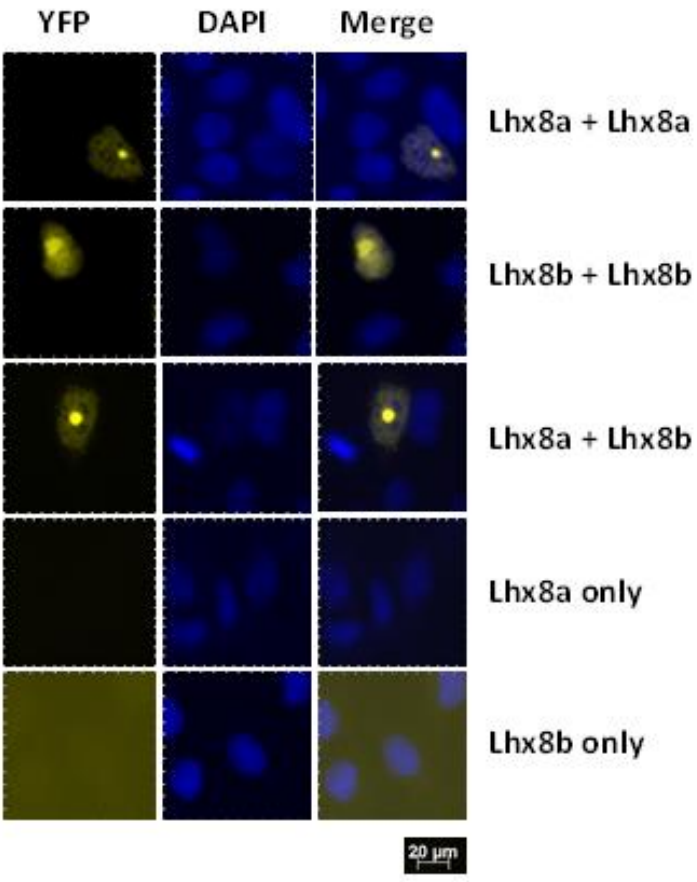

Figure 4. Analysis of interactions between Lhx8a and Lhx8b. A: Yeast two-hybrid analysis showing growth of yeast cells expressing BD and AD fusion proteins. 1. Positive control, 2. Negative control, 3. Lhx8a and Lhx8a, 4. Lhx8a and Lhx8b, 5. Lhx8b and Lhx8b. Right plate: Growth of yeast cells on DDO plate (medium lacking Leucine and tryptophan) showing successful co-transformations. Left plate: growth of yeast cells on selective QDO/X/A plate (Quadruple drop-out medium lacking leucine, tryptophan, adenine and histidine and containing $\mathrm{X}$-gal) indicating protein-protein interactions B: Yeast $\beta$-galactosidase liquid assays confirming interactions between Lhx8a and Lhx8b. C: BiFC analysis of Lhx8a and Lhx8b interactions. HEK293 cells were co-transfected with equal amounts of BiFC expression constructs encoding VN-Lhx8a and VC-Lhx8a, or VN-Lhx8b and VC-Lhx8b, or VN-Lhx8a and VC-Lhx $8 b$ fusion proteins. Single transfections using constructs encoding VN-Lhx8a or VN-Lhx8b served as negative controls. YFP signals due to BiFC were measured by fluorescence microscopy. 


\section{Figure 5.}

A

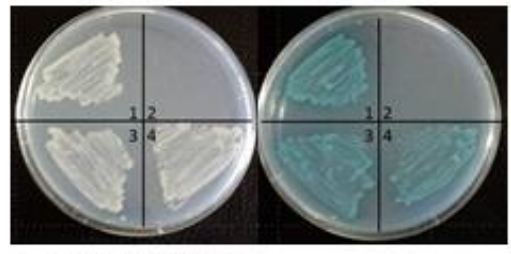

1. Positive control

2. Negative control

3. pGBKT7-Lhx8b + pGADT7-Borealin-2

4. pGBKT7-Lhx8a + pGADT7-Borealin-2

B

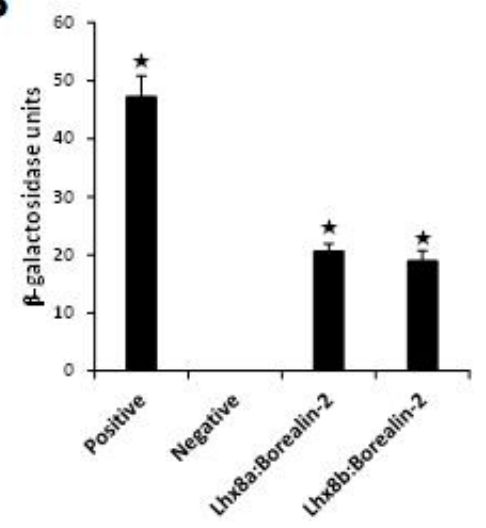

C

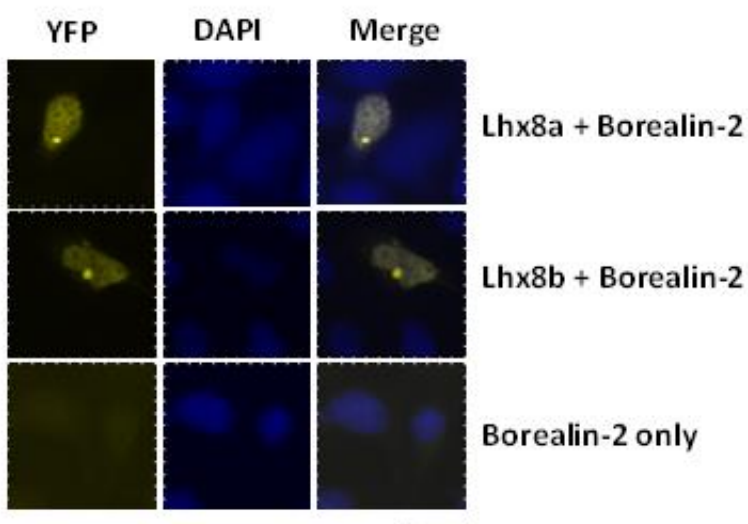

$20 \mathrm{um}$

Figure 5: Analysis of interactions between Lhx8 proteins and Borealin-2. A: Yeast two-hybrid analysis showing growth of yeast cells expressing BD and AD fusion proteins. 1. Positive control, 2. Negative control, 3. Lhx8b and Borealin-2, 4. Lhx8a and Borealin-2. B: Yeast $\beta$-galactosidase liquid assays confirming interactions between $\mathrm{Lhx} 8$ proteins and Borealin-2. C: BiFC analysis showing interactions between Lhx8 proteins and Borealin-2. HEK293 cells were co-transfected with equal amounts of BiFC expression constructs encoding VN-Lhx8a and VC-Borealin-2, or VN-Lhx8b and VC-Borealin-2 fusion proteins. Single transfection using the construct encoding VC-Borealin-2 was served as a negative control. YFP signals due to BiFC of were measured by fluorescence microscopy. 


\section{Figure 6.}

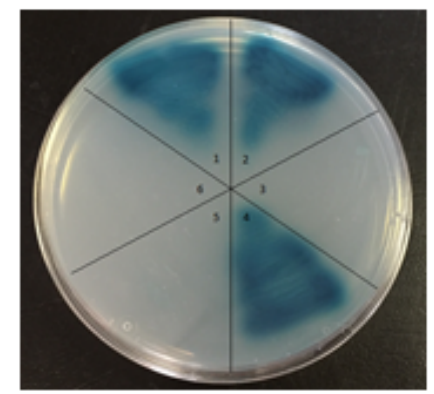

1. Positive control

2. pGBKT7-Lhx8a + pGADT7-Borealin-2-wt

3. pGBKT7-Lhx8a + pGADT7-Borealin-2-mut

4. pGBKT7-Lhx8b + pGADT7-Borealin-2-wt

5. pGBKT7-Lhx8b + pGADT7-Borealin-2-mut

6. Negative control

\section{GAL4AD}

$\mathrm{Nb} \mid 1$

Borealin-2-wt

GAL4AD

Borealin-2-mut

Figure 6: Requirement of the Nbl1 domain of Borealin-2 for interaction with Lhx 8 proteins. Yeast two-hybrid analysis showing growth of yeast cells expressing BD and AD fusion proteins on QDO/X/A plates. 1. Positive control, 2. Lhx8a and wild type Borealin-2, 3. Lhx8a and mutant Borealin-2 (Nbl1 deletion), 4. Lhx8b and wild type Borealin-2, 5. Lhx $8 \mathrm{~b}$ and mutant Borealin-2, 6. Negative control. 


\section{Figure 7.}

A

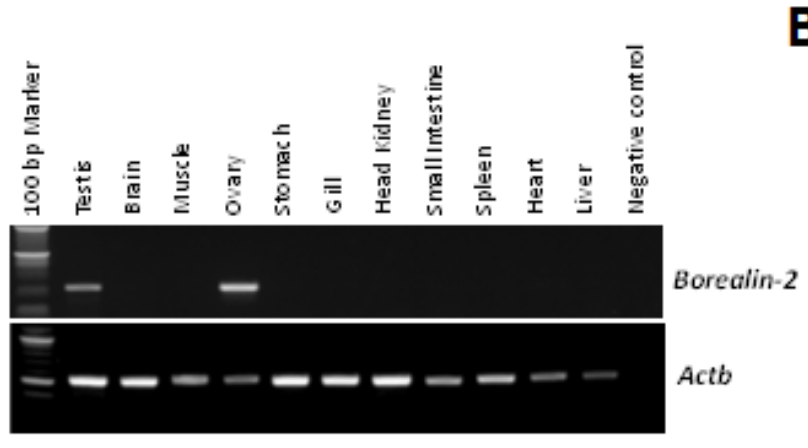

B

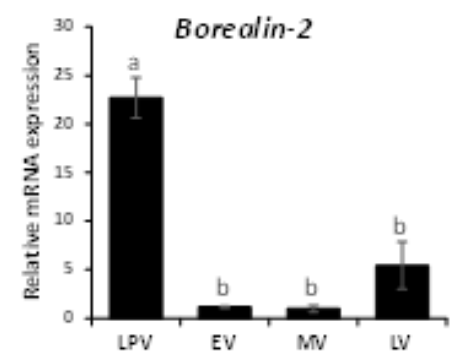

C

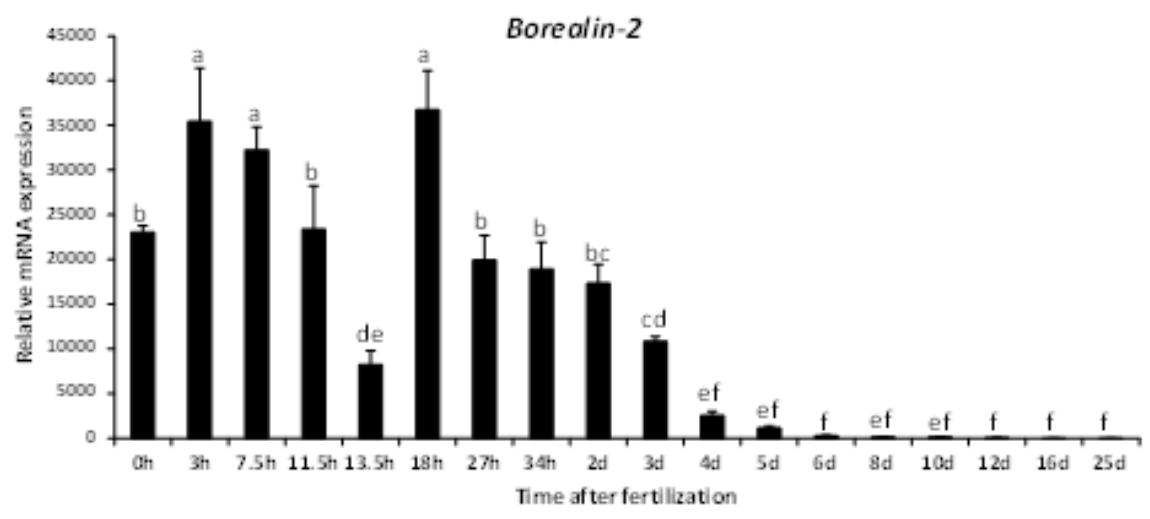

Figure 7. Analysis of Borealin-2 mRNA expression. A: RT-PCR analysis of Borealiln-2 mRNA expression in rainbow trout tissues. Trout tissues tested include testis, brain, muscle, ovary, stomach, gill, head kidney, small intestine, spleen, heart, and liver. Trout Actb gene was used as a control for RNA quality. B: RT-qPCR analysis of Borealin-2 mRNA expression during ovarian development. Ovarian samples at different developmental stages (late pre-, early-, mid-, and late-vitellogenesis) were used in the analysis. C: RT-qPCR analysis of Borealin-2 mRNA expression during embryonic development. Embryos $(n=4)$ were collected at $0,3.5,7.5,11.5,13.5,18,27,34$ hours, $2,3,4,5,6,8,10,12,16$, and 25 days post-fertilization. Rainbow trout $18 S$ rRNA gene was used as internal control. Different letters indicate significant difference $(\mathrm{P}<0.05)$. 
Figure 8.

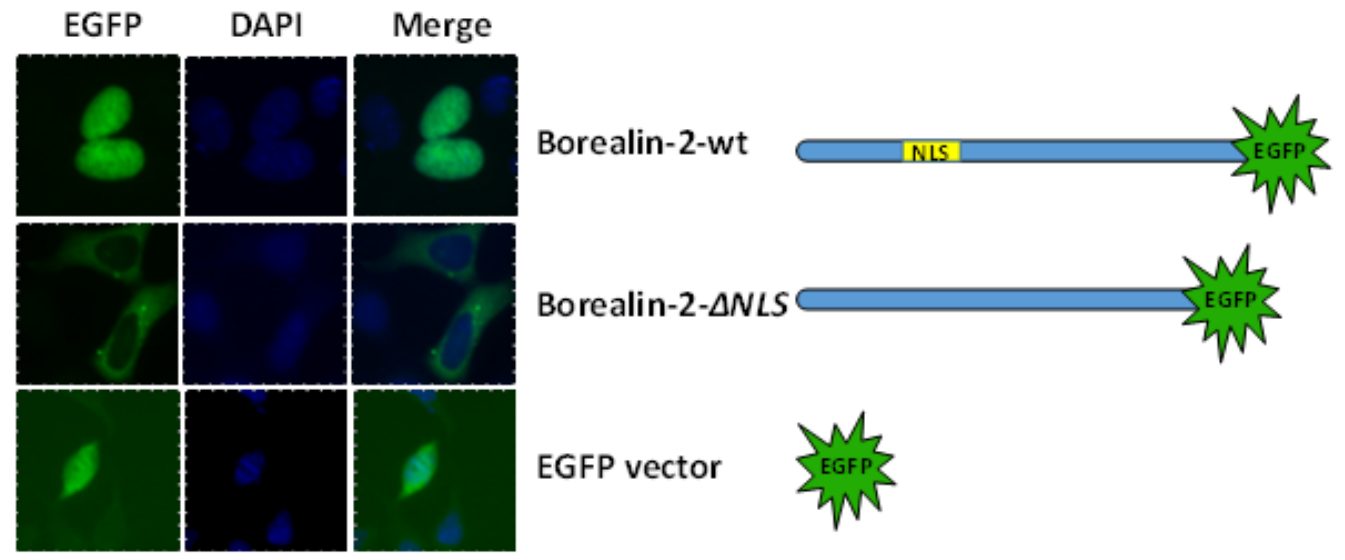

$20 \mathrm{rm}$

Figure 8. EGFP reporter assay showing nuclear localization of Borealin-2 protein. HEK293 cells were transfected with EGFP reporter constructs expressing either an EGFP tagged wild type Borealin-2 or a mutant Borealin-2 with its NLS deleted. Transfection using empty pcDNA3-EGFP vector was used as the control. 
Table 1. Primers used in this study

\begin{tabular}{|c|c|c|}
\hline Primer name & Sequence & Application \\
\hline Lhx8a-RT-PCR-F & CAGGCCATGGAAAGTGGTGTTAC & Reverse transcription PCR \\
\hline Lhx8a-RT-PCR-R & GAGGGAGAGTGCACATCCATG & Reverse transcription PCR \\
\hline Lhx8b-RT-PCR-F & GTTAGAGCAAGAAGGGTCCCAGG & Reverse transcription PCR \\
\hline Lhx8b-RT-PCR-R & CTGTGATCTCCAAGTGCCGACT & Reverse transcription PCR \\
\hline Borealin-2-RT-PCR-F & GTGAGTGAAGGTGCATCGGCTC & Reverse transcription PCR \\
\hline Borealin-2-RT-PCR-R & CCAGGCAGGGAGCAATACAGG & Reverse transcription PCR \\
\hline Actb-RT-PCR-F911 & AAGTGTGACGTGGACATCCGT & Reverse transcription PCR \\
\hline Actb-RT-PCR-R1421 & TAATCCGCTGCTTCACCGTTC & Reverse transcription PCR \\
\hline Lhx8a-realtime-F & ACAGCAGTCCAGGCTTTCTC & Real-time PCR \\
\hline Lhx8a-realtime-R & GAGGGAGAGTGCACATCCATG & Real-time PCR \\
\hline Lhx8b-realtime-F & ACAGACACACCCATGCACAC & Real-time PCR \\
\hline Lhx 8b-realtime-R & CTGTGATCTCCAAGTGCCGACT & Real-time PCR \\
\hline Actb-realtime-F541 & GCCGGCCGCGACCTCACAGACTAC & Real-time PCR \\
\hline Actb-realtime-R613 & CGGCCGTCCTCCTGAAGCTGTAAC & Real-time PCR \\
\hline 18S rRNA-realtime-F & CATGGCCGTTCTTAGTTGGT & Real-time PCR \\
\hline 18S rRNA-realtime-6 & CTCTAAGAAGTTGGACGCCG & Real-time PCR \\
\hline Lhx8a/b-AD/BD-F & GGCCCATATGTATTGGAAAAGTGAACTAATG & Yeast two-hybrid \\
\hline Lhx8a/b-AD/BD-R & GGCCGAATTCGGCATGGCTGATTGGCAGCTGT & Yeast two-hybrid \\
\hline Borealin-2-mut-AD-F & GGCCCATATG GCGGATGACATTTCTGCAGGTG & Y2H NB11 deletion \\
\hline Borealin-2-mut-AD-R & GGCCGAATTC TCATTGCACACTCAGAGGCTG & Y2H NB11 deletion \\
\hline Lhx8a-BiFC-F & GGCCGAATTCGATGTATTGGAAAAGTGAACTAATG & $\mathrm{BiFC}$ \\
\hline Lhx8a-BiFC-R & GGCCTCTAGAGGCATGGCTGATTGGCAGCTGT & $\mathrm{BiFC}$ \\
\hline Lhx8b-BiFC-F & GGCCGAATTCGGATGGATTGGAAAAGTGAACTAATG & $\mathrm{BiFC}$ \\
\hline Lhx8b-BiFC-R & GGCCCTCGAGCGGCATGGCTGATTGGCAGCTGT & $\mathrm{BiFC}$ \\
\hline Borealin-2-BiFC-F & GGCCGAATTCGGATGGCACCAAGAAGGATAAGG & $\mathrm{BiFC}$ \\
\hline Borealin-2-BiFC-R & GGCCCTCGAGCTTGCACACTCAGAGGCTG & $\mathrm{BiFC}$ \\
\hline Borealin-2-EGFP-F & GGCCGAATTCATGGCACCAAGAAGGATAAGG & EGFP reporter assay \\
\hline
\end{tabular}


Borealin-2-EGFP-R GGCCCTCGAGTTGCACACTCAGAGGCTGATTCGC

Borealin-2-delNLS-R AGCCGATGCACCTTCACTCAC

GTGAGTGAAGGTGCATCGGCTGCCAATAGCTCCAGCAC

Borealin-2-delNLS-F TGGAAGCC
EGFP reporter assay

EGFP assay NSL deletion

EGFP assay NSL deletion 


\section{CHAPTER 2}

Molecular characterization of bovine $\mathbf{L h x 8}$ and identification of its interacting partners

Liyuan Fu, Mingxiang Zhang, Kristen Mastrantoni, xxxx, xxxx and Jianbo Yao*

Division of Animal and Nutritional Sciences, West Virginia University, Morgantown, WV 26506 USA

Short title: Characterization of bovine Lhx 8

Key words: Lhxh8, Figla, Sohlh1, protein: protein interaction, oogenesis

Grant sponsor: Agriculture and Food Research Initiative Competitive Grant no. 2009-65203-05706 and Grant no. 2016-67015-24919 from the USDA National Institute of Food and Agriculture

Conflict of interest: The authors have no conflict of interest to declare.

*Corresponding author

Jianbo Yao

West Virginia University

Morgantown, WV 26506-6108

U.S.A.

Tel.: 304-293-1948

Fax: 304-293-2232

E-mail: jianbo.yao@mail.wvu.edu 


\section{ABSTRACT}

LIM homeobox $8(\operatorname{Lhx} 8)$ is a germ cell specific transcription factor essential for oocyte development during early oogenesis. In mice, Lhx 8 deficiency causes postnatal oocyte loss and affects the expression of many oocyte-specific genes in the ovary, such as Gdf9, Pou5f1 and Nobox. Our previous study demonstrated that rainbow trout Lhx 8 interacts with a novel germ cell-specific nuclear protein, Borealin-2. The aims of this study were to characterize the bovine $L h x 8$ gene, determine its mRNA expression during oocyte development and early embryogenesis, and evaluate its interactions with oocyte-specific transcription factors. The open reading frame (ORF) of bovine $L h x 8$ gene was amplified from cDNA of a bovine fetal ovary and sequence analysis revealed that bovine Lhx8 ORF is 1,134 bp in length encoding a protein of 377 amino acids. A splicing variant of $\operatorname{Lh} x 8$ (Lhx8_vl) was identified, which results from alternative splicing of exon 2 and 3, and encodes a protein of 293 amino acids. The predicted bovine Lhx8 protein contains two LIM domains and one homeobox domain. However, one of the LIM domains in the splicing variant, $L h x 8 \_v 1$, is incomplete due to deletion of 83 amino acids near the $\mathrm{N}$ terminus. Both Lhx8 and Lhx8_vl mRNA are specifically expressed in fetal ovaries and testis but neither detectable in the somatic tissues nor in granulosa nor theca cells. Lhx8 mRNA is highly abundant in GV and MII stage oocytes as well as in early stage embryos but not detectable in morula and blastocyst stage embryos. Lhx8_v1 mRNA expression is detectable in oocytes and early embryo but not in morula and blastocyst stage embryos. A GFP reporter assay revealed that Lhx8 is a nuclear protein and the predicted monopartite NLS is required for its transport into the nucleus. Direct yeast two-hybrid analysis revealed that bovine Lhx8 protein interacts with Figla but not Sohlh1. The interaction between Lhx 8 and Figla was confirmed by a co-immunoprecipitation assay. The study provides new information for studying the mechanisms of the regulatory roles of Lhx 8 and Figla in follicular development and early embryogenesis. 


\section{INTRODUCTION}

A well-ordered series of events coordinating multiple molecular pathways regulate oogenesis and embryogenesis. Transcription factors play important roles during these developmental processes. They control the expression of target genes due to their broad DNA-binding specificities (Thesleff et al. 1995) and the specificity of target DNA-binding is achieved through selective protein interactions. Among different categories of transcription factors, germ cell-specific transcription factors are essential for follicle formation and subsequent development (Zheng and Dean 2007). Examples of such factors include LIM homeobox 8 (Lhx8) (Choi et al. 2008), factor in germline alpha (Figla) (Soyal et al. 2000), spermatogenesis and oogenesis specific basic helix-loop-helix 1 (Sohlh1) (Pangas et al. 2006), and newborn ovary homeobox (Nobox) (Rajkovic et al. 2004). Deficiency of these genes in mice leads to the failure of primordial follicle formation or the disruption of early follicular development.

Lhx8 is a germ cell-specific transcription factor highly expressed in mammalian ovaries (Moriguchi et al. 2012; White et al. 2012). In mice, Lhx8-null ovaries fail to maintain primordial follicles due to loss of oocytes within 7 days. Many oocyte-specific genes, such as Gdf9, Pou5f1, and Nobox, are misexpressed in Lhx8-null ovaries (Choi et al. 2008). Lhx8 a LIM homeobox protein containing two tandem LIM domains and one homeobox domain. Most LIM proteins act as negative regulators in cells. For example, loss of Lhxl in Xenopus activates transcriptions (Taira et al. 1994) and over-expression of Islet-3 in zebrafish inhibits homeobox domain binding to DNA (Kikuchi et al. 1997).

The LIM domain is a double-zinc finger motif which mediates protein-protein interactions. LIM domain can interact with LIM domain-containing proteins (Dawid et al. 1998; German et al. 1992; Leonard et al. 1992; Mizuno and Higuchi 1997; Schmeichel and Beckerle 1994; Xue et al. 1993). Most Lhx protein interactions are mediated by LIM domains. Homomeric or heteromeric complexes are formed when a LIM domain interacts with other regulatory proteins (Bach et al. 1997; Jurata et al. 1998). Lhx proteins may also interact with ring finger proteins through the LIM domains causing repression of gene expression (Bach et al. 1999). In tooth morphogenesis, Lhx family members interact with other transcription 
factors in response to Fgf8 and other signals (Tzchori et al. 2009). These studies suggest that LIM containing proteins exert their functions through interactions with other proteins. As a germ cell-specific transcription factor, Lhx8 may also regulate target genes by context-dependent protein interactions. Our previous study demonstrated that Lhx8 interacts with an oocyte-specific nuclear factor in rainbow trout.

Figla is a basic helix-loop-helix (bHLH) transcription factor and is essential for folliculogenesis and activation of oocyte-associated genes during normal oogenesis. In mice, ablation of the Figla gene causes females to become sterile due to failure in the formation of primordial follicles (Soyal et al. 2000). bHLH proteins in association with other transcription factors can regulate tissue-specific gene expression and tumorigenesis. For example, Tal1 (a bHLH protein) interacting with a LIM transcription factor, Lmo2, can induce T-cell leukemia in a collaborative fashion (Larson et al. 1996). Sohlh1 is also a germ cell-specific bHLH transcription factor. Female mice lacking Sohlhl have normal germ cell migration and embryonic gonadogenesis, but form imperfect primordial follicles that do not progress to primary follicles (Pangas et al. 2006). Sohlh1-null ovaries contain significantly less Figla mRNA and transcripts for the Figla target genes, Zpl and Zp2 (Pangas et al. 2006). To date, proteins interacting with either Figla or Sohlh1 have not been discovered.

The main objectives of this study were to clone and analyze the bovine Lhx 8 cDNA and protein sequences, determine the temporal expression of Lhx 8 transcripts during oocyte maturation and early embryonic development, and identify protein partners that directly interact with the Lhx8 protein in vitro and in vivo. We show that expression of bovine Lhx8 is temporally regulated during oogenesis and early embryonic development, and Lhx 8 interacts with Figla. This is the first report of a direct protein-protein interaction between two germ cell-specific transcription factors essential for oocyte and follicular development.

\section{MATERIALS AND METHODS}

\section{Tissue sample collection}

Bovine tissue samples were collected from a local slaughterhouse. These samples include spleen, stomach, brain, muscle, kidney, liver, heart, intestine, adult ovary, adult testis, fetal 
testis and fetal ovary. Fetal ovaries from different gestation stages were collected and the ages of fetuses were estimated based on crown-rump length (Richardson et al. 1990). Granulosa and theca cells were dissected from antral follicles using an established method (Murdoch et al. 1981). Briefly, antral follicles were isolated and frozen in liquid nitrogen. A $3 / 4$ cut around the circumference of the follicle was made and the outer-theca layer was removed by peeling with forceps, leaving the granulose layer that is still adhered to the frozen follicular fluid core. Samples after collection were frozen in liquid nitrogen and subsequently stored in $-80{ }^{\circ} \mathrm{C}$ until use.

\section{RNA isolation, cDNA synthesis, and RT-PCR analysis}

Total RNA from different tissues was isolated using Trizol according to the manufacturer's instructions (Invitrogen, Carlsbad, CA) followed by DNase treatment. Oocytes and embryo samples including GV- and MII-stage oocytes and 2-cell, 4-cell, 8-cell, 16-cell, and morula- and blastocyst-stage embryos (20 oocytes/embryos) were purchased from Bomed, Inc. Total RNA from oocytes and embryos was isolated and simultaneously subjected to DNase treatment using the RNAqueous Micro Scale RNA isolation kit (Ambion). The DNase-treated RNA was converted to cDNA using oligo (dT) 18 primer and SuperScript III reverse transcriptase (Invitrogen, Carlsbad, CA).

For gene expression analysis, RT-PCR was performed in a $25-\mu 1$ reaction using gene-specific primers (Table 1) under the following conditions: 5 min denaturation at $94{ }^{\circ} \mathrm{C}$ followed by 30 cycles of $94{ }^{\circ} \mathrm{C}$ for $30 \mathrm{sec}, 58{ }^{\circ} \mathrm{C}$ for $45 \mathrm{sec}$, and $72{ }^{\circ} \mathrm{C}$ for $30 \mathrm{sec}$, and a final extension at $72{ }^{\circ} \mathrm{C}$ for $10 \mathrm{~min}$. Bovine RPL19 was used as a control for RNA quantity.

For cloning of bovine $L h x 8 \mathrm{cDNA}$, RT-PCR was performed to amplify different regions of the cDNA using primers (Table 1) designed based on a predicted bovine Lhx8 sequence and a partial bovine $\operatorname{Lh} x 85^{\prime}$ transcript. The amplified cDNA fragments were cloned into pGEM-T-easy vector (Promega, Madison, WI) and sequenced.

\section{EGFP reporter assay}

The coding region of bovine Lhx8 was PCR-amplified using gene-specific primers 
containing EcoRI and XhoI sites (Table 1) and cloned in-frame with the EGFP sequence in pcDNA3-EGFP vector (Addgene, Cambridge, MA) to generate the wild-type Lhx8 expression construct, pcDNA3-EGFP-Lhx 8-wt. Lhx8 mutants were produced by 2 -step PCR using primers (Table 1) designed to produce mutants with either the monopartite NLS or the bipartite NLS deleted. Mutant EGFP-Lhx8 constructs (pcDNA3-EGFP-Lhx8-AM-NLS and pcDNA3-EGFP-Lhx8- $\Delta \mathrm{B}-\mathrm{NLS}$ ) were generated by cloning the Lhx8 mutants in pcDNA3-EGFP vector. All constructs were confirmed by sequencing.

HEK 293 cells were seeded on 20-mm Poly-D-lysine coated German coverslips (Neuvitro, E1 Monte, CA) inside 6-well plates. Twenty four hours after plating, cells were transfected with $1 \mu \mathrm{g}$ of each plasmid using transfection reagent X-tremeGENE 9 (Roche). Coverslips containing the cells were washed with PBS $24 \mathrm{~h}$ after transfection and fixed in methanol for 5 min followed by DAPI staining. Cells were analyzed using a fluorescence microscope (MIF Zeiss Fluorescent).

\section{Direct yeast two-hybridization}

Protein interactions between Lhx8 and Figla or Sohlh1 were assayed by direct yeast two-hybrid analysis using the Matchmaker Two-Hybrid System (Clontech Laboratories, Mountain View, CA). The coding region of bovine Lhx 8 was cloned in-frame into pGBKT7 vector (pGBKT7-Lhx8). The plasmid was transformed into Y2HGold strain cells. The coding regions of bovine Figla or Sohlhl were cloned in-frame into the pGADT7 vector, generating AD constructs (pGADT7-Figla and pGADT7-Sohlhl). The AD constructs were transformed into Y187 strain cells. All transformants were tested for toxicity and auto-activation before mating according to the manufacturer's protocol. The yeast cells expressing BD-Lhx8 were mated with cells expressing either AD-Figla or AD-Sohlhl fusion proteins. After mating at $30{ }^{\circ} \mathrm{C}$ for $24 \mathrm{~h}$, yeast cells were plated on synthetic double dropout selection medium $\mathrm{DDO} / \mathrm{X} / \mathrm{A}$ and incubated at $30{ }^{\circ} \mathrm{C}$ for 3 days. Single blue colonies $(>2 \mathrm{~mm})$ were selected and streaked onto fresh QDO/X/A quadruple dropout plates (lacking adenine, histidine, tryptophan and leucine and supplemented with X- $\alpha-G a l$ and Aureobasidin A). 


\section{Co-immunoprecipitation}

To confirm the direct interaction between bovine Lhx8 and Figla, as observed by yeast two-hybridization, co-immunoprecipitation (Co-IP) was performed in HEK293 cells co-expressing tagged Lhx8 and Figla proteins. The plasmid expressing Lhx8-FLAG was constructed by cloning the $L h x 8$ ORF in frame with a 3' FLAG tag sequence into pcDNA3.1 (pcDNA3.1-Lhx8-FLAG). The construct expressing bovine Figla-HA was generated by cloning the Figla ORF in frame with a 3' HA tag sequence into pcDNA3.1 (pcDNA3.1-Figla-HA). Both constructs were confirmed by sequencing.

HEK 293 cells were maintained in Dulbecco modified Eagle medium supplemented with $10 \%(\mathrm{v} / \mathrm{v})$ fetal bovine serum (Life technologies, Carlsbad, CA). Cells were transiently co-transfected with the expression constructs, pcDNA3.1-Lhx8-FLAG and pcDNA3.1-Figla-HA using X-tremeGENE 9 transfection reagent according to the manufacturer's protocol (Roche, Mannheim, Germany). Cells were collected $24 \mathrm{~h}$ after transfection. Whole cell lysates were immunoprecipitated with anti-Flag antibody (Sigma-Aldrich) using the Pierce Co-Immunoprecipitation kit according to the manufacturer's instructions (Life Technologies, Carlsbad, CA). The co-immunoprecipitated proteins were analyzed by Western blotting with anti-HA antibody (Sigma-Aldrich). Protein detection was performed on an Odyssey system (Li-COR, Lincoln, NE).

\section{RESULTS}

\section{Cloning and analysis of bovine $L h x 8$ and $L h x 8-v 1$ cDNA sequences}

The open reading frame (ORF) of bovine $L h x 8$ gene was amplified from cDNA of a bovine fetal ovary using primers designed based on a predicted bovine Lhx 8 cDNA sequence (XM_010803408.1 X1) and a partial transcript obtained from bovine oocyte transcriptome sequencing. Additional 5'untranslated region (5'UTR) and 3'UTR sequences overlapping the ORF were also PCR amplified. The ORF of bovine Lhx8 cDNA is 1,134 bp in length encoding a protein of 377 amino acids. The predicted bovine Lhx8 protein contains two LIM domains and one homeobox domain (Fig. 1), and share over 96\% amino acid sequence identity with its human and mouse counterparts. A BLAST search of the bovine reference 
genome sequence in the NCBI database using the bovine Lhx8 cDNA identified the corresponding gene sequence, which is located on bovine chromosome 3. The bovine Lhx8 gene contains 9 exons separated by 8 introns and spans about $28 \mathrm{~kb}$ (Fig. 2). When analyzing the sequences of cloned ORF DNA fragments, a splice variant of Lhx8 (Lhx8_v1) was identified, which results from alternative splicing of exon 2 and 3. Lhx 8 -v1 encodes a protein of 293 amino acids, and one of the LIM domains in the splice variant is incomplete due to deletion of 83 amino acids near the $\mathrm{N}$ terminus. (Fig. 2).

\section{Expression of bovine $L h x 8$ and $L h x 8-v 1$ mRNA in tissues and fetal ovaries}

Primers designed to specifically amplify either the $L h x 8$ or the $L h x 8-v 1$ transcript were used in RT-PCR analysis of tissue distribution of $L h x 8$ and $L h x 8-v 1$ transcripts. As shown in Fig. 3, both transcripts are predominantly expressed in fetal ovary and adult testis, but barely detectable or undetectable in other tissues. Further RT-PCR analysis showed that $L h x 8$ is not expressed in granulosa and theca cells (Fig. 5), suggesting that Lhx8 expression in the fetal ovary is oocyte-specific. Analysis of expression of both transcripts in fetal ovaries of different developmental stages during gestation revealed that both transcripts can be detected in fetal ovaries as early as day 90 of gestation (Fig. 4), a period when primordial follicles are emerging in cattle. The expression of both transcripts increases steadily in fetal ovaries (starting from day 105) during development, suggesting a role of this gene in supporting development of primary and secondary follicles which are formed around day 140 and 210 of gestation, respectively.

\section{Expression of bovine $L h x 8$ and $L h x 8-v 1$ mRNA during oocyte maturation and early embryonic development}

Temporal expression of bovine $L h x 8$ and $L h x 8-v 1$ mRNA during oocyte maturation (GVand MII-stage) and early embryonic development (2-cell, 4-cell, 8-cell, 16-cell, morula, and blastocyst stage) was examined by RT-PCR. Lhx 8 mRNA is highly abundant in GV and MII stage oocytes as well as in early stage embryos but not detectable in morula and blastocyst stage embryos. Lhx8_vl mRNA expression is detectable in oocytes and early embryo but not 
in morula and blastocyst stage embryos. The expression profiles of these two transcripts are different. Expression of Lhx8_vl appears to be lower, however, a relatively higher expression of Lhx8_vl was observed in 2-cell stage embryos (Fig. 5). These results suggest that bovine Lhx8 is a maternal transcript abundantly present in oocytes and early embryos prior to embryonic genome activation.

\section{Subcellular localization of bovine Lhx8 protein}

Lhx8 is predicted to possess two nuclear localization signals (NLS) indicating that it is a nuclear factor. One of the predicted NLSs is monopartite (position 235-246) and the other one is a bipartite NLS (position 279-295). To determine if bovine Lhx8 is mainly functional in the nucleus and which predicted NLS signal is required for its nuclear localization, we performed a GFP reporter assay. HEK293 cells were transfected with expression constructs expressing either an EGFP-tagged wild-type Lhx8 protein or mutant Lhx8 proteins lacking either the monopartite NLS or the bipartite NLS. Fig. 6 shows that the wild-type Lhx 8 is exclusively localized to the nucleus of the transfected cells, while the mutant Lhx8 lacking the monopartite NLS is enriched in the cytoplasm of the cells. The mutant Lhx8 lacking the bipartite NLS still shows a nuclear localization. Results suggest that Lhx8 is a nuclear protein and the predicted monopartite NLS is required for its nuclear localization.

\section{Evaluation of interactions of Lhx8 with Figla and Sohlh1}

Both Figla and Sohlh1 are germ cell-specific transcription factors essential for early oogenesis. Both proteins contain well conserved bHLH domains, which are likely to interact with LIM domain containing proteins. To determine if Lhx8 protein can interact with these two important nuclear proteins, we performed a direct yeast two-hybrid analysis. Yeast cells expressing GAL4-BD fused Lhx8 (bait) were mated with cells expressing GAL-AD tagged Figla or Sohlh1 (preys). Growth of yeast cells co-expressing GAL4 BD-Lhx8 and GAL4 AD-Figla fusion proteins was observed on selective QDO/X/A plate (Fig. 7). However, no cell growth was observed on selective plate when yeast cells transformed with GAL4-BD-Lhx8 
plasmid were mated with cells expressing GAL-AD-Figla fusion protein. Results indicate that Figla is an interacting partner of Lhx 8 protein.

We further performed Co-IP experiments to confirm the interaction between Lhx 8 and Figla. HEK293 cells, which do not express Lhx8 or Figla, were co-transfected with a construct expressing FLAG tagged Lhx8 and a construct expressing HA tagged Figla. Two days after transfection, the cells were lysed under mild condition and immunoprecipitated with anti-FLAG antibody. The co-immunoprecipitated proteins were analyzed by Western blotting with anti-HA antibody. As shown in Fig. 8, Figla-HA was detected in cells co-expressing both tagged proteins after Co-IP. This result confirms the formation of protein complexes between Lhx8 and Figla in vivo.

\section{Lhx8: Figla interaction is dependent on the LIM domains of Lhx8}

Previous studies have shown that most LIM domains are responsible for protein-protein interactions, and only a small fraction of homeobox domains interact with proteins. To determine which functional domain of Lhx8 is responsible for the Lhx8: Figla interaction, we performed a direct yeast two-hybrid analysis using constructs expressing GAL4 BD-Lhx8 fusion proteins with either the LIM domains or the homeobox domain deleted. The mutant GAL4 BD-Lhx8 fusion proteins (GAL4 BD- $\Delta$ LIM and GAL4 BD- $\Delta$ HB) were evaluated for their ability to interact in vivo with the GAL4 AD-Figla fusion protein. Growth of yeast cells expressing GAL4 BD- $\triangle \mathrm{HB}$ and GAL4 AD-Figla fusion proteins was observed on selective QDO/X/A plate indicating that the LIM domains are required for Lhx 8: Figla interaction (Fig. 9).

\section{DISCUSSION}

Oogenesis is a process that involves appropriate spatial and temporal regulation of genes involved in several regulatory pathways. Transcription factors that contain LIM domains and bHLH domains play critical roles during this process. Transcription factors selectively regulate target genes by context-dependent protein interactions (Mann and Affolter 1998). In this study, we used a bovine oocyte development model to discover proteins interacting with 
Lhx 8. We show that Lhx8 and Figla interact directly. Both Lhx 8 and Figla are crucial for oogenesis, thus, this study reveals for the first time, the existence of a protein-protein interaction between two germ cell-specific transcription factors. It seems reasonable to suggest that these proteins may function in a cooperative fashion during early oocyte development.

Presumably the LIM domains of Lhx proteins function in protein-protein interaction and direct LIM homeodomain binding to DNA, thus regulating transcriptional activity (Arber and Caroni 1996; Bach et al. 1997; Breen et al. 1998a; Dawid et al. 1998). Lhx proteins mostly function as negative regulators. In this report, we have shown that Lhx8 interacts with Figla at the molecular level. This interaction may result in repression of gene expression downstream of Figla. The specificity of the interaction implies a functional relationship between the LIM and bHLH proteins during development. The Lhx8-Figla association described here represents an example of a protein-protein interaction mediated by the LIM and bHLH motifs. The function of the Lhx8-Figla complex may include prevention of Lhx8 and Figla binding to the promoter. These two proteins binding may function to buffer the transcriptional activity, recruitment of transcriptional coactivators or corepressors leading to transcriptional activation or repression. For example, LIM protein interacting with the zinc finger protein Rlim recruits the Sin3A/histone deacetylase corepressor complex (Bach et al. 1997). Combinatorial interactions between Lhx8 and Figla may maintain a stringent control over cell proliferation and differentiation during early development. The regulatory functions of Lhx8 and Figla during early oogenesis may be mediated, at least in part, by interaction between their respective LIM and bHLH domains.

In light of our results, the monopartitie NLS directs nuclear translocation of bovine Lhx 8 protein. However, without the monopartite NLS, some Lhx8 protein still can translocate into the nucleus, which suggests that the monopartite NLS is required but not necessary. Thus, other than the well characterized classical nuclear translocation mechanism, there may be other pathways that facilitate translocation of this important germ cell specific transcription factor. Further studies of the mechanisms governing its nuclear translocation are needed.

In summary, we have characterized the bovine $L h x 8$ gene and analyzed its expression 
during oocyte development and early embryogenesis. In light of its expression profile, we believe that bovine Lhx8 is not only essential for oocyte/follicular development, but also important for development of early embryos. We have also demonstrated that Lhx 8 interacts with Figla, indicating that these two germ cell-specific transcription factors may function in a cooperative fashion during early oocyte development.

\section{ACKNOWLEDGEMENTS}

This work was supported by Agriculture and Food Research Initiative Competitive Grant no. 2009-65203-05706 and 2016-67015-24919 from the US Department of Agriculture National Institute of Food and Agriculture and funds from the West Virginia Agricultural and Forestry Experiment Station (Hatch project no. 427). The study is published with the approval of the station director as scientific paper No. xxxx.

\section{REFERENCES}

Arber S, Caroni P. 1996. Specificity of single LIM motifs in targeting and LIM/LIM interactions in situ. Genes Dev 10(3):289-300.

Bach I, Carriere C, Ostendorff HP, Andersen B, Rosenfeld MG. 1997. A family of LIM domain-associated cofactors confer transcriptional synergism between LIM and Otx homeodomain proteins. Genes Dev 11(11):1370-1380.

Bach I, Rodriguez-Esteban C, Carriere C, Bhushan A, Krones A, Rose DW, Glass CK, Andersen B, Izpisua Belmonte JC, Rosenfeld MG. 1999. RLIM inhibits functional activity of LIM homeodomain transcription factors via recruitment of the histone deacetylase complex. Nat Genet 22(4):394-399.

Breen JJ, Agulnick AD, Westphal H, Dawid IB. 1998. Interactions between LIM domains and the LIM domain-binding protein Ldb1. J Biol Chem 273(8):4712-4717.

Choi Y, Ballow DJ, Xin Y, Rajkovic A. 2008. Lim homeobox gene, lhx8, is essential for mouse oocyte differentiation and survival. Biol Reprod 79(3):442-449.

Dawid IB, Breen JJ, Toyama R. 1998. LIM domains: multiple roles as adapters and functional modifiers in protein interactions. Trends Genet 14(4):156-162. 
German MS, Wang J, Chadwick RB, Rutter WJ. 1992. Synergistic activation of the insulin gene by a LIM-homeo domain protein and a basic helix-loop-helix protein: building a functional insulin minienhancer complex. Genes Dev 6(11):2165-2176.

Jurata LW, Pfaff SL, Gill GN. 1998. The nuclear LIM domain interactor NLI mediates homoand heterodimerization of LIM domain transcription factors. J Biol Chem 273(6):3152-3157.

Kikuchi Y, Segawa H, Tokumoto M, Tsubokawa T, Hotta Y, Uyemura K, Okamoto H. 1997. Ocular and cerebellar defects in zebrafish induced by overexpression of the LIM domains of the islet-3 LIM/homeodomain protein. Neuron 18(3):369-382.

Larson RC, Lavenir I, Larson TA, Baer R, Warren AJ, Wadman I, Nottage K, Rabbitts TH. 1996. Protein dimerization between Lmo2 (Rbtn2) and Tal1 alters thymocyte development and potentiates $\mathrm{T}$ cell tumorigenesis in transgenic mice. Embo Journal 15(5):1021-1027.

Leonard J, Serup P, Gonzalez G, Edlund T, Montminy M. 1992. The LIM family transcription factor Isl-1 requires cAMP response element binding protein to promote somatostatin expression in pancreatic islet cells. Proc Natl Acad Sci U S A 89(14):6247-6251.

Mann RS, Affolter M. 1998. Hox proteins meet more partners. Curr Opin Genet Dev $8(4): 423-429$.

Mizuno K, Higuchi O. 1997. [LIM domains: double zinc finger motifs involved in protein-protein interactions]. Tanpakushitsu Kakusan Koso 42(13):2061-2071.

Moriguchi H, Zhang Y, Mihara M, Sato C. 2012. Successful cryopreservation of human ovarian cortex tissues using supercooling. Sci Rep 2:537.

Murdoch WJ, Dailey RA, Inskeep EK. 1981. Preovulatory changes prostaglandins E2 and F2 alpha in ovine follicles. J Anim Sci 53(1):192-205.

Pangas SA, Choi Y, Ballow DJ, Zhao Y, Westphal H, Matzuk MM, Rajkovic A. 2006. Oogenesis requires germ cell-specific transcriptional regulators Sohlh1 and Lhx8. Proc Natl Acad Sci U S A 103(21):8090-8095.

Rajkovic A. 2004. NOBOX Deficiency Disrupts Early Folliculogenesis and Oocyte-Specific Gene Expression. Science 305(5687):1157-1159. 
Richardson C, Jones PC, Barnard V, Hebert CN, Terlecki S, Wijeratne WV. 1990. Estimation of the developmental age of the bovine fetus and newborn calf. Vet Rec 126(12):279-284.

Schmeichel KL, Beckerle MC. 1994. The Lim Domain Is a Modular Protein-Binding Interface. Cell 79(2):211-219.

Soyal SM, Amleh A, Dean J. 2000. FIGalpha, a germ cell-specific transcription factor required for ovarian follicle formation. Development 127(21):4645-4654.

Taira M, Otani H, Saint-Jeannet JP, Dawid IB. 1994. Role of the LIM class homeodomain protein Xlim-1 in neural and muscle induction by the Spemann organizer in Xenopus. Nature 372(6507):677-679.

Thesleff I, Vaahtokari A, Partanen AM. 1995. Regulation of organogenesis. Common molecular mechanisms regulating the development of teeth and other organs. Int J Dev Biol 39(1):35-50.

Tzchori I, Day TF, Carolan PJ, Zhao Y, Wassif CA, Li L, Lewandoski M, Gorivodsky M, Love PE, Porter FD, Westphal H, Yang Y. 2009. LIM homeobox transcription factors integrate signaling events that control three-dimensional limb patterning and growth. Development 136(8):1375-1385.

White YA, Woods DC, Takai Y, Ishihara O, Seki H, Tilly JL. 2012. Oocyte formation by mitotically active germ cells purified from ovaries of reproductive-age women. Nat Med 18(3):413-421.

Xue D, Tu Y, Chalfie M. 1993. Cooperative interactions between the Caenorhabditis elegans homeoproteins UNC-86 and MEC-3. Science 261(5126):1324-1328.

Zheng P, Dean J. 2007. Oocyte-specific genes affect folliculogenesis, fertilization, and early development. Semin Reprod Med 25(4):243-251. 


\section{Figure 1.}
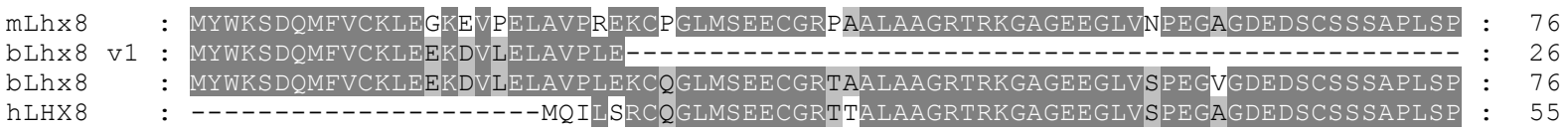

LIM domain

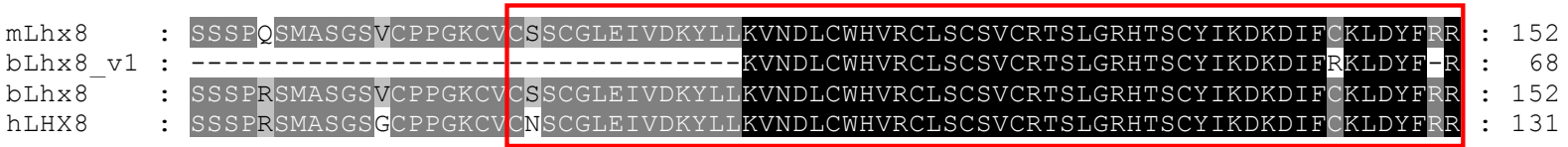

LIM domain

$\operatorname{mLh} \times 8$

bLhx 8 v1

$\mathrm{b} \operatorname{Lh} \times 8$

LIM domain

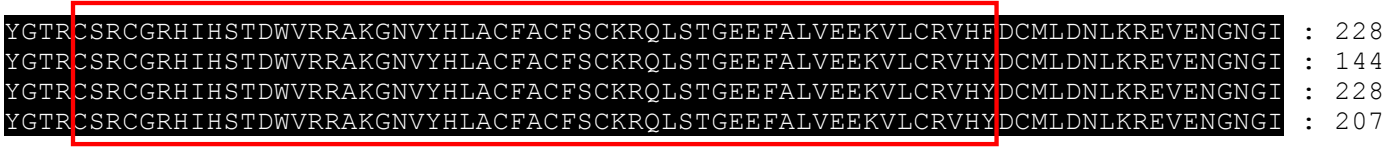

Homeobox domain

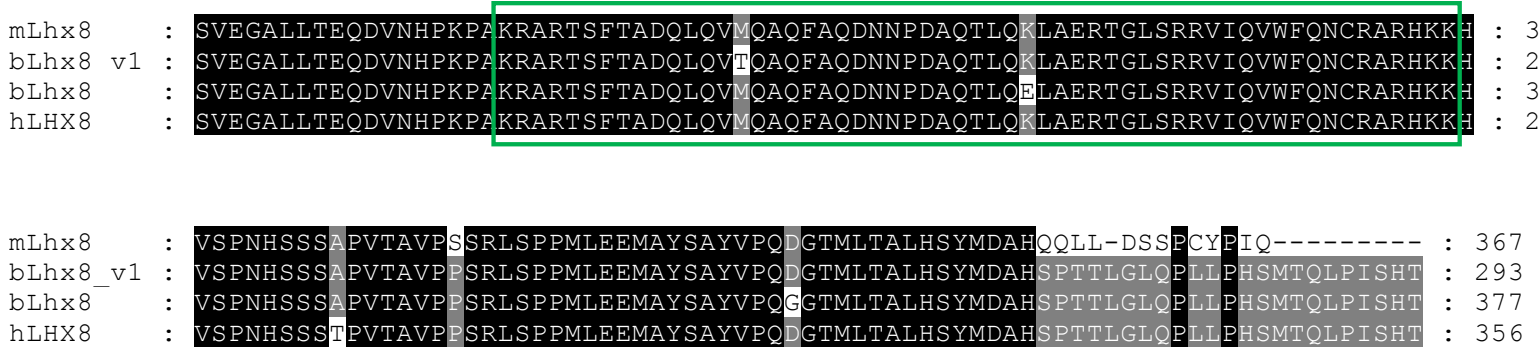

Figure 1. Multiple sequence alignment of Lhx8 proteins. Sequence alignment was performed using Clustal Omega (http://www.ebi.ac.uk/Tools/msa/clustalo/). The functional domains were determined by searching the Pfam database (http://pfam.xfam.org/search). The LIM and Homeobox domains are indicated by red and green boxes, respectively. mLhx8: mouse Lhx8 (NP_034843.2), hLhx8: human Lhx8 (NP_001001933.1), bLhx8: bovine Lhx8. 
Figure 2.
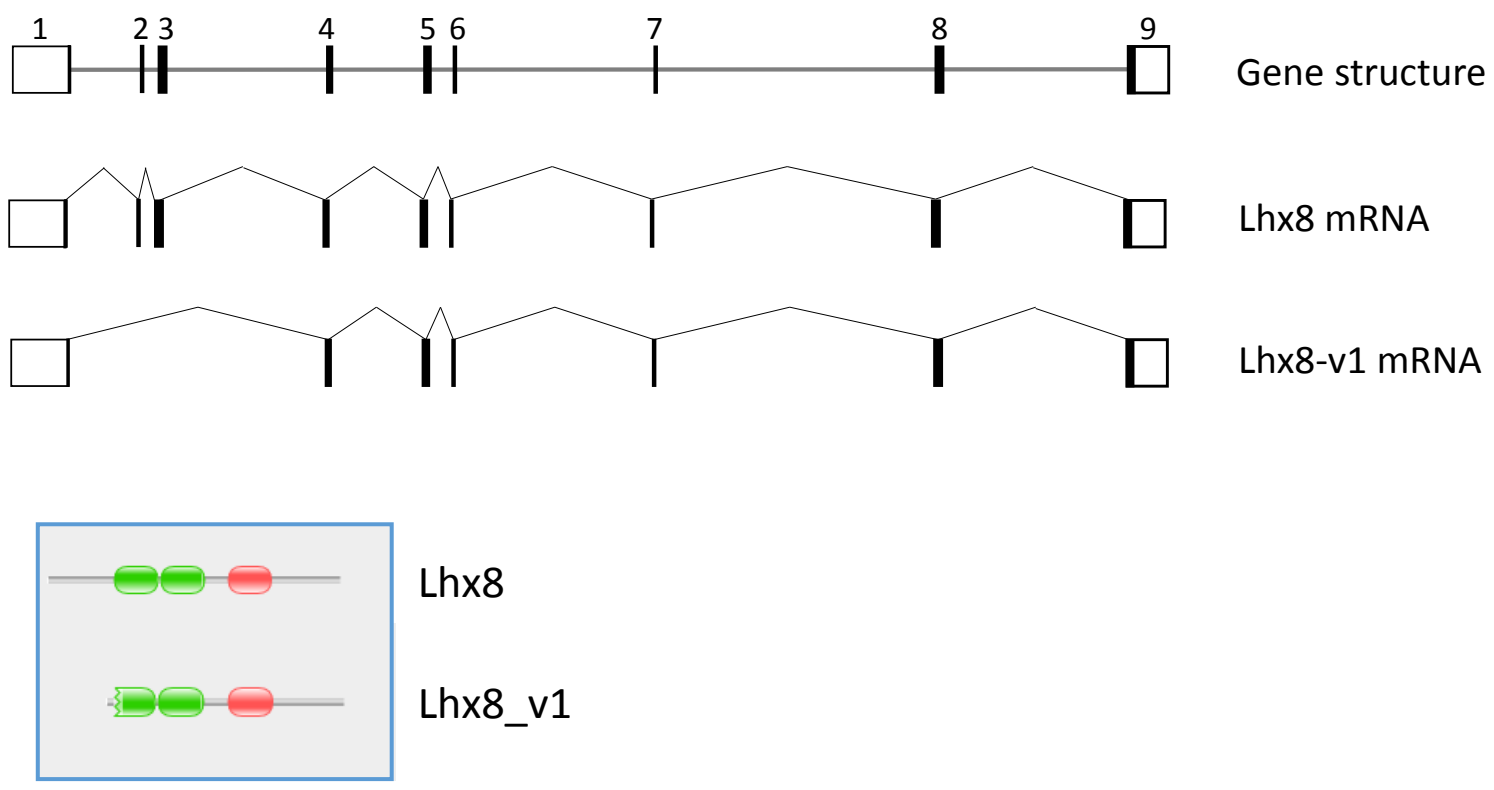

Figure 2. Structure of bovine $\operatorname{Lh} x 8$ gene and its transcripts, $L h x 8$ and $L h x 8 \_v 1$. The bovine Lhx 8 gene contains 9 exons and spans about $28 \mathrm{~kb}$. Lhx 8 encodes a protein of 377 amino acids. The splice variant, $L h x 8 \_v l$ which results from alternative splicing of exon 2 and 3, codes for a protein of 293 amino acids. One of the LIM domains in the splice variant is incomplete due to deletion of 83 amino acids near the $\mathrm{N}$ terminus. 
Figure 3.

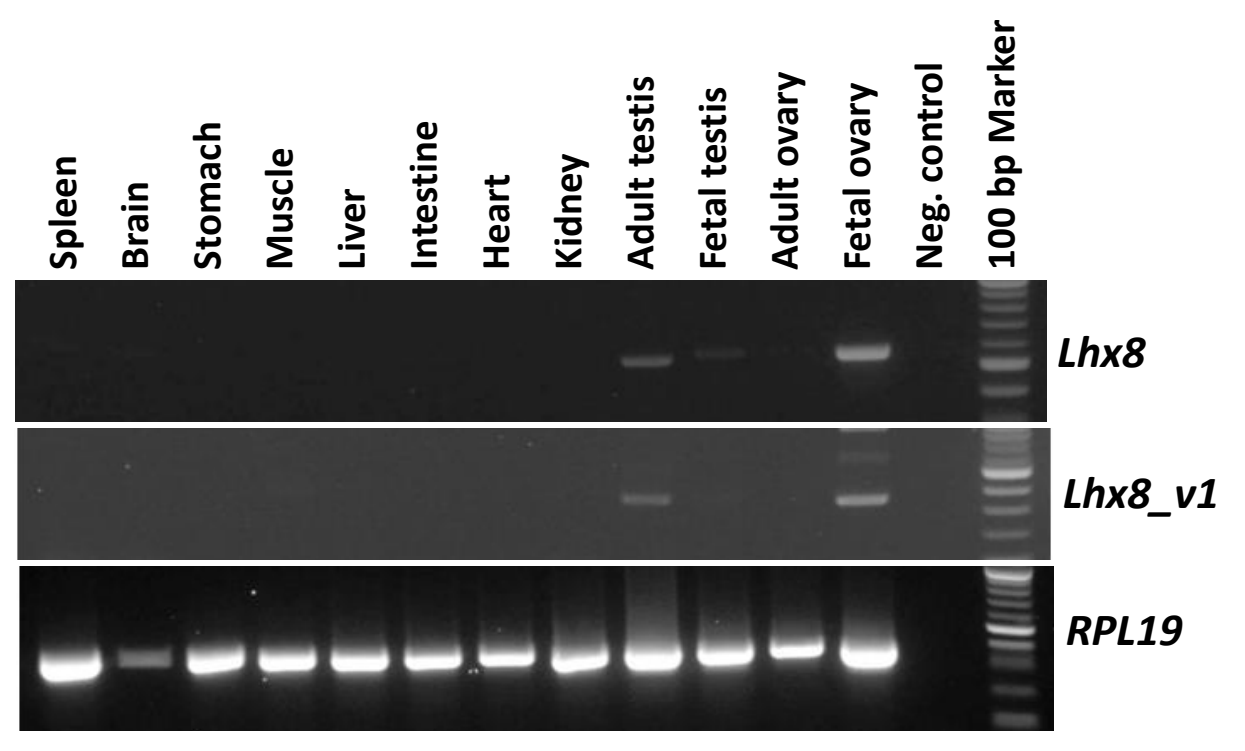

Figure 3. RT-PCR analysis of bovine $L h x 8$ and $L h x 8-v 1$ mRNA expression in bovine tissues. Tissues tested include spleen, stomach, brain, muscle, kidney, liver, heart, intestine, adult ovary, adult testis, fetal testis and fetal ovary. Bovine RPL19 gene was used as a control for RNA quantity. 
Figure 4.

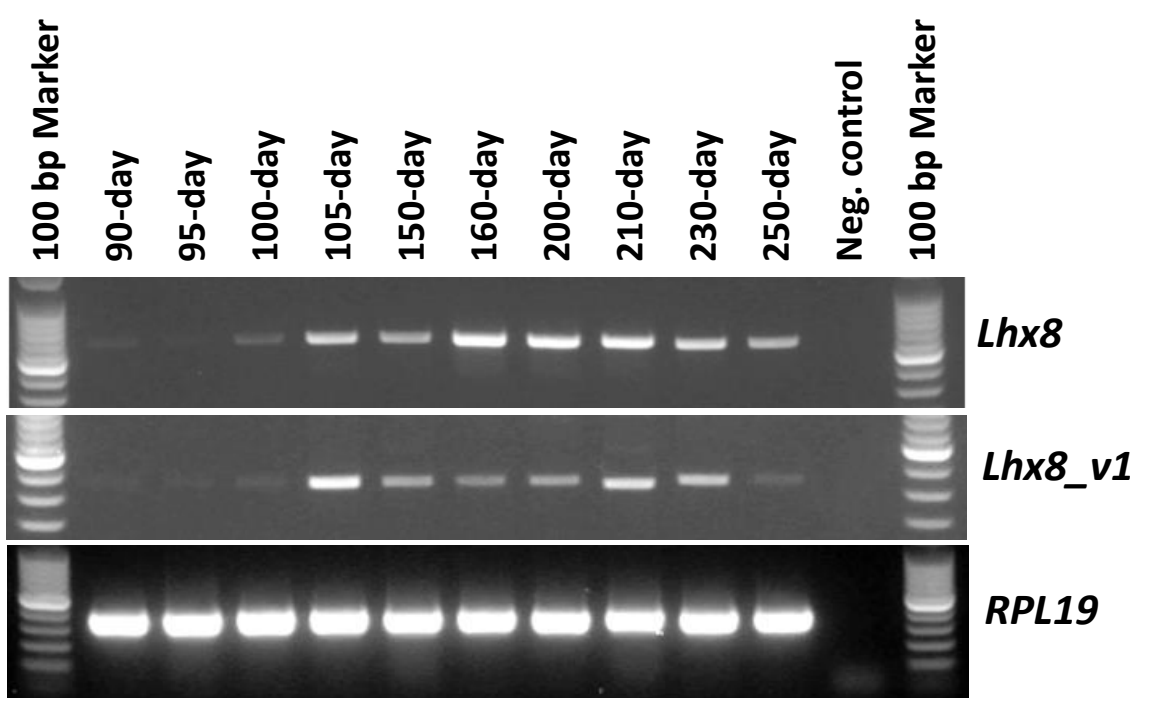

Figure 4. RT-PCR analysis of bovine $\operatorname{Lh} x 8$ and $\operatorname{Lh} x 8-v 1$ mRNA expression in bovine fetal ovaries from different gestation stages. Fetal ovaries from 90, 95, 100, 150, 160, 200, 210, 230 and 250 day fetuses were analyzed. The ages of fetuses were estimated based on crown-rump length. Bovine RPL19 gene was used as a control for RNA quantity. 


\section{Figure 5.}

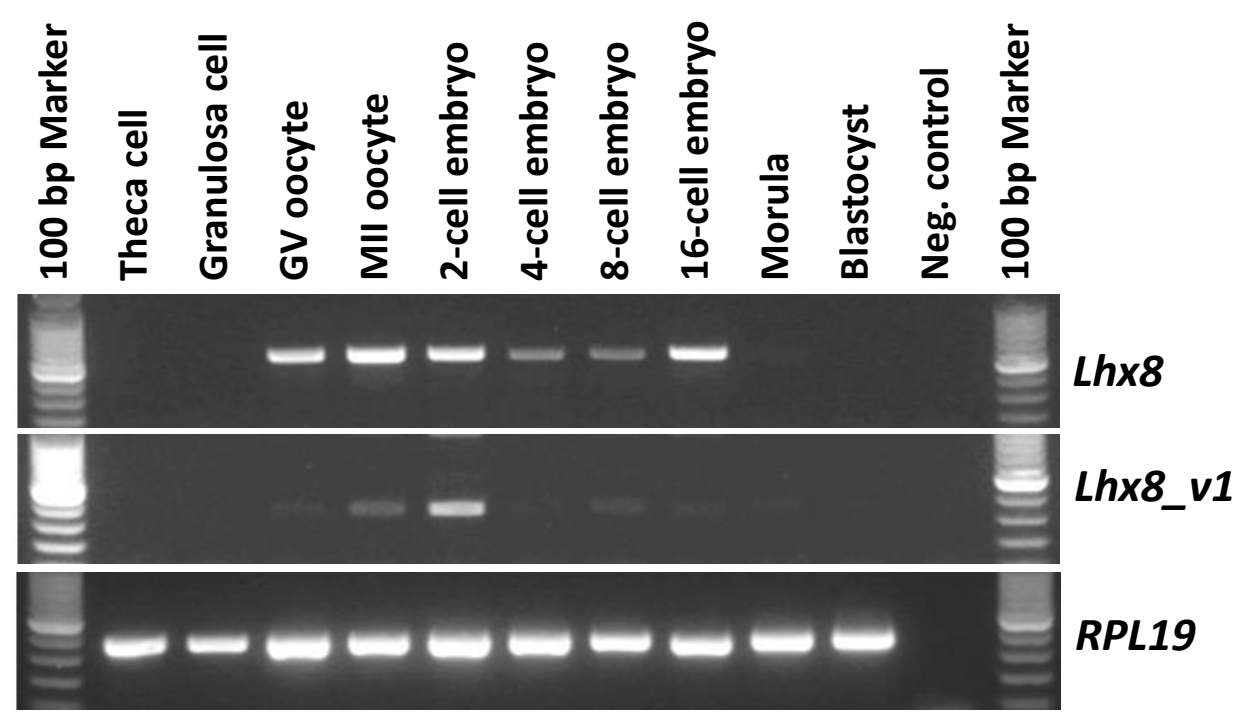

Figure 5. RT-PCR analysis of bovine $L h x 8$ and $L h x 8-v 1$ mRNA expression in oocytes and early embryos. Oocytes and embryos samples used in the analysis include GV-and MII-stage oocytes and 2-cell, 4-cell, 8-cell, 16-cell, and morula- and blastocyst-stage embryos. Bovine RPL19 gene was used as a control for RNA quantity. 
Figure 6.

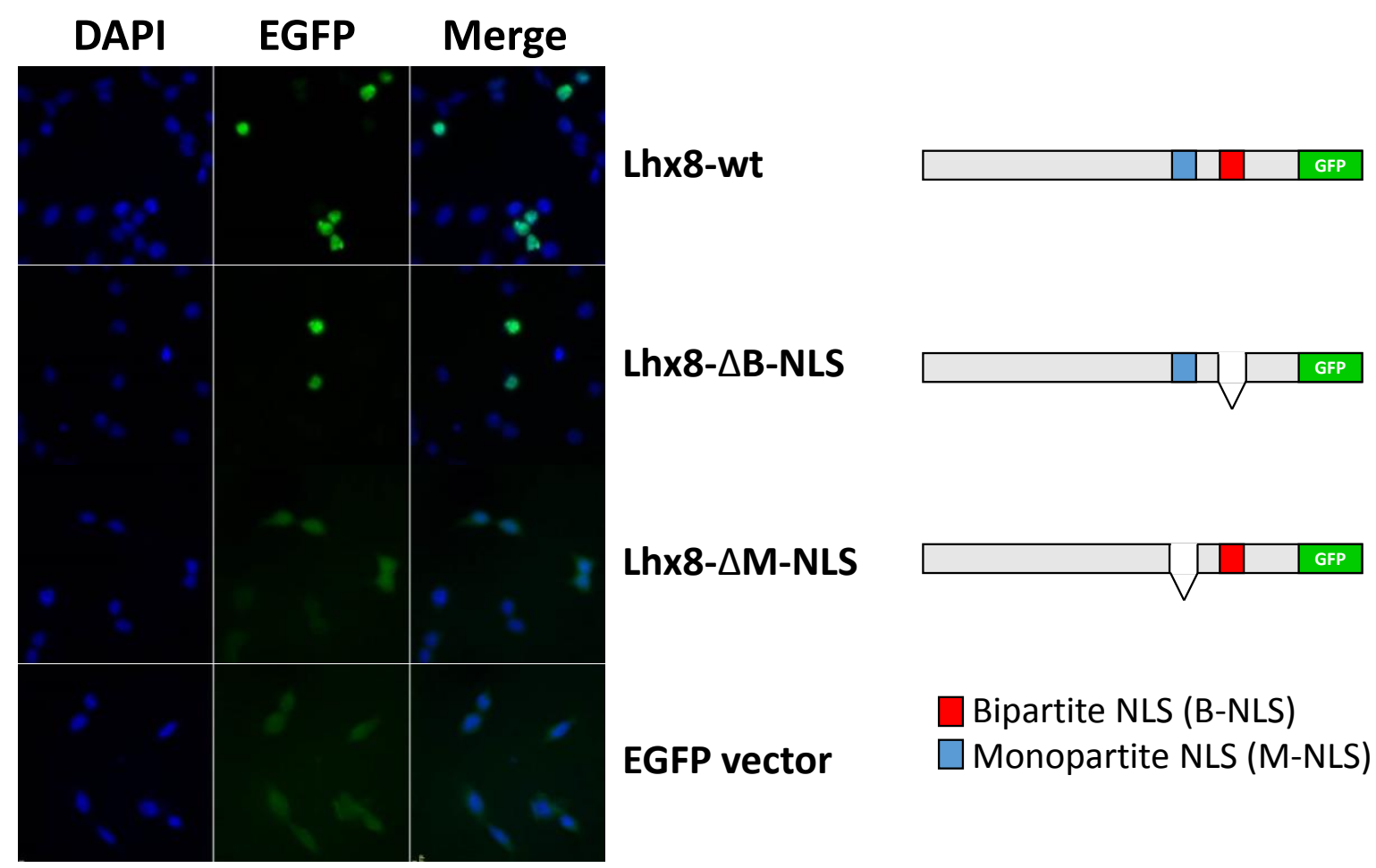

Figure 6. Cellular localization of bovine Lhx8 protein analyzed by a GFP reporter assay. HEK293 cells were transfected with GFP reporter constructs expressing either an EGFP-tagged wild type Lhx8 (Lhx8-wt) or Lhx8 mutants with either the monopartite NLS (Lhx8-AM-NLS) or the bipartite NLS deleted (Lhx8-AB-NLS). Empty pcDNA3-EGFP vector was used as a control. Nuclear DNA was stained with DAPI and cells were analyzed with a fluorescence microscope. 


\section{Figure 7.}

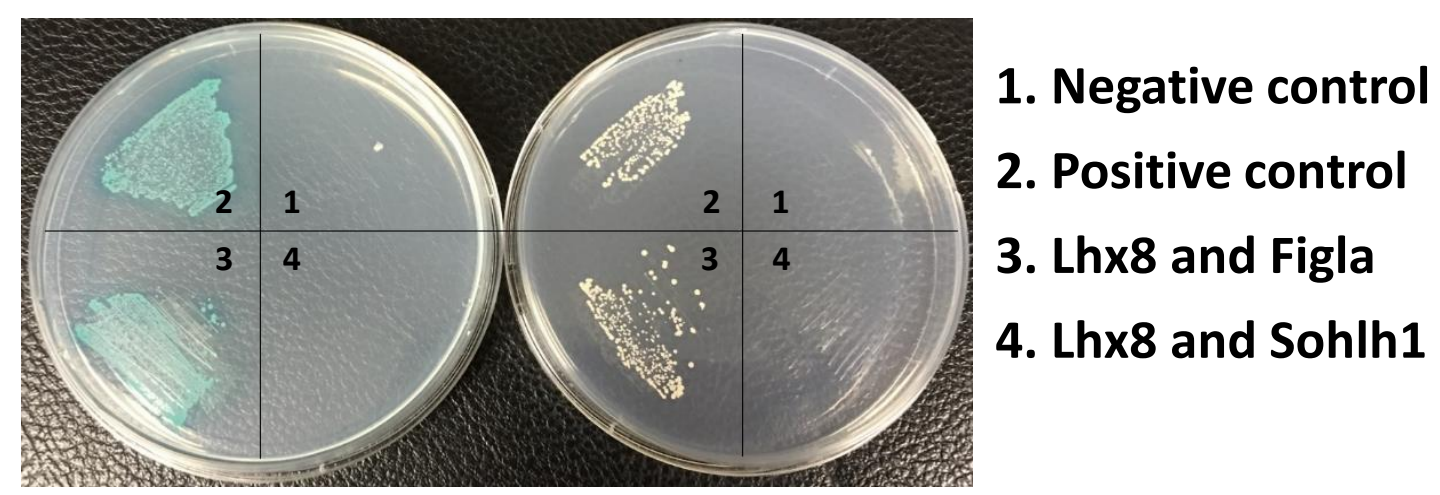

Figure 7. Yeast two-hybrid analysis of protein interactions between Lhx8 and Figla or Sohlh1.

1. Negative control, 2. Positive control, 3. Figla and Lhx8, 4. Sohlh1 and Lhx8. Right plate: Growth of yeast cells on DDO plate (medium lacking Leucine and tryptophan) showing successful co-transformations. Left plate: growth of yeast cells on selective QDO/X/A plate (Quadruple drop-out medium lacking leucine, tryptophan, adenine and histidine and containing $\mathrm{X}$-gal) indicating protein-protein interactions. 
Figure 8.

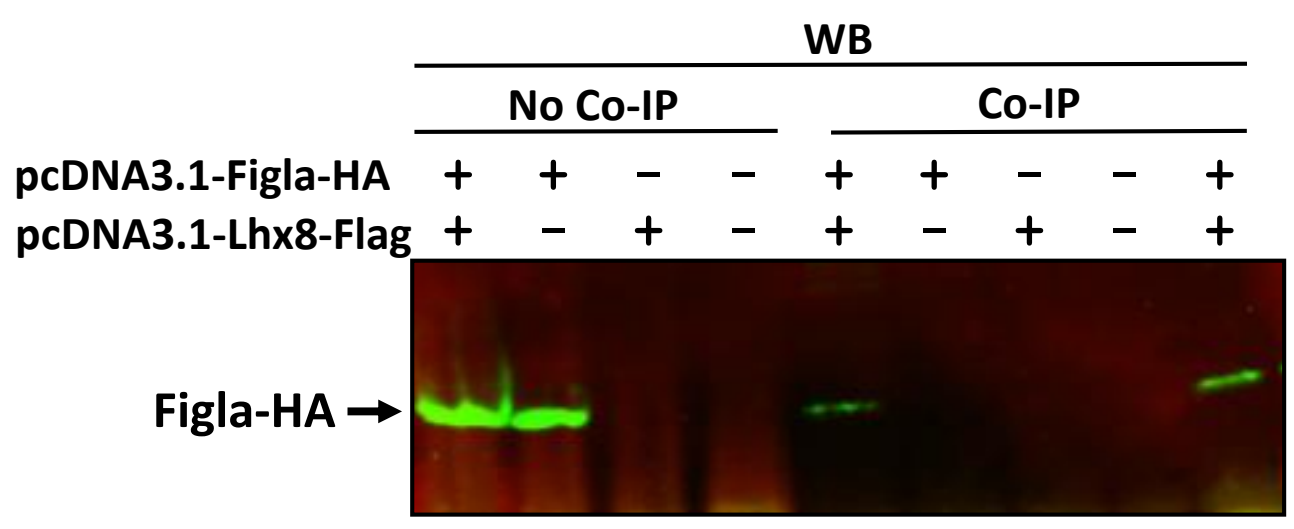

\section{Co-IP with Flag antibody, WB with HA antibody}

Figure 8. Co-IP analysis of interaction between Lhx8 and Figla. HEK293 cells were co-transfected with the expression constructs, pcDNA3.1-Lhx8-FLAG and pcDNA3.1-Figla-HA. Cell lysates were immunoprecipitated with anti-Flag antibody followed by Western blot analysis with anti-HA antibody. 


\section{Figure 9.}

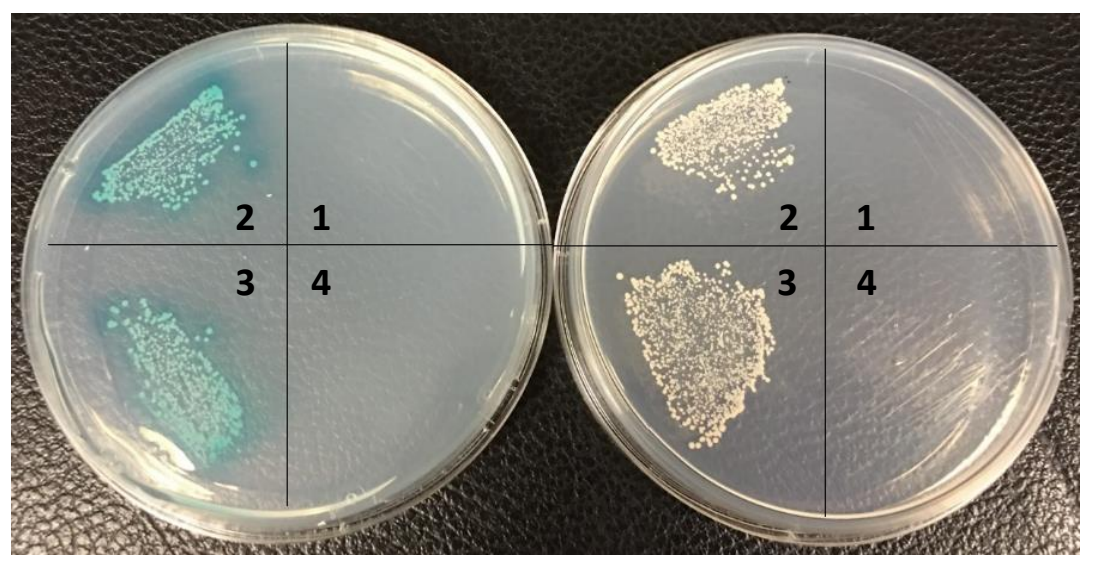

\section{Negative control \\ 2. Positive control \\ 3. LIM domains and Filga \\ 4. Homeobox domain and Figla}

Figure 9. Direct yeast two-hybrid analysis showing LIM domains of Lhx8 are required for interaction with Figla. 1. Negative control, 2. Positive control, 3. LIM domain and Figla, 4. Homeobox domain and Figla. Right plate: Growth of yeast cells on DDO plate (medium lacking Leucine and tryptophan) showing successful co-transformations. Left plate: growth of yeast cells on selective QDO/X/A plate (Quadruple drop-out medium lacking leucine, tryptophan, adenine and histidine and containing X-gal) indicating protein-protein interactions. 
Table 1. Primers used in this study

Cloning of bovine Lhx8 ORF into AD and BD vectors (EcoRI \& BamHI)

BovineLhx8inADBDF

BovineLhx8inADBDR

BovineFiglainADF

BovineFiglainADR

BovineSohlh1inADF

BovineSohlh1inADR
GGCC GAATTC ATGTTTGTGTGTAAACTAGAAG

GGCC GGATCC TTAGGTATGACTTATTGGCAG

GGCC CATATG GACGCCGCGCCCGAGCTCC

GGCC GAATTC CTATCCACTGCCACCATCTGGC

GGCC CATATG GCGTCCCGGGCTCCTGAG

GGCC GAATTC TCAGCAGGCGAAGAAGTCGGG

Cloning of Lhx8 ORF into EGFP vector (EcoRI \& XhoI)

bLhx8inEGFPF

GGCCGAATTC ATGTTTGTGTGTAAACTAGAAGA

bLhx8inEGFPR GGCCCTCGAG GGTATGACTTATTGGCAGTTG

Two step PCR for deletion of Monopartite NLS (EcoRI \& XhoI)

MutmonobLhx8F1

GGCCGAATTC ATGTTTGTGTGTAAACTAGAAGA

MutmonobLhx8R1

ATGATTAACATCTTGCTCTGTAAGG

MutmonobLhx8F2

CCTTACAGAGCAAGATGTTAATCAT

ACAGCAGATCAGCTCCAGGTTATGC

MutmonobLhx8R2

GGCCCTCGAG GGTATGACTTATTGGCAGTTG

Two step PCR for deletion of Bipartite NLS (EcoRI \& XhoI)

MutbibLhx8F1

GGCCGAATTC ATGTTTGTGTGTAAACTAGAAGA

MutbibLhx8R1

GCTCAAGCCTGTCCTTTCTGCCAG

MutbibLhx8F2

CTGGCAGAAAGGACAGGCTTGAGC

CATGTCAGTCCTAATCACTCC

MutbibLhx8R2

GGCCCTCGAG GGTATGACTTATTGGCAGTTG

Cloning of LIM domain and homeobox domain of Lhx8

Lhx8LIMF

GGCC GAATTC ATGTTTGTGTGTAAACTAGAAG

Lhx8LIMR

GGCC GGATCC GTAAGGAGGGCGCCTTCAAC

Lhx8HomeoboxF

GGCC GAATTC ATGGGTAATGGAATTAGTGTTGAAGG

Lhx8HomeoboxR

GGCC GGATCC TTAGGTATGACTTATTGGCAG

Cloning of Co-IP constructs (Lhx8 + FLAG, Figla + HA, EcoRI \& BamHI) 
CoIPBovineLhx8F

CoIPBovineFiglaF

CoIPBovineFiglaR
CoIPBovineLhx8R

GGCC GGATCC gecgecacc ATGTTTGTGTGTAAACTAGAAG

GGCC GAATTC TTA CTTGTCATCGTCGTCCTTGTAGTC

GGTATGACTTATTGGCAGTTG

GGCC GGATCC gecgecacc ATGGACGCCGCGCCCGAGCTCC

GGCC GAATTC CTA AGCGTAATCTGGAACATCGTATGGGTA

TCCACTGCCACCATCTGGCCAG

RT-PCR analysis of Lhx8 and Lhx8-v1 mRNA

bLxh8-F-v1

CAGTTCCCCTTGAGAAGGTGA

bLxh8-F

GTCTCATGTCGGAGGAGTGC

bLxh8-R-common CCAGCATGCAGTCATAATGCA 


\section{REFERENCES}

Arber S, Caroni P. 1996. Specificity of single LIM motifs in targeting and LIM/LIM interactions in situ. Genes Dev 10(3):289-300.

Bach I, Carriere C, Ostendorff HP, Andersen B, Rosenfeld MG. 1997. A family of LIM domain-associated cofactors confer transcriptional synergism between LIM and Otx homeodomain proteins. Genes Dev 11(11):1370-1380.

Bach I, Rodriguez-Esteban C, Carriere C, Bhushan A, Krones A, Rose DW, Glass CK, Andersen B, Izpisua Belmonte JC, Rosenfeld MG. 1999. RLIM inhibits functional activity of LIM homeodomain transcription factors via recruitment of the histone deacetylase complex. Nat Genet 22(4):394-399.

Breen JJ, Agulnick AD, Westphal H, Dawid IB. 1998. Interactions between LIM domains and the LIM domain-binding protein Ldb1. J Biol Chem 273(8):4712-4717.

Choi Y, Ballow DJ, Xin Y, Rajkovic A. 2008. Lim homeobox gene, lhx8, is essential for mouse oocyte differentiation and survival. Biol Reprod 79(3):442-449.

Dawid IB, Breen JJ, Toyama R. 1998. LIM domains: multiple roles as adapters and functional modifiers in protein interactions. Trends Genet 14(4):156-162.

Denaxa M, Sharpe PT, Pachnis V. 2009. The LIM homeodomain transcription factors Lhx6 and Lhx7 are key regulators of mammalian dentition. Dev Biol 333(2):324-336.

German MS, Wang J, Chadwick RB, Rutter WJ. 1992. Synergistic activation of the insulin gene by a LIM-homeo domain protein and a basic helix-loop-helix protein: building a functional insulin minienhancer complex. Genes Dev 6(11):2165-2176.

German MS, Wang J, Fernald AA, Espinosa R, 3rd, Le Beau MM, Bell GI. 1994. Localization of the genes encoding two transcription factors, LMX1 and CDX3, regulating insulin gene expression to human chromosomes 1 and 13. Genomics 24(2):403-404.

Grigoriou M, Tucker AS, Sharpe PT, Pachnis V. 1998. Expression and regulation of Lhx6 and Lhx7, a novel subfamily of LIM homeodomain encoding genes, suggests a role in mammalian head development. Development 125(11):2063-2074. 
Hu W, Gauthier L, Baibakov B, Jimenez-Movilla M, Dean J. 2010. FIGLA, a basic helix-loop-helix transcription factor, balances sexually dimorphic gene expression in postnatal oocytes. Mol Cell Biol 30(14):3661-3671.

Jurata LW, Pfaff SL, Gill GN. 1998. The nuclear LIM domain interactor NLI mediates homoand heterodimerization of LIM domain transcription factors. J Biol Chem 273(6):3152-3157.

Kikuchi Y, Segawa H, Tokumoto M, Tsubokawa T, Hotta Y, Uyemura K, Okamoto H. 1997. Ocular and cerebellar defects in zebrafish induced by overexpression of the LIM domains of the islet-3 LIM/homeodomain protein. Neuron 18(3):369-382.

Larson RC, Lavenir I, Larson TA, Baer R, Warren AJ, Wadman I, Nottage K, Rabbitts TH. 1996. Protein dimerization between Lmo2 (Rbtn2) and Tal1 alters thymocyte development and potentiates $\mathrm{T}$ cell tumorigenesis in transgenic mice. Embo Journal 15(5):1021-1027.

Leonard J, Serup P, Gonzalez G, Edlund T, Montminy M. 1992. The LIM family transcription factor Isl-1 requires cAMP response element binding protein to promote somatostatin expression in pancreatic islet cells. Proc Natl Acad Sci U S A 89(14):6247-6251.

Mann RS, Affolter M. 1998. Hox proteins meet more partners. Curr Opin Genet Dev 8(4):423-429.

Mizuno K, Higuchi O. 1997. [LIM domains: double zinc finger motifs involved in protein-protein interactions]. Tanpakushitsu Kakusan Koso 42(13):2061-2071.

Moriguchi H, Zhang Y, Mihara M, Sato C. 2012. Successful cryopreservation of human ovarian cortex tissues using supercooling. Sci Rep 2:537.

Murdoch WJ, Dailey RA, Inskeep EK. 1981. Preovulatory changes prostaglandins E2 and F2 alpha in ovine follicles. J Anim Sci 53(1):192-205.

Ren Y, Suzuki H, Jagarlamudi K, Golnoski K, McGuire M, Lopes R, Pachnis V, Rajkovic A. 2015. Lhx8 regulates primordial follicle activation and postnatal folliculogenesis. BMC Biol 13:39. 
Richardson C, Jones PC, Barnard V, Hebert CN, Terlecki S, Wijeratne WV. 1990. Estimation of the developmental age of the bovine fetus and newborn calf. Vet Rec 126(12):279-284.

Schmeichel KL, Beckerle MC. 1994. The Lim Domain Is a Modular Protein-Binding Interface. Cell 79(2):211-219.

Taira M, Otani H, Saint-Jeannet JP, Dawid IB. 1994. Role of the LIM class homeodomain protein Xlim-1 in neural and muscle induction by the Spemann organizer in Xenopus. Nature 372(6507):677-679.

Thesleff I, Vaahtokari A, Partanen AM. 1995. Regulation of organogenesis. Common molecular mechanisms regulating the development of teeth and other organs. Int J Dev Biol 39(1):35-50.

Tzchori I, Day TF, Carolan PJ, Zhao Y, Wassif CA, Li L, Lewandoski M, Gorivodsky M, Love PE, Porter FD, Westphal H, Yang Y. 2009. LIM homeobox transcription factors integrate signaling events that control three-dimensional limb patterning and growth. Development 136(8):1375-1385.

Wadman I, Li J, Bash RO, Forster A, Osada H, Rabbitts TH, Baer R. 1994. Specific in vivo association between the bHLH and LIM proteins implicated in human T cell leukemia. EMBO J 13(20):4831-4839.

White YA, Woods DC, Takai Y, Ishihara O, Seki H, Tilly JL. 2012. Oocyte formation by mitotically active germ cells purified from ovaries of reproductive-age women. Nat Med 18(3):413-421.

Xue D, Tu Y, Chalfie M. 1993. Cooperative interactions between the Caenorhabditis elegans homeoproteins UNC-86 and MEC-3. Science 261(5126):1324-1328. 


\section{APPENDIX}

\section{Evaluation of interactions between KPNA7 and important oocyte-specific nuclear factors}

Nuclear protein translocation into the nucleus through the nuclear pores is facilitated by KPNA and KPNB, which are the major cargo carriers in the cytoplasm. Proteins larger than $40 \mathrm{kDa}$ need a signal-mediated transport system with KPNA and KPNB involved. Proteins with nuclear localization signals (NLSs) are recognized and bound by KPNA and KPNB heterodimers and then translocated into the nucleus.

In human, there are six KPNA family members, which have been grouped into three subfamilies based on sequence homology. Each of these KPNA is able to import the target proteins. Moreover, different KPNA features distinct properties of NLS recognition and nuclear transport efficiency for specific cargo proteins (Miyamoto, Imamoto et al. 1997; Sekimoto, Imamoto et al. 1997; Nachury, Ryder et al. 1998; Kohler, Speck et al. 1999; Welch, Franke et al. 1999; Jans, Xiao et al. 2000; Franke, Reimann et al. 2001). RNAi knockdown studies revealed individual KPNAs has their own specific cellular pathways. During neural differentiation in mouse embryonic stem cells, nuclear importation of a specific set of transcription factors changed by switching KPNA subtype expression (Yasuhara, Shibazaki et al. 2007).

Throughout the developmental stages of early embryos in cattle, nuclear proteins including transcription factors and chromatin remodeling proteins control gene transcription before embryonic genome activation. Nuclear transport mechanisms for these proteins getting into the nucleus are critical for the whole process. The well characterized classical KPNA/KPNB-mediated import pathway may play a major role. A novel bovine KPNA protein named KPNA7 has been identified which is expressed specifically in ovary and important for early embryogenesis (Tejomurtula, Lee et al. 2009). Also, six bovine KPNA orthologues of all known human KPNAs were identified and grouped together with KPNA7 into three subfamilies. KPNA7 is more closely related to KPNA2, which belongs to the first subfamily. Second subfamily includes KPNA3 and KPNA4. KPNA1, KPNA5, and KPNA6 
are grouped to the third family (Tejomurtula, Lee et al. 2009). Different KPNA subtypes differ in their cell- and tissue-specific expression patterns. Most bovine KPNA family members are expressed ubiquitously except KPNA7, which is specifically expressed in oocytes and early embryos with at least 30 times higher expression in GV oocytes than other bovine KPNA subtypes (Tejomurtula, Lee et al. 2009).

Previous studies demonstrated that KPNA7 interact with a key chromatin remodeling factor in early embryogenesis. Therefore, we suggest that KPNA7 may also interact with other key oocyte-specific nuclear proteins during early development, such as chromatin remodeling and transcription factors. To determine the ability of KPNA7 protein interact with other proteins which transport into the nucleus and are critical for the early embryogenesis, we performed direct yeast two-hybrid assay to asses potential interactions centered by KPNA7. We detected interactions between KPNA7 and bovine LHX8, FIGLA, SOHLH1, NANOG, in which, interaction between KPNA7 and Lhx8 showed more colonies compared with other pairs (Fig. 1). In addition, Lhx8 has both typical monopartite and bipartite NLS signal which may facilitate the binding with KPNA7. To further define whether KPNA7 is more specific for the transportation of Lhx8 compared with other KPNA family members. Direct yeast two-hybrid assay was performed on bovine KPNA1, KPNA2, KPNA3, KPNA4 and KPNA5 with LHX8. We were unable to get the yeast transformant of KPNA6, so interaction of KPNA6 with LHX8 was not tested. Based on the growth of colonies after each mating, we found that only KPNA7 and KPNA2 have strong binding with LHX8. KPNA1 showed minor affinity with LHX8. Few blue colonies on the mating plates of KPNA3, KPNA4 and KPNA5 with LHX8 indicated KPNA3, KPNA4, and KPNA5 have very week binding with LHX8 (Fig. 2). These results are surprisingly consistent with the oocyte RNA Seq data which showed the abundant of KPNA family members (Fig. 3). Also, based on sequence homology, KPNA7 and KPNA2 were grouped together. They may share similar functional domains which are critical for the binding with Lhx8. Further confirmation of these protein-protein interactions needs to be accomplished by performing Co-immunoprecipitation (Co-IP) or GST-pull down in vitro. The functions of these proteins interactions need to be further investigated. 


\section{Figure 1.}

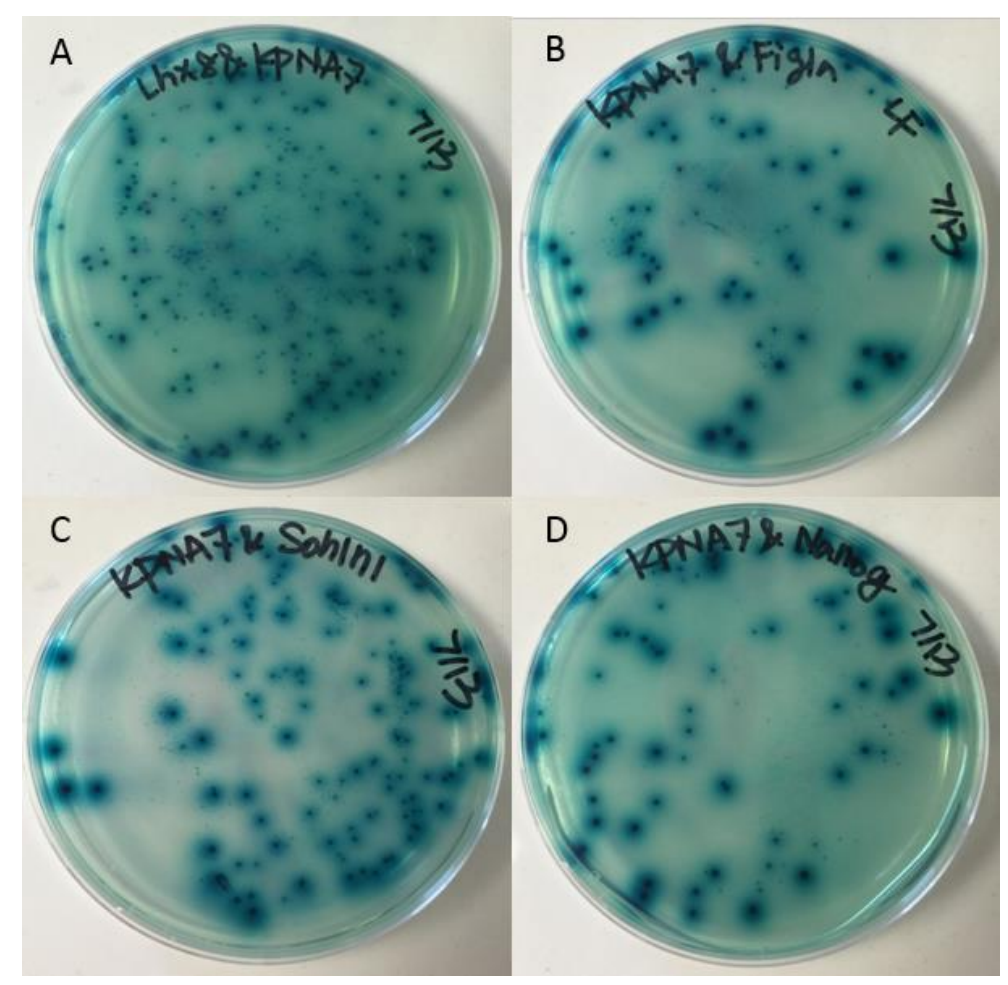

Figure 1. Analysis of interactions between KPNA7 protein and Lhx8 (A), Figla (B), Sohlh1 (C), Nanog (D). Growth of yeast cells (blue colonies) on selective QDO/X/A plate (quadruple drop-out medium lacking leucine, tryptophan, adenine and histidine and containing X-gal and Aureobasidin. Blue colonies indicates protein-protein interactions. 


\section{Figure 2.}

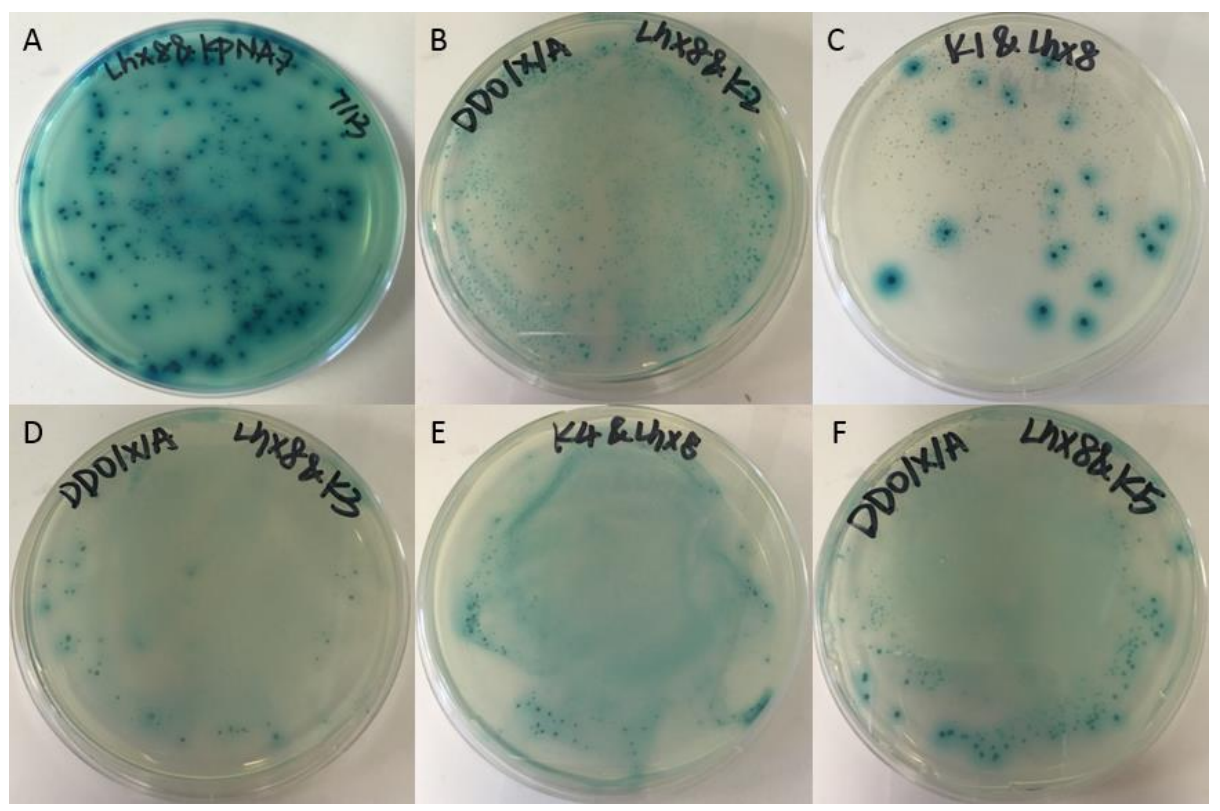

Figure 2. Analysis of interactions between Lhx8 protein and KPNA7, KPNA2, KPNA1, KPNA3, KPNA4, KPNA5. Growth of yeast cells (blue colonies) on selective QDO/X/A plate (quadruple drop-out medium lacking leucine, tryptophan, adenine and histidine and containing X-gal and Aureobasidin) indicates protein-protein interactions. 


\section{Figure 3.}

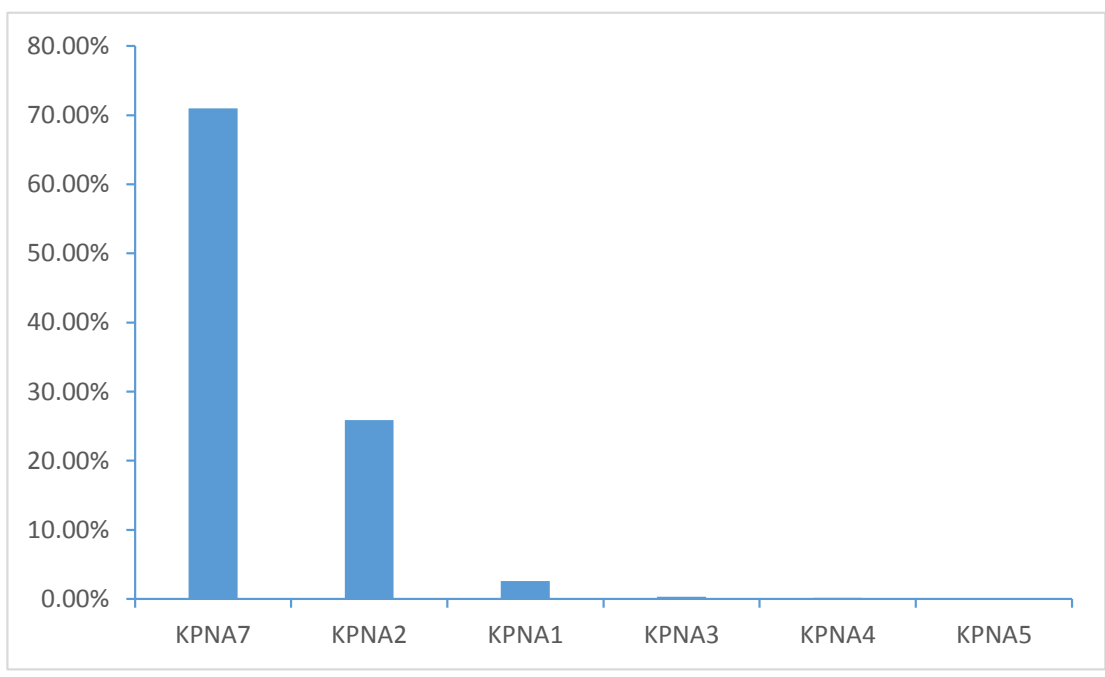

Figure 3. Relative abundance of KPNA7, KPNA2, KPNA1, KPNA3, KPNA4 and KPNA5 mRNA in bovine oocytes revealed by RNA-Seq analysis. 


\section{REFERENCES}

Aakre CD, Herrou J, Phung TN, Perchuk BS, Crosson S, Laub MT. 2015. Evolving New Protein-Protein Interaction Specificity through Promiscuous Intermediates. Cell 163(3):594-606.

Abdel-Rahman B, Fiddler M, Rappolee D, Pergament E. 1995. Expression of transcription regulating genes in human preimplantation embryos. Hum Reprod 10(10):2787-2792.

Allendorf FW, Thorgaard GH. 1984. Evolutionary Genetics of Fishes. in:Tetraploidy and the Evolution of Salmonid Fishes Ch, ed Turner B. J. 55-93 Plenum Press

Aloy P, Russell RB. 2004. Ten thousand interactions for the molecular biologist. Nat Biotechnol 22(10):1317-1321.

Arber S, Caroni P. 1996. Specificity of single LIM motifs in targeting and LIM/LIM interactions in situ. Genes Dev 10(3):289-300.

Bach I, Carriere C, Ostendorff HP, Andersen B, Rosenfeld MG. 1997. A family of LIM domain-associated cofactors confer transcriptional synergism between LIM and Otx homeodomain proteins. Genes Dev 11(11):1370-1380.

Bach I, Rodriguez-Esteban C, Carriere C, Bhushan A, Krones A, Rose DW, Glass CK, Andersen B, Izpisua Belmonte JC, Rosenfeld MG. 1999. RLIM inhibits functional activity of LIM homeodomain transcription factors via recruitment of the histone deacetylase complex. Nat Genet 22(4):394-399.

Barritt J, Willadsen S, Brenner C, Cohen J. 2001. Cytoplasmic transfer in assisted reproduction. Hum Reprod Update 7(4):428-435.

Bohren KM, Bullock B, Wermuth B, Gabbay KH. 1989. The Aldo-Keto Reductase Superfamily - Cdnas and Deduced Amino-Acid Sequences of Human Aldehyde and Aldose Reductases. Journal of Biological Chemistry 264(16):9547-9551.

Bouilly J, Veitia RA, Binart N. 2014. NOBOX is a key FOXL2 partner involved in ovarian folliculogenesis. Journal of Molecular Cell Biology 6(2):175-177.

Breen JJ, Agulnick AD, Westphal H, Dawid IB. 1998a. Interactions between LIM domains and the LIM domain-binding protein Ldb1. J Biol Chem 273(8):4712-4717.

Breen JJ, Agulnick AD, Westphal H, Dawid IB. 1998b. Interactions between LIM domains and the LIM domain-binding protein Ldb1. J Biol Chem 273(8):4712-4717.

Brevini TA, Cillo F, Colleoni S, Lazzari G, Galli C, Gandolfi F. 2004. Expression pattern of the maternal factor zygote arrest 1 (Zar1) in bovine tissues, oocytes, and embryos. Mol Reprod Dev 69(4):375-380.

Bruckner A, Polge C, Lentze N, Auerbach D, Schlattner U. 2009. Yeast two-hybrid, a powerful tool for systems biology. Int J Mol Sci 10(6):2763-2788.

Campana WM, Myers RR, Rearden A. 2003. Identification of PINCH in Schwann cells and DRG neurons: shuttling and signaling after nerve injury. Glia 41(3):213-223.

Choi Y, Ballow DJ, Xin Y, Rajkovic A. 2008. Lim homeobox gene, lhx8, is essential for mouse oocyte differentiation and survival. Biol Reprod 79(3):442-449.

Choi Y, Qin Y, Berger MF, Ballow DJ, Bulyk ML, Rajkovic A. 2007. Microarray analyses of newborn mouse ovaries lacking Nobox. Biol Reprod 77(2):312-319.

Collins MO, Choudhary JS. 2008. Mapping multiprotein complexes by affinity purification 
and mass spectrometry. Curr Opin Biotechnol 19(4):324-330.

Corcoran LM, Karvelas M, Nossal GJV, Ye ZS, Jacks T, Baltimore D. 1993. Oct-2, Although Not Required for Early B-Cell Development, Is Critical for Later B-Cell Maturation and for Postnatal Survival. Genes \& Development 7(4):570-582.

Cyert MS. 2001. Regulation of nuclear localization during signaling. J Biol Chem 276(24):20805-20808.

Dawid IB, Breen JJ, Toyama R. 1998. LIM domains: multiple roles as adapters and functional modifiers in protein interactions. Trends Genet 14(4):156-162.

Dong JW, Albertini DF, Nishimori K, Kumar TR, Lu NF, Matzuk MM. 1996. Growth differentiation factor-9 is required during early ovarian folliculogenesis. Nature 383(6600):531-535.

Donohoe ME, Silva SS, Pinter SF, Xu N, Lee JT. 2009. The pluripotency factor Oct4 interacts with Ctcf and also controls X-chromosome pairing and counting. Nature 460(7251):128-U147.

Ellis JD, Barrios-Rodiles M, Colak R, Irimia M, Kim T, Calarco JA, Wang XC, Pan Q, O'Hanlon D, Kim PM, Wrana JL, Blencowe BJ. 2012. Tissue-Specific Alternative Splicing Remodels Protein-Protein Interaction Networks. Molecular Cell 46(6):884-892.

Elnitski L, Jin VX, Farnham PJ, Jones SJ. 2006. Locating mammalian transcription factor binding sites: a survey of computational and experimental techniques. Genome Res 16(12):1455-1464.

Finney M, Ruvkun G. 1990. The unc-86 gene product couples cell lineage and cell identity in C. elegans. Cell 63(5):895-905.

Ge H, Walhout AJM, Vidal M. 2003. Integrating 'omic' information: a bridge between genomics and systems biology. Trends in Genetics 19(10):551-560.

German MS, Wang J, Chadwick RB, Rutter WJ. 1992. Synergistic activation of the insulin gene by a LIM-homeo domain protein and a basic helix-loop-helix protein: building a functional insulin minienhancer complex. Genes Dev 6(11):2165-2176.

Han JD, Bertin N, Hao T, Goldberg DS, Berriz GF, Zhang LV, Dupuy D, Walhout AJ, Cusick ME, Roth FP, Vidal M. 2004. Evidence for dynamically organized modularity in the yeast protein-protein interaction network. Nature 430(6995):88-93.

Herr W, Cleary MA. 1995. The POU domain: versatility in transcriptional regulation by a flexible two-in-one DNA-binding domain. Genes Dev 9(14):1679-1693.

Hobert O, Westphal H. 2000. Functions of LIM-homeobox genes. Trends Genet 16(2):75-83.

Hua XX, Liu XD, Ansari DO, Lodish HF. 1998. Synergistic cooperation of TFE3 and Smad proteins in TGF-beta-induced transcription of the plasminogen activator inhibitor-1 gene. Genes \& Development 12(19):3084-3095.

Inoue M, Kawakami M, Tatsumi K, Manabe T, Makinodan M, Matsuyoshi H, Kirita T, Wanaka A. 2006. Expression and regulation of the LIM homeodomain gene L3/Lhx8 suggests a role in upper lip development of the chick embryo. Anat Embryol (Berl) 211(3):247-253.

Jeong H, Mason SP, Barabasi AL, Oltvai ZN. 2001. Lethality and centrality in protein networks. Nature 411(6833):41-42.

Joshi S, Davies H, Sims LP, Levy SE, Dean J. 2007. Ovarian gene expression in the absence 
of FIGLA, an oocyte-specific transcription factor. BMC Dev Biol 7:67.

Jurata LW, Pfaff SL, Gill GN. 1998. The nuclear LIM domain interactor NLI mediates homoand heterodimerization of LIM domain transcription factors. J Biol Chem 273(6):3152-3157.

Kikuchi Y, Segawa H, Tokumoto M, Tsubokawa T, Hotta Y, Uyemura K, Okamoto H. 1997. Ocular and cerebellar defects in zebrafish induced by overexpression of the LIM domains of the islet-3 LIM/homeodomain protein. Neuron 18(3):369-382.

Kummerfeld SK, Teichmann SA. 2006. DBD: a transcription factor prediction database. Nucleic Acids Res 34(Database issue):D74-81.

Kurosaka S, Eckardt S, McLaughlin KJ. 2004. Pluripotent lineage definition in bovine embryos by Oct4 transcript localization. Biol Reprod 71(5):1578-1582.

Larson RC, Lavenir I, Larson TA, Baer R, Warren AJ, Wadman I, Nottage K, Rabbitts TH. 1996. Protein dimerization between Lmo2 (Rbtn2) and Tal1 alters thymocyte development and potentiates $\mathrm{T}$ cell tumorigenesis in transgenic mice. Embo Journal 15(5):1021-1027.

Leonard J, Serup P, Gonzalez G, Edlund T, Montminy M. 1992. The LIM family transcription factor Isl-1 requires cAMP response element binding protein to promote somatostatin expression in pancreatic islet cells. Proc Natl Acad Sci U S A 89(14):6247-6251.

Mann RS, Affolter M. 1998. Hox proteins meet more partners. Curr Opin Genet Dev 8(4):423-429.

Massari ME, Murre C. 2000. Helix-loop-helix proteins: regulators of transcription in eucaryotic organisms. Mol Cell Biol 20(2):429-440.

Mizuno K, Higuchi O. 1997. [LIM domains: double zinc finger motifs involved in protein-protein interactions]. Tanpakushitsu Kakusan Koso 42(13):2061-2071.

Morell M, Espargaro A, Aviles FX, Ventura S. 2007. Detection of transient protein-protein interactions by bimolecular fluorescence complementation: the Abl-SH3 case. Proteomics 7(7):1023-1036.

Moriguchi H, Zhang Y, Mihara M, Sato C. 2012. Successful cryopreservation of human ovarian cortex tissues using supercooling. Sci Rep 2:537.

Murdoch WJ, Dailey RA, Inskeep EK. 1981. Preovulatory changes prostaglandins E2 and F2 alpha in ovine follicles. J Anim Sci 53(1):192-205.

Murre C, Mccaw PS, Vaessin H, Caudy M, Jan LY, Jan YN, Cabrera CV, Buskin JN, Hauschka SD, Lassar AB, Weintraub H, Baltimore D. 1989. Interactions between Heterologous Helix-Loop-Helix Proteins Generate Complexes That Bind Specifically to a Common DNA-Sequence. Cell 58(3):537-544.

Nix DA, Fradelizi J, Bockholt S, Menichi B, Louvard D, Friederich E, Beckerle MC. 2001. Targeting of zyxin to sites of actin membrane interaction and to the nucleus. J Biol Chem 276(37):34759-34767.

Nooren IM, Thornton JM. 2003. Diversity of protein-protein interactions. EMBO J 22(14):3486-3492.

Ovchinnikov S, Kamisetty H, Baker D. 2014. Robust and accurate prediction of residue-residue interactions across protein interfaces using evolutionary information. Elife 3.

Ovitt CE, Scholer HR. 1998. The molecular biology of Oct-4 in the early mouse embryo. Mol 
Hum Reprod 4(11):1021-1031.

Pangas SA, Choi Y, Ballow DJ, Zhao Y, Westphal H, Matzuk MM, Rajkovic A. 2006. Oogenesis requires germ cell-specific transcriptional regulators Sohlh1 and Lhx8. Proc Natl Acad Sci U S A 103(21):8090-8095.

Qin Y, Choi Y, Zhao H, Simpson JL, Chen ZJ, Rajkovic A. 2007. NOBOX homeobox mutation causes premature ovarian failure. Am J Hum Genet 81(3):576-581.

Rajkovic A, Pangas SA, Ballow D, Suzumori N, Matzuk MM. 2004. NOBOX deficiency disrupts early folliculogenesis and oocyte-specific gene expression. Science 305(5687):1157-1159.

Ramachandra RK, Lankford SE, Weber GM, Rexroad CE, 3rd, Yao J. 2007. Identification of OORP-T, a novel oocyte-specific gene encoding a protein with a conserved oxysterol binding protein domain in rainbow trout. Mol Reprod Dev 74(4):502-511.

Richardson C, Jones PC, Barnard V, Hebert CN, Terlecki S, Wijeratne WV. 1990. Estimation of the developmental age of the bovine fetus and newborn calf. Vet Rec 126(12):279-284.

Roberts RM, Smith GW, Bazer FW, Cibelli J, Seidel GE, Jr., Bauman DE, Reynolds LP, Ireland JJ. 2009. Research priorities. Farm animal research in crisis. Science 324(5926):468-469.

Ryan AK, Rosenfeld MG. 1997. POU domain family values: flexibility, partnerships, and developmental codes. Genes Dev 11(10):1207-1225.

Saraste M, Sibbald PR, Wittinghofer A. 1990. The P-loop--a common motif in ATP- and GTP-binding proteins. Trends Biochem Sci 15(11):430-434.

Schmeichel KL, Beckerle MC. 1994. The Lim Domain Is a Modular Protein-Binding Interface. Cell 79(2):211-219.

Schmitt T, Ogris C, Sonnhammer EL. 2014. FunCoup 3.0: database of genome-wide functional coupling networks. Nucleic Acids Res 42(Database issue):D380-388.

Scholer HR, Hatzopoulos AK, Balling R, Suzuki N, Gruss P. 1989. A family of octamer-specific proteins present during mouse embryogenesis: evidence for germline-specific expression of an Oct factor. EMBO J 8(9):2543-2550.

Seet BT, Dikic I, Zhou MM, Pawson T. 2006. Reading protein modifications with interaction domains. Nat Rev Mol Cell Biol 7(7):473-483.

Shoemaker BA, Panchenko AR. 2007. Deciphering protein-protein interactions. Part I. Experimental techniques and databases. PLoS Comput Biol 3(3):e42.

Soyal SM, Amleh A, Dean J. 2000. FIGalpha, a germ cell-specific transcription factor required for ovarian follicle formation. Development 127(21):4645-4654.

Stern S, Herr W. 1991. The herpes simplex virus trans-activator VP16 recognizes the Oct-1 homeo domain: evidence for a homeo domain recognition subdomain. Genes Dev 5(12B):2555-2566.

Sugiura K, Pendola FL, Eppig JJ. 2005. Oocyte control of metabolic cooperativity between oocytes and companion granulosa cells: energy metabolism. Developmental Biology 279(1):20-30.

Suzumori N, Yan CN, Matzuk MM, Rajkovic A. 2002. Nobox is a homeobox-encoding gene preferentially expressed in primordial and growing oocytes. Mechanisms of Development 111(1-2):137-141. 
Taira M, Otani H, Saint-Jeannet JP, Dawid IB. 1994. Role of the LIM class homeodomain protein Xlim-1 in neural and muscle induction by the Spemann organizer in Xenopus. Nature 372(6507):677-679.

Thesleff I, Vaahtokari A, Partanen AM. 1995. Regulation of organogenesis. Common molecular mechanisms regulating the development of teeth and other organs. Int $\mathbf{J}$ Dev Biol 39(1):35-50.

Thorgaard GH, Bailey GS, Williams D, Buhler DR, Kaattari SL, Ristow SS, Hansen JD, Winton JR, Bartholomew JL, Nagler JJ, Walsh PJ, Vijayan MM, Devlin RH, Hardy RW, Overturf KE, Young WP, Robison BD, Rexroad C, Palti Y. 2002. Status and opportunities for genomics research with rainbow trout. Comp Biochem Physiol B Biochem Mol Biol 133(4):609-646.

Tong ZB, Gold L, Pfeifer KE, Dorward H, Lee E, Bondy CA, Dean J, Nelson LM. 2000. Mater, a maternal effect gene required for early embryonic development in mice. Nat Genet 26(3):267-268.

Tzchori I, Day TF, Carolan PJ, Zhao Y, Wassif CA, Li L, Lewandoski M, Gorivodsky M, Love PE, Porter FD, Westphal H, Yang Y. 2009. LIM homeobox transcription factors integrate signaling events that control three-dimensional limb patterning and growth. Development 136(8):1375-1385.

Walhout AJ. 2006. Unraveling transcription regulatory networks by protein-DNA and protein-protein interaction mapping. Genome Res 16(12):1445-1454.

Wang J, Rao S, Chu J, Shen X, Levasseur DN, Theunissen TW, Orkin SH. 2006. A protein interaction network for pluripotency of embryonic stem cells. Nature 444(7117):364-368.

Wang L, Ma H, Fu L, Yao J. 2014. Kpna7 interacts with egg-specific nuclear factors in the rainbow trout (Oncorhynchus mykiss). Mol Reprod Dev 81(12):1136-1145.

Wang L, Tripurani SK, Wanna W, Rexroad CE, 3rd, Yao J. 2013. Cloning and characterization of a novel oocyte-specific gene encoding an F-Box protein in rainbow trout (Oncorhynchus mykiss). Reprod Biol Endocrinol 11:86.

White YA, Woods DC, Takai Y, Ishihara O, Seki H, Tilly JL. 2012. Oocyte formation by mitotically active germ cells purified from ovaries of reproductive-age women. Nat Med 18(3):413-421.

Wilkins MR, Kummerfeld SK. 2008. Sticking together? Falling apart? Exploring the dynamics of the interactome. Trends Biochem Sci 33(5):195-200.

Wu XM, Viveiros MM, Eppig JJ, Bai YC, Fitzpatrick SL, Matzuk MM. 2003a. Zygote arrest 1 (Zar1) is a novel maternal-effect gene critical for the oocyte-to-embryo transition. Nature Genetics 33(2):187-191.

Wu XM, Wang P, Brown CA, Zilinski CA, Matzuk MM. 2003b. Zygote arrest 1 (Zar1) is an evolutionarily conserved gene expressed in vertebrate ovaries. Biology of Reproduction 69(3):861-867.

Xue D, Tu Y, Chalfie M. 1993. Cooperative interactions between the Caenorhabditis elegans homeoproteins UNC-86 and MEC-3. Science 261(5126):1324-1328.

Yaffe MB. 2002. How do 14-3-3 proteins work?-- Gatekeeper phosphorylation and the molecular anvil hypothesis. FEBS Lett 513(1):53-57.

Zhao M, Gupta V, Raj L, Roussel M, Bei M. 2013. A network of transcription factors 
operates during early tooth morphogenesis. Mol Cell Biol 33(16):3099-3112.

Zheng P, Dean J. 2007. Oocyte-specific genes affect folliculogenesis, fertilization, and early development. Semin Reprod Med 25(4):243-251.

Zuberi K, Franz M, Rodriguez H, Montojo J, Lopes CT, Bader GD, Morris Q. 2013. GeneMANIA prediction server 2013 update. Nucleic Acids Res 41(Web Server issue):W115-122. 